\title{
Credit Growth and the Financial Crisis: A New Narrative*
}

\author{
Stefania Albanesi, University of Pittsburgh, NBER and CEPR \\ Giacomo DeGiorgi, GSEM-University of Geneva, ICREA/MOVE, BGSE, CEPR \\ Jaromir Nosal, Boston College
}

September 10, 2017

\begin{abstract}
A broadly accepted view contends that the 2007-09 financial crisis in the U.S. was caused by an expansion in the supply of credit to subprime borrowers during the 2001-2006 credit boom, leading to the spike in defaults and foreclosures that sparked the crisis. We use a large administrative panel of credit file data to examine the evolution of household debt and defaults between 1999 and 2013. Our findings suggest an alternative narrative that challenges the large role of subprime credit in the crisis.

We show that credit growth between 2001 and 2007 was concentrated in the prime segment, and debt to high risk borrowers was virtually constant for all debt categories during this period. The rise in mortgage defaults during the crisis was concentrated in the middle of the credit score distribution, and mostly attributable to real estate investors. We argue that previous analyses confounded life cycle debt demand of borrowers who were young at the start of the boom with an expansion in credit supply over that period.
\end{abstract}

\footnotetext{
${ }^{*}$ We are grateful to Christopher Carroll, Gauti Eggertsson, Joel Elvery, Nicola Gennaioli, Marianna Kudlyak, Douglas McManus, Virgiliu Midrigan, Giuseppe Moscarini, Joe Tracy, Eric Swanson, Paul Willen and many seminar and conference participants for useful comments and suggestions. We also thank Matt Ploenzke, Harry Wheeler and Richard Svoboda for excellent research assistance. Correspondence to: stefania.albanesi@gmail.com.
} 


\section{Introduction}

The broadly accepted narrative about the financial crisis is based on the findings in Mian and Sufi (2009) suggesting that most of the growth in credit during the 2001-2006 boom was concentrated in the subprime segment, despite the fact that income did not rise over the same period for this group of borrowers. The expansion of subprime credit then led to a rise in mortgage delinquencies and foreclosures, which caused the housing crisis and subsequent the 2007-2009 recession (see Mian and Sufi (2010), Mian and Sufi (2011), Mian, Rao, and Sufi (2013) and Mian, Sufi, and Trebbi (2015)).

This paper studies the evolution of household borrowing and default between 1999 and 2013, leading up and following the 2007-09 great recession. Our analysis is based on the Federal Reserve Bank of New York Consumer Credit Panel/Equifax data, a large administrative panel of anonymous credit files from the Equifax credit reporting bureau. The data contains information on individual debt holdings, delinquencies, public records and credit scores. We examine the evolution of mortgage debt and defaults during the credit boom and throughout the financial crisis and its aftermath. Our findings suggest an alternative narrative that challenges the view that the expansion of the supply of mortgage credit to subprime borrowers played a large role in the credit boom in 2001-2007 and the subsequent financial crisis. Specifically, we show that credit growth between 2001 and 2007 is concentrated in the middle and and at the top of the credit score distribution. Borrowing by individuals with low credit score is virtually constant during the boom. We also find that the rise in defaults during the financial crisis is concentrated in the middle of the credit score distribution. While low credit score individuals typically have higher default rates than individuals with higher credit scores, during the financial crisis the fraction of mortgage delinquencies to the lowest quartile of of the credit score distribution dropped from $40 \%$ to $30 \%$, and the fraction of foreclosures from $70 \%$ to $35 \%$.

Mian and Sufi (2009) and Mian and Sufi (2016) identify subprime individuals based on their credit score in 1996 and 1997, respectively. We show that, since low credit score individuals at any time are disproportionally young, this approach confounds an expansion of the supply of credit with the life cycle demand for credit of borrowers who were young at the start of the boom. To avoid this pitfall, our approach is based on ranking individuals by a recent lagged credit score, following industry practices. This prevents joint endogeneity of credit scores with borrowing and delinquency behavior but ensures that the ranking best reflects the borrower's likely ability to repay debt at the time of borrowing. Our analysis shows that income growth and debt growth are positively related during the credit boom 
for individual borrowers. Using payroll data for 2009, we show that the cross sectional dispersion of credit scores is mostly explained by the cross sectional dispersion of labor income, conditional on age. Moreover, the lifecycle pattern of borrowing and credit scores is tightly related to the lifecycle evolution of income.

Our finding that borrowers in middle and at the top of the credit score distribution disproportionally default during the crisis is puzzling, as these borrowers historically exhibit very low default rates on any type of debt, as well as very low foreclosure rates. To gain insight on what may have driven defaults by borrowers with relatively high credit scores, we explore the role of real estate investors. Using our data, we can identify real estate investors as borrowers who hold 2 or more first mortgages, following Haughwout et al. (2011). There are four main reasons that may lead real estate investors to display higher default rates than other borrowers with similar credit scores. First, mortgages for non owner occupied properties must meet stricter credit standards and are usually charged an additional premium to qualify for GSE insurance. This makes it more likely for real estate investors to contract non-standard mortgages, which are intrinsically more risky! Second, if investors are motivated by the prospect of capital gains ${ }^{2}$ they have an incentive to maximize leverage, as this strategy increases the potential gains from holding a property, while the potential losses are limited, especially in states in which foreclosure is non recourse. $3^{3}$ Third, only the primary residence is protected in personal bankruptcy, via the homestead exemption (see $\mathrm{Li}(2009)$ ). Thus, a financially distressed borrower could potentially file for Chapter 7 bankruptcy and discharge unsecured debt using non exempt assets to avoid missing payments on the mortgage for their primary residence 4 Finally, the financial and psychological costs of default for mortgage borrowers who reside in the home are typically quite substantial, as the resulting relocation would generate moving and storage costs, and possibly cause difficulties for household members in reaching their workplace or their school.

We find that real estate investors play a critical role in the rise in mortgage debt only for

\footnotetext{
1 Agarwal et al. (2016) document clear patterns of product steering by mortgage brokers, who directed borrowers eligible for conventional fixed interest rate mortgages to riskier products with higher margins, increasing default risk even for standard borrowers.

${ }^{2}$ Case, Shiller, and Thompson (2012) show using survey evidence that long-term home price expectations reached abnormally high levels relative to mortgage rates during the housing boom. Foote, Gerardi, and Willen (2012) and Adelino, Schoar, and Severino (2015) also emphasize the role of overoptimistic house price expectations.

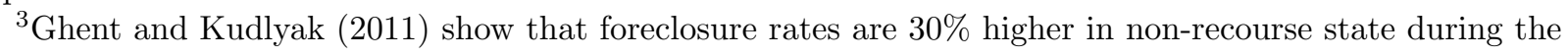
crisis.

4 Albanesi and Nosal (2015) provide empirical evidence on the relation between consumer bankruptcy, delinquency and foreclosure, while Mitman (2016) develops a quantitative model of bankruptcy where default on unsecured debt prioritized over mortgage default.
} 
the middle and the top of the credit score distribution. The share of mortgage balances of real estate investors rose from 20\% to 35\% between 2004 and 2007 for quartiles 2 and 3 of the credit score distribution. Most importantly, we find that the rise in mortgage delinquencies is virtually exclusively accounted for by real estate investors. The fraction of borrowers with delinquent mortgage balances grew by 30 percentage points between 2005 and 2008 for the lowest three quartiles of the credit score distribution, and by 10 percentage points for borrowers in the top quartile, while it was virtually constant for borrowers with only one first mortgage. This striking result provides guidance to policy makers interested in understanding the cause of the housing crisis and designing interventions to mitigate and prevent future such episodes $:^{5}$

We also explore the broader macroeconomic implications of our findings, linking them to the theoretical literature that emphasizes the role of the collateral channel in the transmission of financial shocks to real economic activity, and more directly, to the sizable empirical literature that uses geographical variation in mortgage borrowing to relate mortgage debt growth to the severity of the recession at a regional level. There is a large theoretical literature on the role of collateral constraints in causing or amplifying swings in economic activity, following the pioneering work of Kiyotaki and Moore (1997). This literature proliferated in response to the financial crisis, leading to numerous theoretical and quantitative contributions ${ }^{6}$ Following the 2007-2009 recession, a large empirical literature also developed, linking the size of the credit boom and the depth of the recession in different geographical areas.7

We examine the behavior of debt and defaults at the zip code level, using the Federal Reserve Bank of New York Equifax Data/Consumer Credit Panel. Because we also have access to individual data, our analysis can provide important insights into the relation between individual and geographically aggregated outcomes, shedding light on the mechanism through which credit growth affects other economic variables 8

Following Mian and Sufi (2009), we rank zip codes by the fraction of subprime borrowers in 1999, the first available year in our data..$^{9}$ Based on our data, zip codes in the top quartile

\footnotetext{
${ }^{5}$ One implication of our findings is that many renters were displaced as their landlords defaulted on their mortgages, leading to foreclosure of the home. See Bazikyan (2009) for a discussion.

${ }^{6}$ Some recent contributions include Iacoviello (2004), Guerrieri and Lorenzoni (2011), Berger et al. (2015), Corbae and Quintin (2015), Mitman (2016), Justiniano, Primiceri, and Tambalotti (2016), Kaplan, Mitman, and Violante (2017).

'Some examples include Mian and Sufi (2011), Mian, Sufi, and Trebbi (2015), Mian, Rao, and Sufi (2013), Mian and Sufi (2010), Midrigan and Philippon (2011), Kehoe, Pastorino, and Midrigan (2016), Keys et al. (2014).

${ }^{8}$ Most existing analyses have access to either geographically aggregated data or individual data.

${ }^{9}$ Subprime borrowers have credit scores below 660, as captured by the Equifax Risk Score. See Section 8 for more detail.
} 
of the distribution of the fraction of subprime borrowers exhibit larger growth in per capita mortgage balances (but not in total debt balances), confirming previous findings. However, in all quartiles prime borrowers are responsible for most of the credit growth. The growth in mortgage debt by subprime borrowers during the boom is modest in terms of balances, and even weaker in terms of number of mortgages and originations. We also show that irrespective of the fraction of subprime borrowers, the rise in defaults during the crises is mostly driven by prime borrowers.

Based on our findings with individual level data, we examine the role of the age distribution in different quartiles of the fraction of subprime borrowers. The median age declines by quartile of the fraction of subprime, while the proportion of borrowers younger than 35 rises. This is not surprising, given that low credit score borrowers are disproportionately young. We conduct counterfactuals to quantify the role of the age distribution, and find that $83 \%$ of the difference in credit growth between the top and bottom quartile of the fraction of subprime is accounted for by differences in the age distribution of borrowers in these zip codes. These findings confirm our findings at the individual level on the effect of life cycle demand for credit on the observed borrowing behavior during the boom.

The empirical papers that exploit geographical variation to link the size of mortgage debt growth during the credit boom to the depth of the recession (measured in terms of consumption drop or unemployment rate increase) attribute this correlation to the tightening of collateral constraints during the crisis, resulting from mortgage defaults by high risk/low income borrowers. Our findings are not consistent with this causal mechanism. We therefore explore additional characteristics of these geographical areas that may explain this correlation. We show that several indicators that are critical to business cycle sensitivity are systematically related to the fraction of subprime borrowers. Zip codes with higher fraction of subprime borrowers are younger, as previously noted, have lower levels of educational attainment and have a disproportionately large minority and African American share in the population. It is well known that younger, less educated, minority workers suffer larger and more persistent employment loss during recessions ( see Mincer (1991) and Shimer (1998)). Zip codes with a large fraction of subprime borrowers also have higher population density and exhibit more income inequality. It follows that the aggregation bias that is generated by the fact that, within zip code, prime borrowers experience larger credit growth than subprime borrowers is accentuated 10

\footnotetext{
${ }^{10}$ The distribution of the fraction of subprime borrowers is quite stable at the zip code level, and this is also true for other characteristics salient to business cycle sensitivity, as shown in Section 8 . Therefore, the timing of the ranking by fraction of subprime does not change zip code level patterns. However, some aggregate trends, such as the historical decline in wages, labor force participation and employment rates for
} 
Taken together, our findings suggest that using geographically aggregated data does not provide an accurate account of the patterns of borrowing at the individual level. Moreover, the positive correlation between credit growth during the boom and the depth of the recession may be due to other geographical characteristics, such as the prevalence of young, minority or low education workers.

Our findings confirm and expand those in Adelino, Schoar, and Severino (2015) and Adelino, Schoar, and Severino (2017), who show that the growth in mortgage balances during the boom and the new defaults during the financial crisis are concentrated in the middle of the income distribution. We show that the large contribution of middle and upper credit score (and income) households to credit growth during the 2001-2007 boom and the stark rise in defaults and foreclosures for these households is primarily driven by real estate investor activity. Moreover, we explain the role of the positive relation between credit score and age in generating the discrepancy in distribution of debt based on initial and recent credit scores. ${ }^{11}$ Our results are also consistent with Foote, Loewenstein, and Willen (2016), who find that the geographical relation of mortgage debt growth and income does not change relative to previous periods during the 2001-2006 credit boom, and there is no relative growth in debt for low income households. Our analysis also reconciles the pattern of borrowing at the individual level and at the zip code level, showing that though mortgage balances grows more in areas with a larger fraction of subprime borrowers, within those areas, debt growth is driven by high credit score borrowers. The fact that zip codes with high fraction of subprime borrowers are associated with low income levels and growth during the boom is explained by demographics, specifically the high fraction of young, low education minority borrowers. High population density and very extreme levels of income inequality in these zip codes exacerbates the aggregation bias associated with using geographically aggregated data.

The rest of the paper is organized as follows. Section 2 describes the data used in this analysis. Section 3 reports the existing evidence on credit growth and default behavior by credit score. Section 4 examines the role of life cycle factors for credit demand and credit scores. Section 5 explores the relation between credit score and income. Section 6 examines the behavior of debt and defaults by recent credit score and Section 7 discusses the role of investors. Section 8 presents the zip code level analysis and Section 9 concludes.

unskilled, young and minority workers, and the rise in income inequality may influence economic outcomes at the zip code level over time.

${ }^{11}$ Ferreira and Gyourko (2015) also find that default activity by prime borrowers intensifies during the crisis, however, their definition of prime/subprime borrowers is based on lender characteristics, not on the individual characteristics of the borrower. 


\section{Data}

We use the Federal Reserve Bank of New York's Consumer Credit Panel/Equifax Data (CCP), which is an anonymous longitudinal panel of individuals, comprising a $5 \%$ random sample of all individuals who have a credit report with Equifax. Our quarterly sample starts in 1999:Q1 and ends in 2013:Q3. The data is described in detail in Lee and van der Klaauw (2010). We use a 1\% sample for the individual analysis, which includes information for approximately 2.5 million individuals in each quarter. We use the $5 \%$ sample for the zip code level analysis.

The data contains over 600 variables, allowing us to track all aspects of individuals' financial liabilities, including bankruptcy and foreclosure, mortgage status, detailed delinquencies, various types of debt, with number of accounts and balances. Apart from the financial information, the data contains individual descriptors such as age, ZIP code and credit score. The variables included in our analysis are described in detail in Appendix A.

\section{Existing Evidence}

The credit score is a summary indicator intended to predict the risk of default by the borrower and it is widely used by the financial industry. For most unsecured debt, lenders typically verify a perspective borrower's credit score at the time of application and sometimes a short recent sample of their credit history. For larger unsecured debts, lenders also typically require some form of income verification, as they do for secured debts, such as mortgages and auto loans. Still, the credit score is often a key determinant of crucial terms of the borrowing contract, such as the interest rate, the downpayment or the credit limit.

The most widely known credit score is the FICO score, a measure generated by the Fair Isaac Corporation, which has been in existence in its current form since 1989. Each of the three major credit reporting bureaus- Equifax, Experian and TransUnion- also have their own proprietary credit scores. Credit scoring models are not public, though they are restricted by the law, mainly the Fair Credit Reporting Act of 1970 and the Consumer Credit Reporting Reform Act of 1996. The legislation mandates that consumers be made aware of the 4 main factors that may affect their credit score adversely. Based on available descriptive materials from FICO and the credit bureaus, these are payment history and outstanding debt, which account for more than $60 \%$ of the variation in credit scores, followed by credit history, or the age of existing accounts, which accounts for 15-20\% of the variation, followed by new accounts and types of credit used (10-5\%) and new "hard" inquiries, that is credit 
report inquiries coming from perspective lenders after a borrower initiated credit application.

U.S. law prohibits credit scoring models from considering a borrower's race, color, religion, national origin, sex and marital status, age, address, as well as any receipt of public assistance, or the exercise of any consumer right under the Consumer Credit Protection Act. The credit score cannot be based on information not found in a borrower's credit report, such as salary, occupation, title, employer, date employed or employment history, or interest rates being charged on particular accounts. Finally, any items in the credit report reported as child/family support obligations are not permitted, as well as "soft" inquiries ${ }^{12}$ and any information that is not proven to be predictive of future credit performance.

We have access to the Equifax Risk Score, which is a proprietary measure designed to capture the likelihood of a consumer becoming 90+ days delinquent within the subsequent 24 months. The measure has a numerical range of 280 to 850 , where higher scores indicate lower default risk. It can be accessed by lenders together with the borrower's credit report. Mian and Sufi (2009) rank MSA zip codes by the fraction of residents with Equifax Risk Score below 660 in 1996, and Mian and Sufi (2016) rank individuals by their 1997 Vantage Score, the credit score produced by the Experian credit bureau. Based on this approach, they show that zip codes and individuals with lower credit scores exhibit stronger credit growth during the credit boom. We will show that this result is a consequence of the fact that low credit score individuals are disproportionately young and zip codes with a high share of subprime borrowers have a younger population. Individuals who are young exhibit subsequent life cycle growth in income, debt and credit scores. Hence, the growth in borrowing by individuals who have low credit score at some initial date does not necessarily reflect an expansion in the supply of credit, but simply the typical life cycle demand for borrowing.

To illustrate the results associated with ranking borrowers by their initial credit score, we consider data at the individual and at the zip code level and, following Mian and Sufi (2016) and Mian and Sufi (2009), we rank them by the earliest available date. For individuals, we consider quartiles of the Equifax Risk Score distribution in 1999. For the zip code level analysis, we rank zip codes by the fraction of individuals with Equifax Risk Score lower than 660. The 660 cutoff is a standard characterization for subprime individuals, and mirrors the approach in Mian and Sufi (2009). In order to avoid small sample problems associated with missing initial credit scores for zip codes with very small population, we use 2001 credit scores for this ranking.

\footnotetext{
${ }^{12}$ These include "consumer-initiated" inquiries, such as requests to view one's own credit report, "promotional inquiries," requests made by lenders in order to make pre-approved credit offers, or "administrative inquiries," requests made by lenders to review open accounts. Requests that are marked as coming from employers are also not counted.
} 
Figure 1 displays the growth of per capita mortgage debt balances relative to 2001Q3, which is the last quarter of the 2001 recession, according to the NBER business cycle dates. The left panel displays the individual data, where borrowers are ranked based on their average credit score in 1999. The first quartile contains the individuals with the lowest credit score ${ }^{13}$ The right panel presents zip code level evidence. Here, quartile 1 corresponds to the zip codes with the lowest fraction of subprime borrowers in 2001, where subprime borrowers are identified as having an Equifax Risk Score lower than 660. The median fraction of subprime borrowers in 2001 is $19 \%$ in quartile 1, 32\% in quartile 2, $44 \%$ in quartile 3 and $60 \%$ in quartile 4.14 All statistics are computed for the population of 20-85 year old individuals.

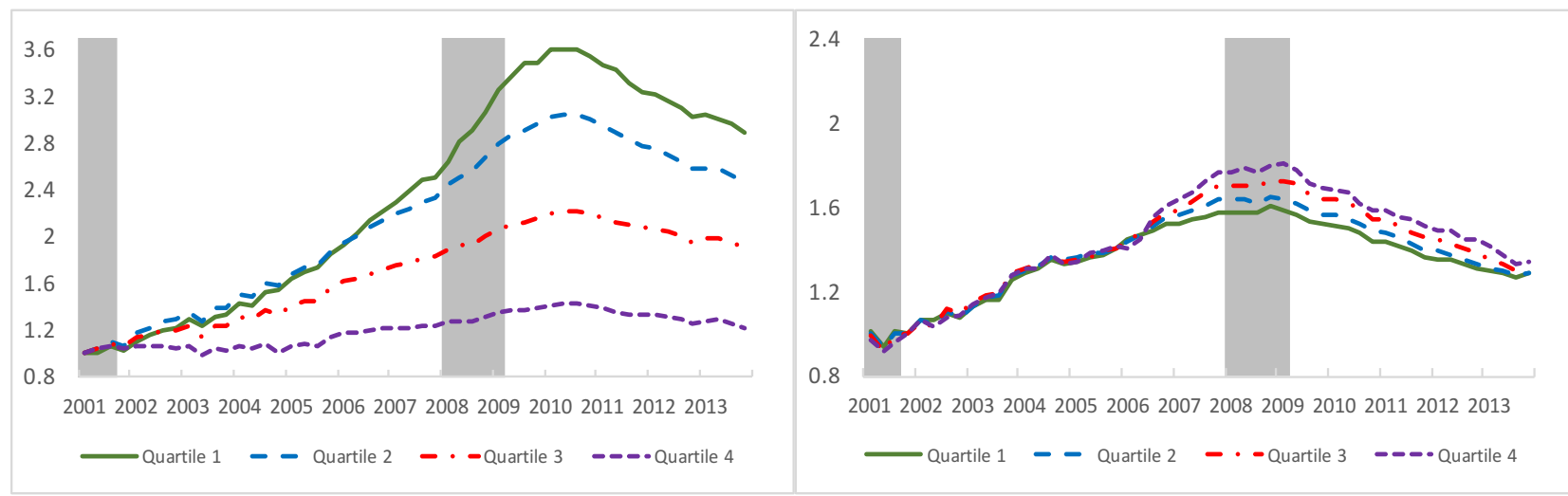

(a) Individuals: Ranked by 1999 Equifax Risk Score (b) Zip Codes: Ranked by Fraction of Subprime in 2001

Figure 1: Per capita real mortgage balances, ratio to 2001Q3. Deflated by CPI-U. Source: Authors' calculation based on Federal Reserve Bank of New York's Consumer Credit Panel/Equifax Data.

For the individual data, the growth in per capita mortgage balances between 2001Q3 and 2007Q4 is $146 \%$ for quartile 1, 121\% for quartile 2, $74 \%$ for quartile 3, and $20 \%$ for quartile 4 of the 1999 credit score distribution. The expansion of mortgage balances continues well into and past the recession, reaching a peak of $255 \%$ for quartile 1, $188 \%$ for quartile 2 , $111 \%$ for quartile 3, and 38\% for quartile 4 in 2010Q2. The drop in mortgage balances in the aftermath of the crisis is very dramatic for quartiles 1 and 2, approximately one third from the peak, whereas it is considerably smaller for quartiles 3 and 4, approximately $10 \%$ and $5 \%$ from the peak.

\footnotetext{
${ }^{13}$ The cut-off for the individual ranking are 615 for quartile 1, 710 for quartile 2, 778 for quartile 3, and 836 for quartile 4 . The cut-off used to identify subprime borrowers with the Equifax Risk Score is 660, therefore, quartile 1 comprises only subprime borrowers, while quartile 2 contains mainly prime individuals and a small subset of subprime.

${ }^{14}$ Section 8 presents more detailed summary statistics at the zip code level.
} 
At the zip code level, the growth of per capita mortgage balances by the fraction of subprime borrowers during the expansion is $58 \%$ for quartile 1 (lowest fraction), $64 \%$ for quartile 2, 70\% for quartile 3, and $77 \%$ for quartile 4 (highest fraction). For quartile 4, mortgage balances grow by an additional 5 percentage points during the recession, while they are approximately stable for the other quartiles. Between 2009Q2 and the end of the sample, mortgage balances drop from $19 \%$ for quartile 1 to $24 \%$ for quartile 4 . While at the individual level there is much more dispersion across quartiles in mortgage debt growth, both the individual and the zip code level data suggest a stronger growth in mortgage balances for individuals with low credit score in 1999 and zip codes with a large share of subprime borrowers in 2001 15

Another basic tenet of the commonly accepted view of the financial crisis is that the growth in credit extended to subprime individuals during the boom led to a rise in defaults for that segment during the crisis. Specifically, this view emphasizes that the rise in mortgage defaults and foreclosures was concentrated among subprime borrowers. We examine this premise in the next two charts, which display the per capita default rate and foreclosure rate at the individual and at the zip code level, based on the initial credit score and fraction of subprime ranking.

Figure 2 presents the per capita default rate, defined as the fraction of individuals who show a new $90+$ delinquency in the last four quarters. For the individual data, the default rate for individuals in quartile 1 and 2 of the 1999 credit score distribution is quite similar and fluctuates between $1 \%$ and $2 \%$ over the same period. Individuals with credit score below the median experience a sustained reduction in the default rate until 2005 and then an increase of approximately $50 \%$ and $25 \%$ for quartile 1 and 2, respectively. For quartile 3, the default rate hovers at around $0.4 \%$ until 2007Q3 when it starts rising, to peak at approximately double its pre-recession value in early 2010. For quartile 4 the default rate is an order magnitude smaller, with very little response to the recession. At the zip code level, there is a notable convergence in defaults rates across quartiles during the boom. Defaults rates start rising in mid-2007 only for quartiles 2-4, with a higher growth for quartile 4.

Figure 3 presents the per capita foreclosure rate, specifically the difference in this variable relative to the 2001Q3 value. For individuals (left), the foreclosure rate is virtually constant

\footnotetext{
${ }^{15}$ The growth in mortgage balances mostly involves intensive margins. If we consider mortgage originations, displayed in Appendix B the growth is limited only to individuals with 1999 credit scores in quartiles 2-4, and occurs only in the period between 2001Q3 and the end of 2004. A similar pattern prevails at the zip code level, where and the growth in originations is negatively related to fraction of subprime borrowers, and there is virtually no growth in the fraction with new mortgage originations in the last year for quartile 4 , the zip codes with the largest fraction of subprime borrowers displays the behavior of originations.
} 


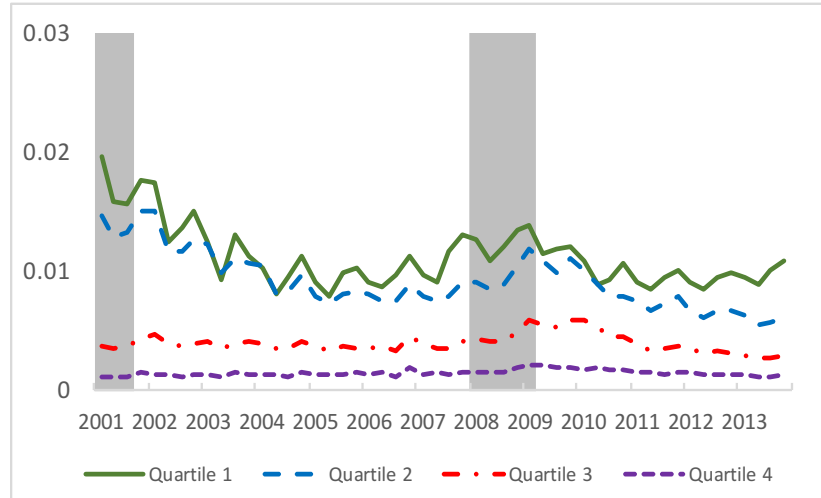

(a) Individuals: Ranked by 1999 Equifax Risk Score

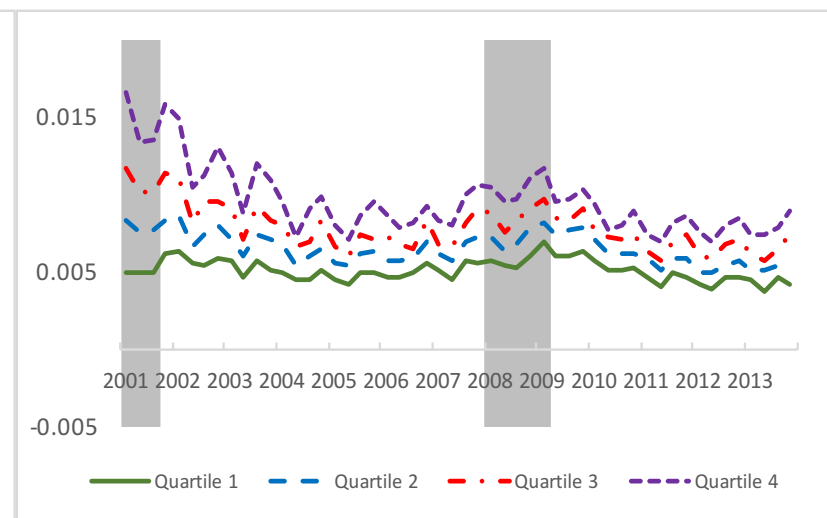

(b) Zip Codes: Ranked by Fraction of Subprime in 2001

Figure 2: Per capita default rate. Source: Authors' calculation based on Federal Reserve Bank of New York's Consumer Credit Panel/Equifax Data.

until the end of 2006. The foreclosure rates during the boom are significantly higher for borrowers with low credit scores and modestly higher in zip codes with higher fraction of subprime borrowers, though these differences are very small. However, at the individual level, during the crisis they notably converge, so that the change in the foreclosure rate relative to 2006Q4 is larger for borrowers in quartile 2 than in quartile 1, and also sizable for borrowers in quartile 3. At the zip code level, the growth in the foreclosure rate is virtually identical for quartiles 1-3 and is lower for zip codes in quartile 4, which have the highest share of subprime borrowers.

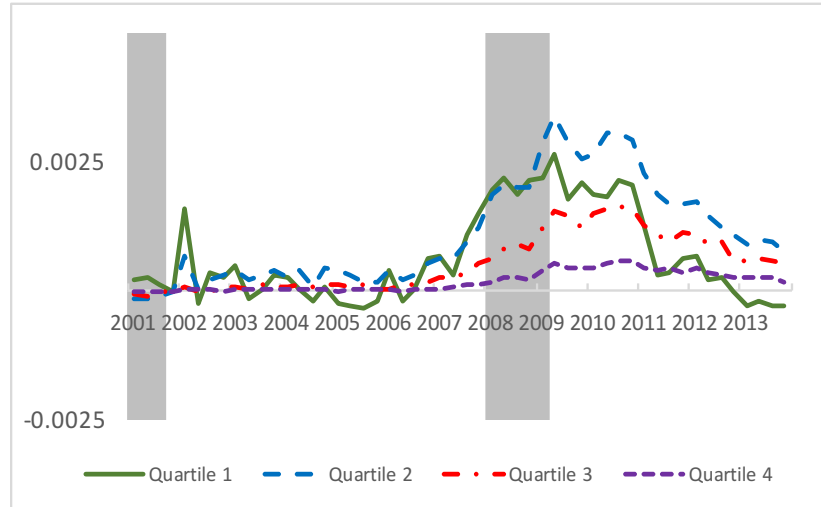

(a) Individuals: Ranked by 1999 Equifax Risk Score

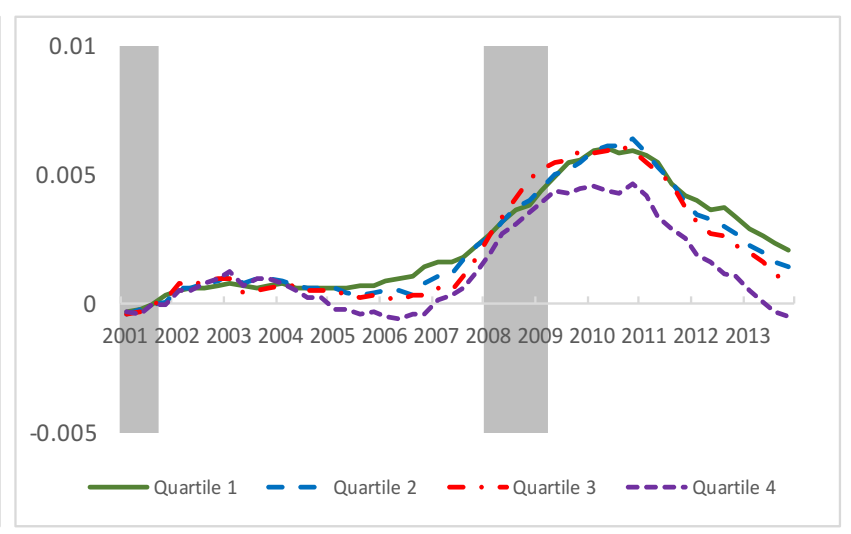

(b) Zip Codes: Ranked by Fraction of Subprime in 2001

Figure 3: Per capita foreclosure rate, difference from 2001Q3. Source: Authors' calculation based on Federal Reserve Bank of New York's Consumer Credit Panel/Equifax Data.

In Section 6.1, we take a lenders' perspective and estimate credit growth at various 
horizons based on a recent lagged credit score. This approach prevents joint endogeneity between credit score and borrowing behavior, and at the same time provides a more accurate description of borrowers creditworthiness as perceived by lenders at the time in which the loans are extended. The use of a recent credit score to rank individuals, in addition to being closer to industry practices, also better reflects the probability of default at the time of borrowing. In the next section, we examine in detail the link between age, debt and credit scores. This analysis illustrates the flaws associated to using initial credit scores to rank individuals and rationalizes the use of recent credit scores by showing that the most important determinant of credit score variation, in addition to age, is income, which is closely related to a borrower's ability to remain current on debt payments.

\section{The Role of Age}

We now explain why ranking individuals by their credit score 15 years prior, as in Mian and Sufi (2016) and Mian and Sufi (2009) magnifies credit growth for low credit score individuals. Specifically, we will show that low credit score individuals are disproportionately young, and they experience future credit growth, as well as income and credit score growth, due to life cycle factors. As a consequence, their credit score at the time of borrowing is considerably higher than when young. On this basis, we will argue that using a recent lagged credit score provides a better assessment of a borrower's default risk. We will also show that a recent lagged credit score is closely related to income at time of borrowing.

We begin by showing that low credit score individuals are disproportionately young. Figure 5 displays the fraction of borrowers in each 1999 credit score quartile by age. We consider 5 age groups. For the youngest groups, up to age 34, the fraction is the first quartile is $44 \%$, the fraction in the second quartile is $33 \%$, the fraction in the third quartile is $19 \%$, and the fraction in the fourth quartile is $5 \%$. The weight for older age groups increases gradually by quartiles. For 45-54 year olds, the fraction in quartiles 1-4 is approximately $20 \%$. For the oldest age group, 65 and older, the fraction in quartile 1 is $4 \%$, while the fraction in quartile 4 is $44 \%$. This distribution is extremely stable over time, and a similar chart for a later quarter would look virtually identical to the one for 1999 presented here.

Given their relatively young age, and correspondingly short credit history, low credit score individuals in 1999 exhibit credit score growth over time. This is illustrated in figure 5 , which plots the current/1999 credit score ratio over the sample period by 1999 credit score quartile. For individuals in the first credit score quartile in 1999, the credit scores grows by more than $10 \%$ between 2001 and the end of 2013 . The credit score grows by about $2 \%$ for 


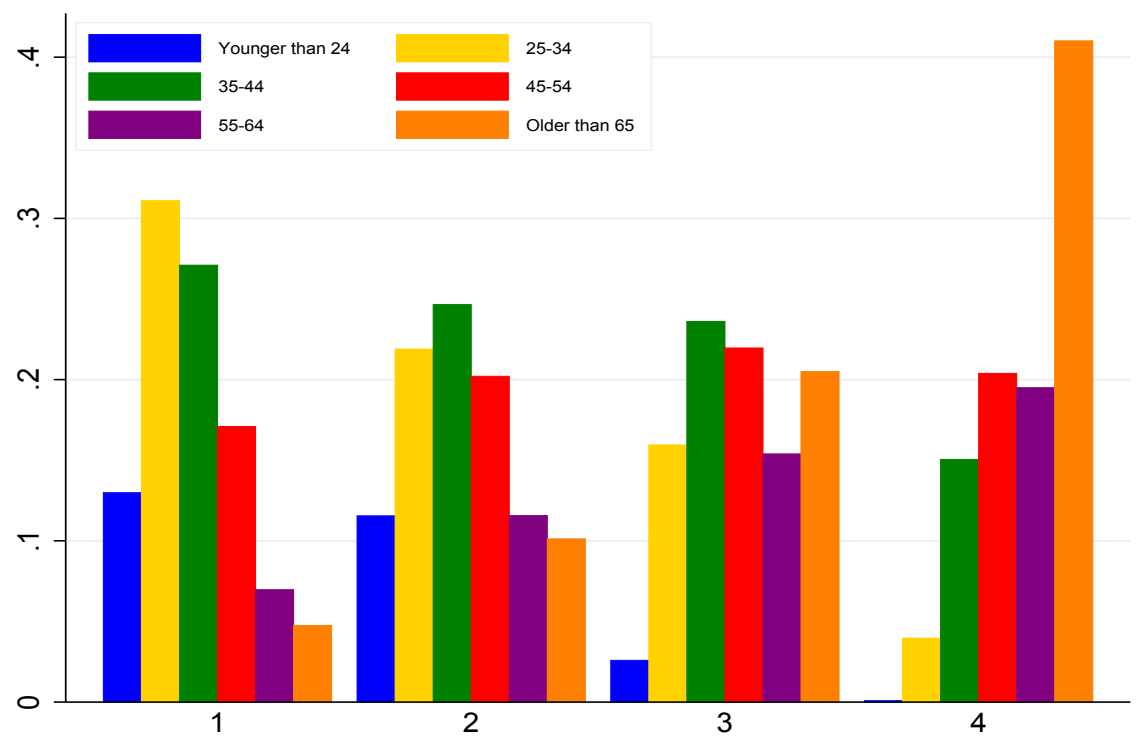

Figure 4: Fraction in each age bin in 1999 by Equifax Risk Score quartile in 1999. Source: Authors' calculation based on Federal Reserve Bank of New York's Consumer Credit Panel/Equifax Data.

individuals in the second quartile, and is essentially flat for quartiles 3 and 4 of the 1999 credit score distribution.

\subsection{Age Effects}

To more precisely assess the relation between age, credit score and credit growth, we regress the Equifax Risk Score in each quarter on age fixed effects, time effects and state fixed effects. We include state effects due to the sizable cross state variation in important regulations regarding foreclosure, health insurance and other factors that could affect the incidence of financial distress and the resulting credit score distribution ${ }^{16}$

Figure 6 plots the estimated age effects between age 20 and 85 (left panel). The growth in credit score as a function of age is strongest between age 25 and 35 , and weakest after age 65 . Between the age of 25 and 35, credit score rise by approximately 40 points, and by 60 points between the age 25 and 45 . Therefore, an individual in the first quartile of the credit score distribution at age 25 would typically be in the second quartile at 35 and in the third at 45 . We adopt the same approach to evaluate the relation between age and debt balances, regressing them on age fixed effects, time effects and state fixed effects. Figure

\footnotetext{
${ }^{16}$ Recall that U.S. legislation prevents credit scoring agencies to use location as a factor in their models, even if location may affect default behavior.
} 


\section{Ratio to 2001Q1 (3QMA)}

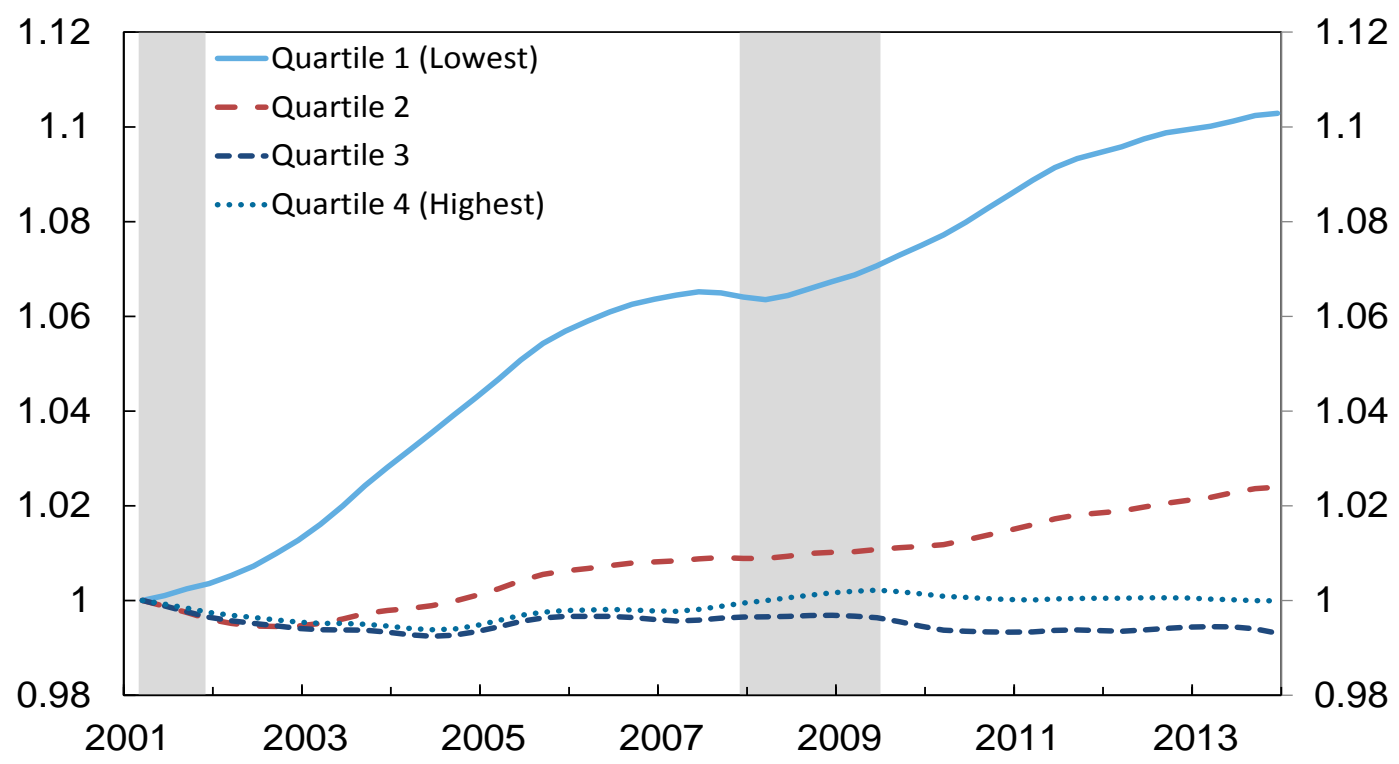

Figure 5: Current credit score as ratio to 1999, by Equifax Risk Score quartile in 1999. Source: Authors' calculation based on Federal Reserve Bank of New York's Consumer Credit Panel/Equifax Data.

6 (right panel) plots the age effects of this regression for total debt balances and mortgage balances, which both show a strong life cycle pattern. Mortgage balances do not start rising until age 25 , then peak just above $\$ 25,000$ at age 45 . Total debt balances reflect the path of mortgage balances.

\subsection{Counterfactuals}

To further illustrate the role of the life cycle for credit demand, we construct a series of counterfactuals using the individual data. We will consider similar counterfactuals at the zip code level in Section 8. The objective of these calculations is to remove life cycle effects on credit growth by assigning to borrowers in each 1999 age bin the debt balances of borrowers who are in that same age bin in later quarters. For example, 35-44 year olds in 1999 will be attributed average debt balances of current 35-44 year olds in each subsequent quarter.

We consider the following age bins: $1=[20,35), 2=[35,45), 3=[45,55), 4=[55,64)$ and $5=[65,85]$. Let $\pi^{i, j_{1999}}$ be the fraction of individuals in age bin $i=1,2, \ldots$ and Equifax 


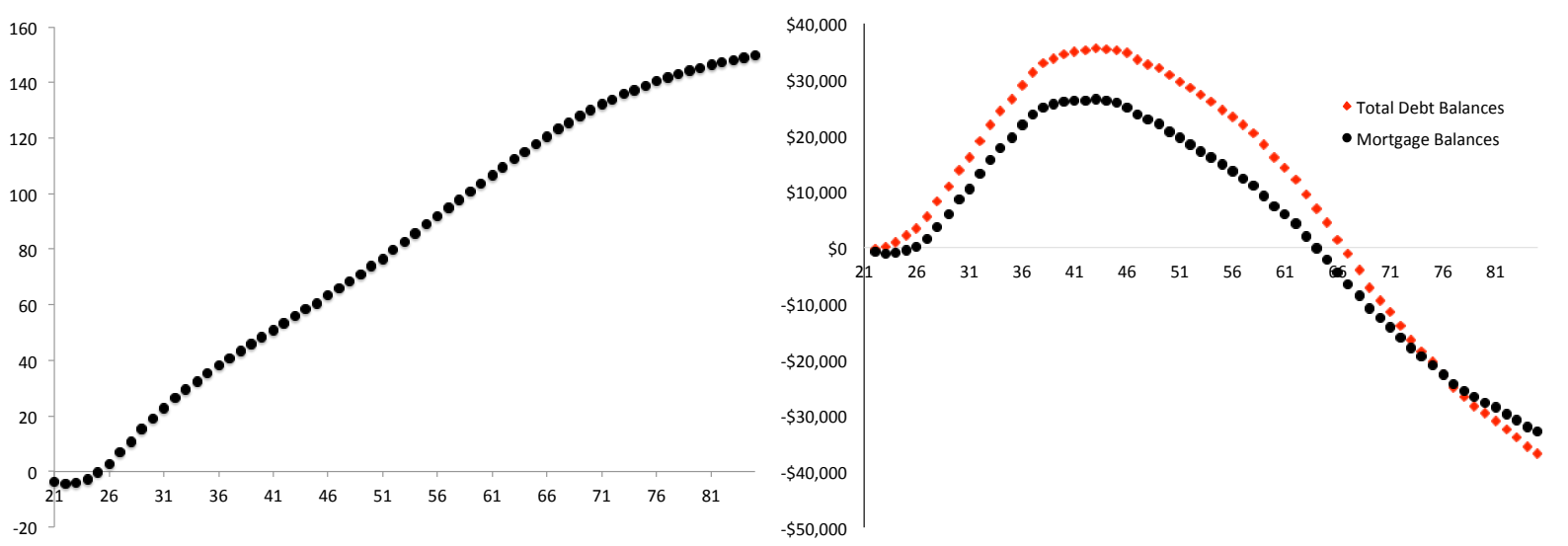

Figure 6: Estimated age effects for the Equifax Risk Score (left) and total debt balances and mortgage balances (right). Source: Authors' calculation based on Federal Reserve Bank of New York's Consumer Credit Panel/Equifax Data.

Risk Score quartile $j=1,2,3,4$ in 1999. Let $\bar{x}_{t}^{i_{s}}$ be the average value of a variable $x$ in quarter $t$ for individuals in age bin $i$ in quarter $s$. We compute $\bar{x}_{t}^{i_{1999}}$ the per capita value of the variable at $t$ for individuals in age bin $i$ in 1999. This measure forces individuals to continue to behave according to their age in 1999 in all future time periods. Since age is kept constant, this counterfactual eliminates life cycle effects.

The results are displayed in figure 7. We find that 25-34 year olds in 1999 experience more debt growth than current 25-34 year olds, whereas 45-54 and 65+ year olds in 1999 experience lower debt growth than current 45-64. The 35-44 year olds in 1999 experience very similar debt growth to the current $35-44$ year olds. The gap between aggregate debt balances for individuals currently in each age group and those in that age group in 1999 measures the component of credit demand due to the life cycle. For example, in 2007Q1, aggregate debt balances for 25-34 year olds in 1999 would have been approximately $\$ 25,000$ lower if their age had remained constant. By contrast, for 55-64 year olds in 1999, per capita total debt balances would have been approximately $\$ 30,000$ higher in 2007Q1 had they not aged.

To quantify the role of life cycle borrowing by 1999 credit score, we compute the same counterfactual by quartile of the credit score distribution. Let $x_{t}^{i_{1999,} j_{1999}}$ be the value of a variable $x$ for individuals in age bin $i$ and Equifax Risk Score quartile $j=1,2,3,4$ in 1999 at quarter $t$. Then, the value of that variable for quartile $j=1,2,3,4$ of the 1999 credit score distribution is:

$$
x_{t}^{j_{1999}}=\sum_{i} \pi^{i_{1999,} j_{1999}} \times x_{t}^{i_{1999} j_{1999}} .
$$



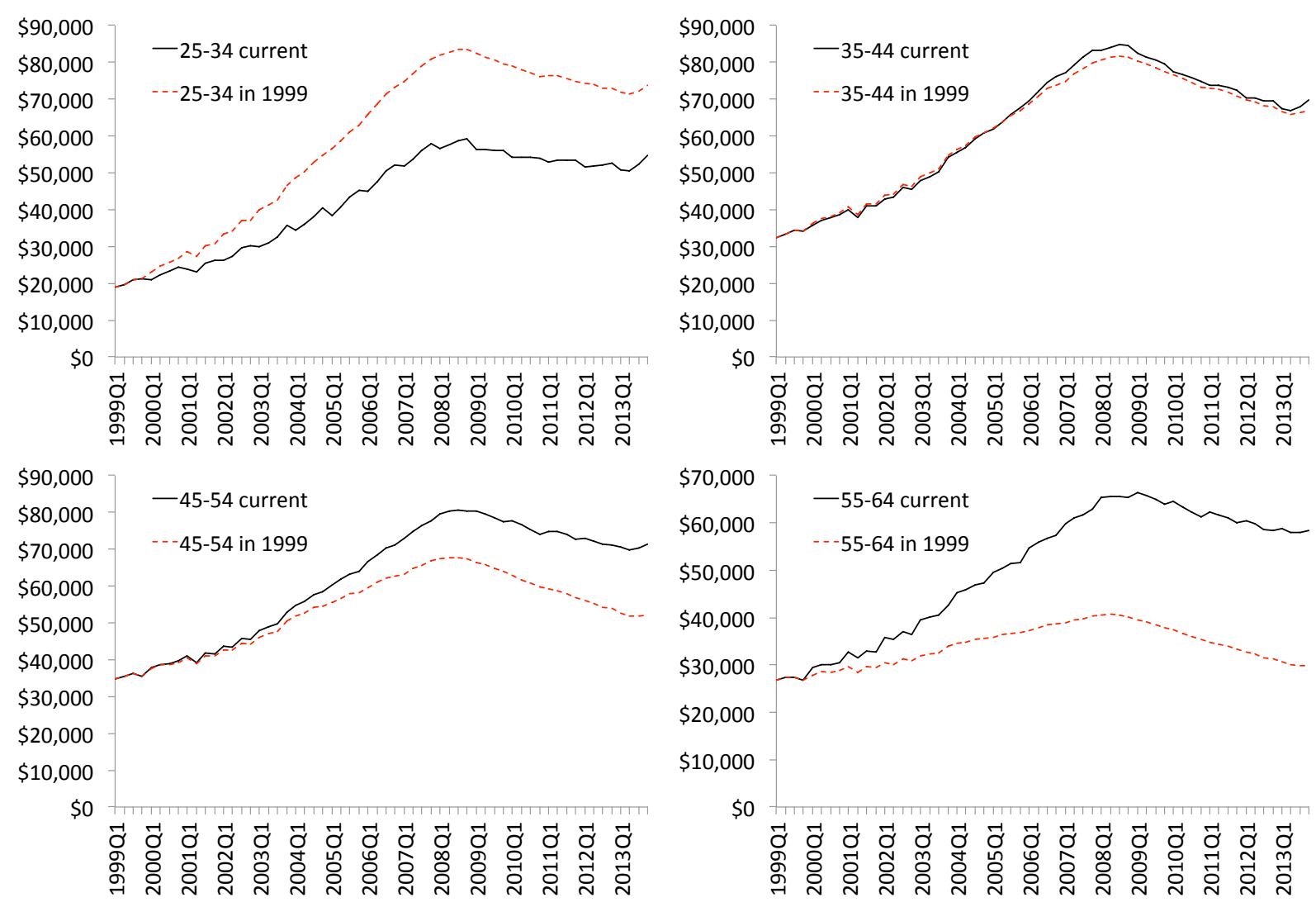

Figure 7: Aggregate debt balances by current age, and by age in 1999. Source: Authors' calculation based on Federal Reserve Bank of New York's Consumer Credit Panel/Equifax Data.

The first counterfactual that we consider is designed to isolate the differential role of life cycle borrowing for individuals in different quartiles of the 1999 Equifax Risk Score distribution. To do so, we maintain individuals at their age in 1999, by attributing borrowing in age bin $i$ in 1999 and 1999 credit score quartile $j$ the debt balances of individuals in age bin $i_{t}$ and credit score quartile $j_{t}$ in each subsequent quarter $t$. That is:

$$
\hat{x}_{t}^{j_{1999}}=\sum_{i} \pi^{i_{1999} j_{1999}} \times x_{t}^{i_{t}, j_{t}}
$$

This approach maintains borrowers' age constant to the time in which they are classified in a particular initial credit score quartile.

We compare the cumulative growth from 2001Q3 in counterfactual and actual balances by quartile of the 1999 credit score distribution. Figure 8 displays the actual and counterfactual series for mortgage debt balances. The results suggest that there is virtually no difference 
across quartiles in the counterfactual debt growth, which is consistent with differences in life cycle credit demand accounting for most of the difference in borrowing between the 1999 credit score quartiles.

ACTUAL

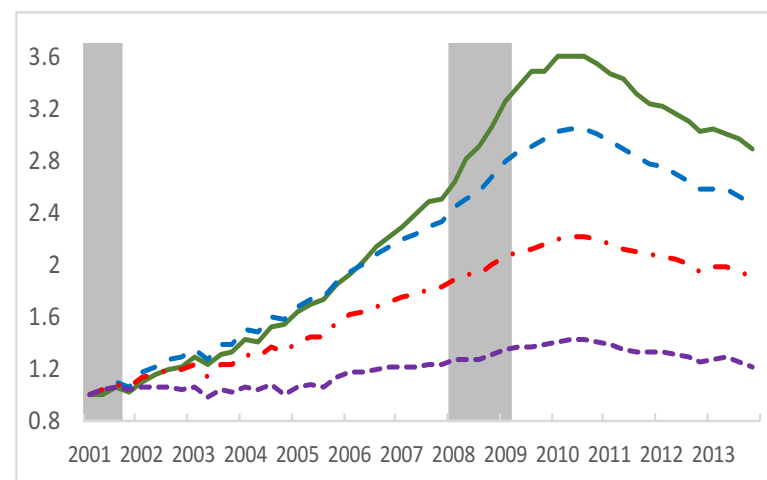

2001200220032004200520062007200820092010201120122013
Counterfactual

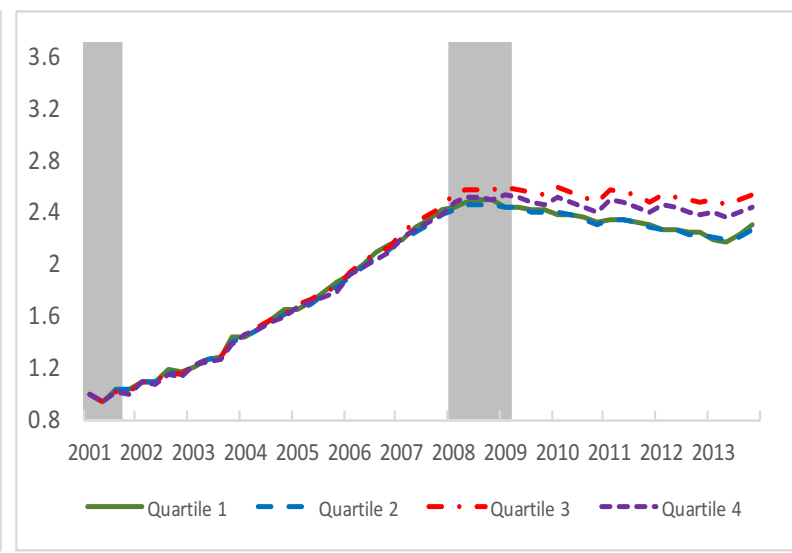

Figure 8: Real mortgage balances by 1999 Equifax Risk Score quartile, actual and counterfactual. Ratio to 2001Q3. Counterfactual assigns to each 1999 age bin, in each quarter, debt balances of those who currently are in that age bin. Source: Authors' calculations based on FRBNY CCP/Equifax Data.

We also compute a counterfactual designed to isolate the role of differences in the age distribution of across 1999 credit score quartiles. To do so, we alternatively set the age distribution in each quartile to be the same as in quartile 1 or 4 . That is, for each $j=1,2,3,4$, we compute:

$$
\tilde{x}_{t}^{j_{1999}}=\sum_{i} \pi^{i_{1999}, k_{1999}} \times x_{t}^{i_{1999} j_{1999}} .
$$

Figure 9 plots the actual real growth in mortgage balances against the two counterfactuals for each quartile of the 1999 Equifax Risk Score ranking. The biggest effects can be seen for quartiles 1 and 4, which have the most extreme age distributions. For quartile 1, the growth in real mortgage balances between 2001Q3 and 2007Q4 would have been 100 percentage points lower with the quartile 4 age distribution. By contrast, the growth for quartile 4 , would have been 50 percentage points higher with the quartile 1 age distribution. Based on this approach, we can compute the fraction of the difference between quartile 1 to 3 and quartile 4 in cumulative 2001Q3-2007Q4 growth in mortgage balances accounted by the difference in the age distribution relative to quartile 4 . This amounts to $26 \%$ for quartile 1 , $20 \%$ for quartile 2 and $14 \%$ for quartile 3 .

Taken together, these results suggest that life cycle effects in borrowing are very strong and sizably affect debt growth especially for individuals at the extremes of the 1999 credit 
QUARTILE 1

QUARTILE 2
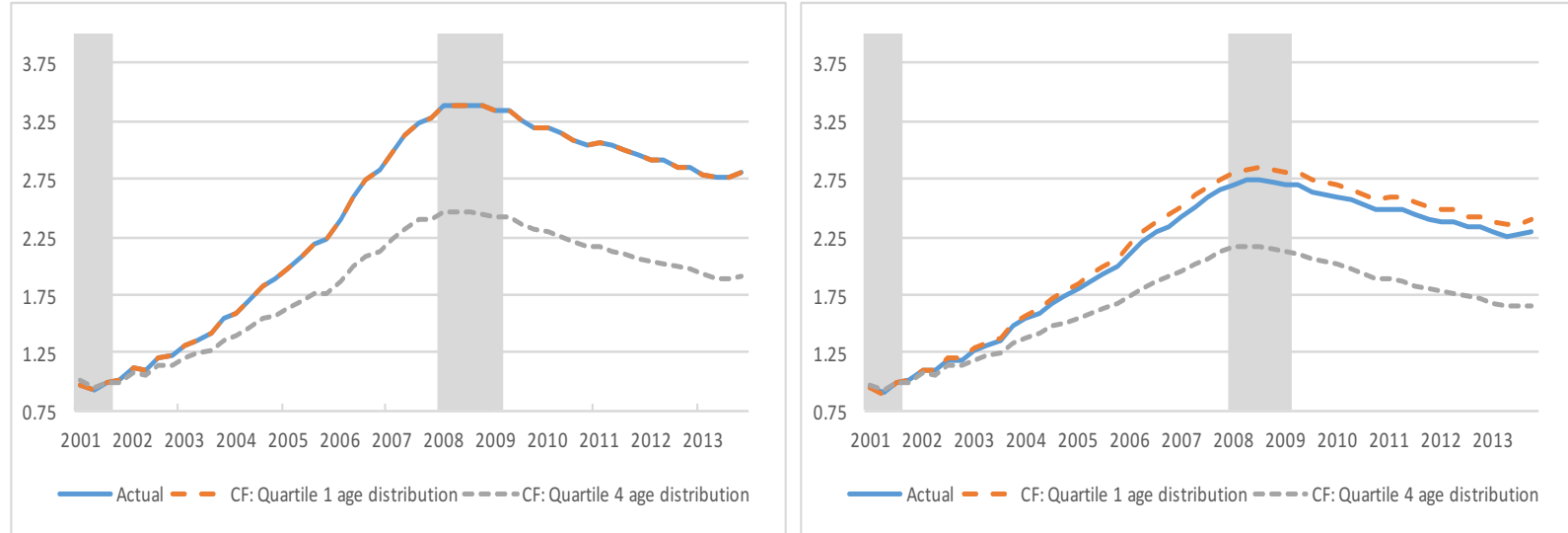

QUARTILE 3

QuARTILE 4
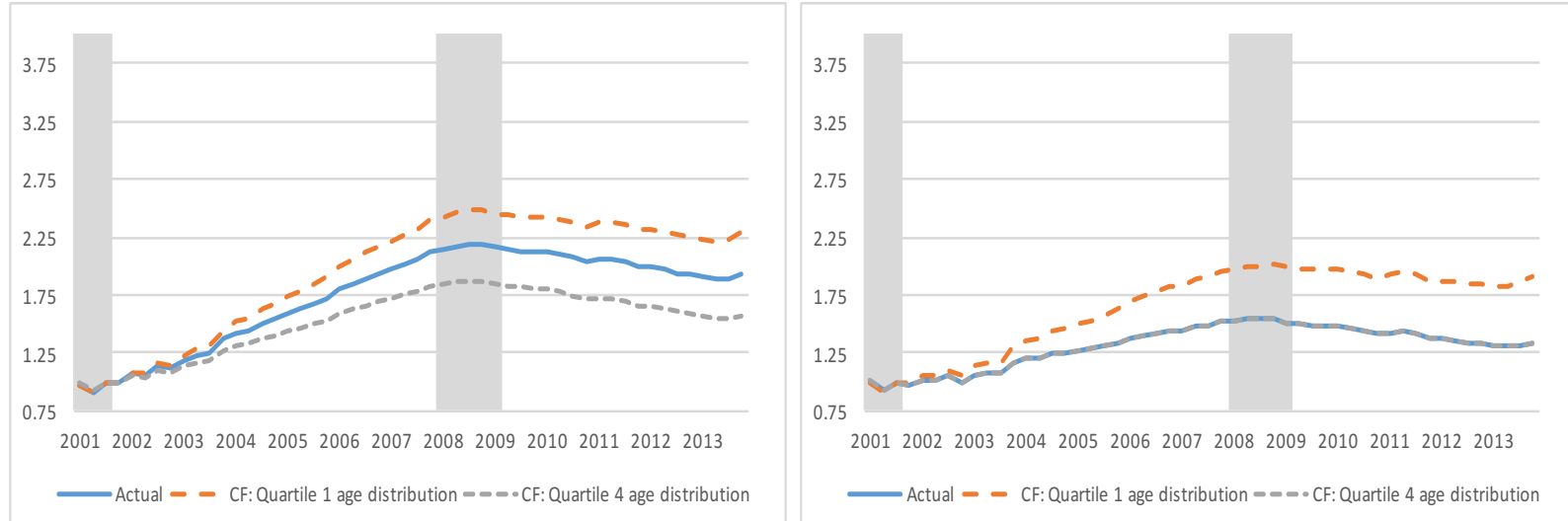

Figure 9: Real mortgage balances by 1999 Equifax Risk Score quartile, actual and counterfactual. Counterfactuals set the age distribution equal to the one for quartile 1 and quartile 4. Source: Authors' calculation based on Federal Reserve Bank of New York's Consumer Credit Panel/Equifax Data.

distribution. They are especially important for individuals in the first quartile of the credit score distribution in 1999, for whom most of the subsequent credit growth is due exclusively to these life cycle considerations.

\section{Credit Scores, Income and Debt Over the Life Cycle}

This section documents the life cycle relation between income, credit score and borrowing. Based on this analysis, we argue that a recent lagged credit score should be used to assess a borrower's probability of default, as this measure better reflects default risk at the time of borrowing. In addition, we show that the life time evolution of credit score and debt is closely related to the lifetime evolution of income. Since the ability to make timely payments 
on outstanding debt critically depends on income at the time of borrowing and throughout the life of the loan, the tight relation between a recent credit score and contemporaneous income conditional on age supports the notion that it should be used as an indicator of default risk.

To estimate the relation between credit scores and income, we use payroll information- so called Worknumber data- for 2009 from a large income verification firm, which is linked to the Equifax credit files. The income data is available for a nationally representative subsample of over 11,000 individuals in the credit panel. We construct a total labor income measure using information on pay rate and pay frequency. Appendix C reports detailed information on the construction of this income measure, and shows that the distribution of our income measure is comparable by age and location to that of similar measures obtained from the CPS and the ACS.

\subsection{Cross-Sectional Relation}

We first examine the cross-sectional relation between credit scores and income, conditional on age. We will show that recent credit scores are strongly positively related to income, given age, and that the slope of the relation between recent credit scores and income declines with age.

To evaluate the relation between income and credit score, we regress the 8 quarter lagged credit score on income, income square, age, age square, and interactions between age, income and state fixed effects 17 Specifically, we estimated the following:

$$
C S_{2009-h}^{i}=\alpha+\beta_{1} y_{2009}^{i}+\beta_{2}\left(y_{2009}^{i}\right)^{2}+\gamma_{1} \operatorname{age}_{2009}^{i}+\gamma_{2}\left(\operatorname{age}_{2009}^{i}\right)^{2}+\text { interactions }+\varepsilon_{2009}^{i}
$$

where $i$ denoted individual borrowers, $C S_{2009-h}^{i}=$ is a borrower's credit score in quarter $2009-h$, and $h$ denotes the leads/lags in the credit score relative to income, with $h \in\{-8 Q,-4 Q, 0,4 Q, 8 Q\}$. The coefficient $\alpha$ corresponds to the constant and $y_{2009}^{i}$ is a borrower's total labor income in 2009.

Figure 10 displays the in sample projected relation between the 8 quarter lagged credit score and income for different age levels. The range of income levels varies by age as they do in our sample. Clearly, credit scores are strongly positively related to income given age, and the slope of this relation declines with age. We estimate the same specification for the

\footnotetext{
${ }^{17}$ Since the credit score is bounded above, we use a truncated regression approach. Standard errors are clustered at the state level.
} 
4 quarter lagged, current, and 4 quarter and 8 quarter ahead credit score, with very similar results.

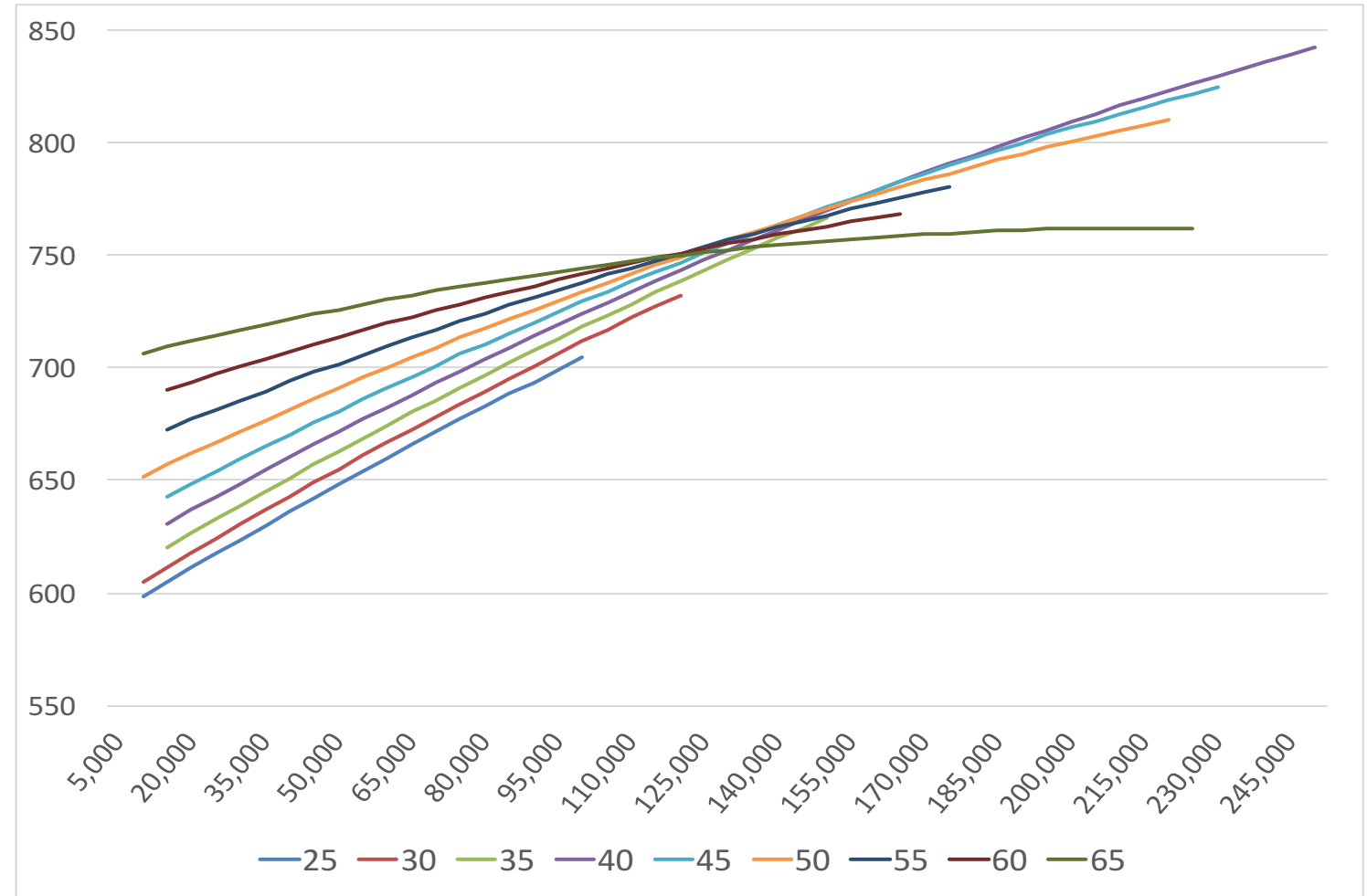

Figure 10: Predicted 8Q lagged Equifax Risk Score by age and 2009 Worknumber total annual labor income, for age specific 1-99 percentile of income range. Source: Authors' calculations based on FRBNY CCP/Equifax Data.

\section{$5.2 \quad$ Life-Cycle Relation}

The availability of labor income data for a subsample of borrowers in 2009 and their full credit profile enables us to assess the lifecycle relation between income, credit score and debt.

We begin by relating the debt and credit score evolution from 1999 to 2009, by 2009 total labor income and 1999 age. We find that young borrowers in 1999 with high income in 2009 exhibit the largest growth in mortgage and total balances, and credit score between 1999 and 2009. Figure 11 illustrates this pattern for the 25-34 year olds in 1999 that are in our Worknumber Data sample for 2009. The charts clearly show that 25-34 year olds in 1999 who are in the top quintile of the labor income distribution in 2009 exhibit a much stronger growth in credit scores and mortgage balances. For those in the bottom quintile, the credit 

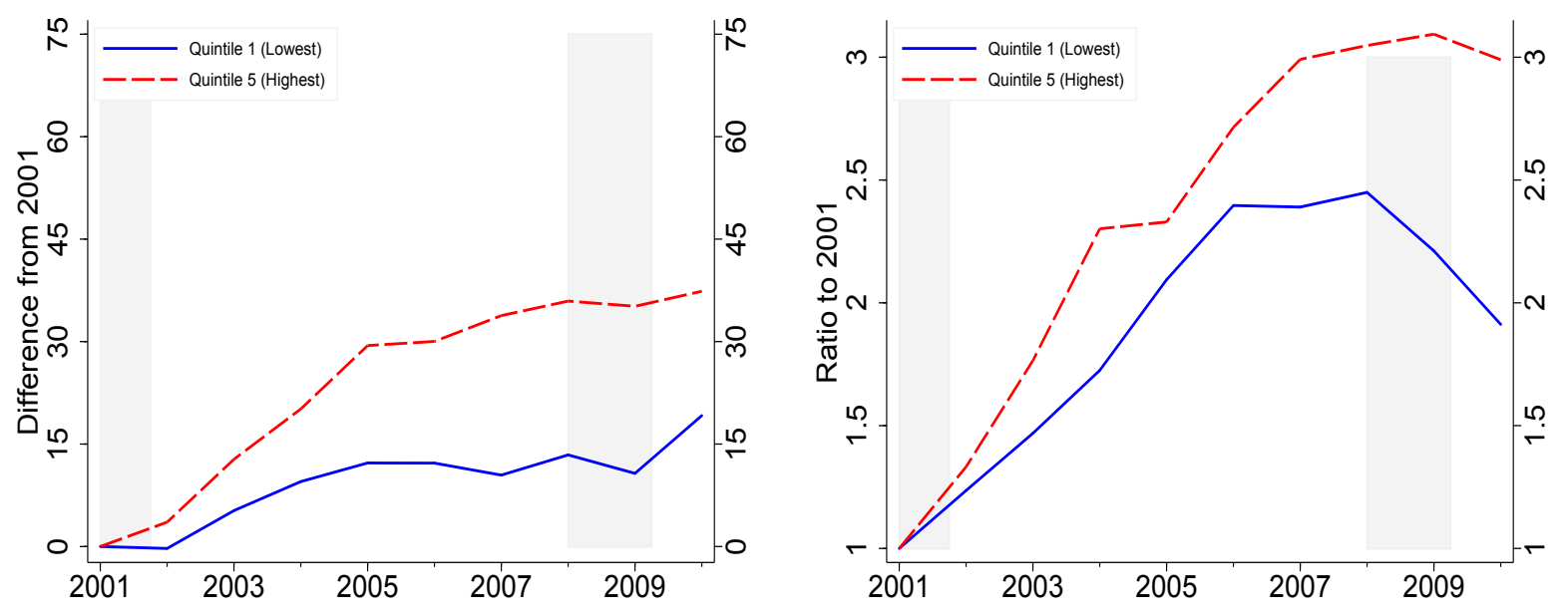

Figure 11: Equifax Risk Score and mortgage balances for 25-34 yo in 1999 by their 2009 Worknumber total annual labor income quantile. Difference with 2001 (credit score) and ratio to 2001 (balances). Source: Authors' calculations based on FRBNY CCP/Equifax Data.

score rises by only 10 points between 2001 and 2009, while it grows by 40 points for those in the top quintile. Similarly, (real) mortgage balances grow by a factor of 3.3 between 2001 and and the start of the recession for the top quartile, and by a factor of 2.4 for the bottom quintile. The growth in both credit scores and mortgage debt balances is monotonically increasing in 2009 income quintile. We report only quintile 1 and 5 for clarity.

Figures 12 and 13 present the same variables for 35-44 year olds in 1999 and 45-54 year olds in 1999. The same qualitative patterns apply, however, the magnitude of the increase in both credit score and mortgage balances between 2001 and 2009 is much smaller, as credit demand is much smaller for these age groups.

Our second exercise relates credit score growth between 1999 and 2009 to income levels and debt levels in 2009 for borrowers in the bottom quartile of the credit score distribution in 1999. Table 1 summarizes these results. The columns correspond to the quartiles on the 2009 credit distributions for borrowers (of any age) that were in the first quartile of the credit score distribution in 1999. We report mean income and mean total debt balances. Clearly, 2009 income and total debt balances are increasing in the 2009 credit score, even if all these borrowers begin in the bottom quartile of the credit score distribution in 1999 . 

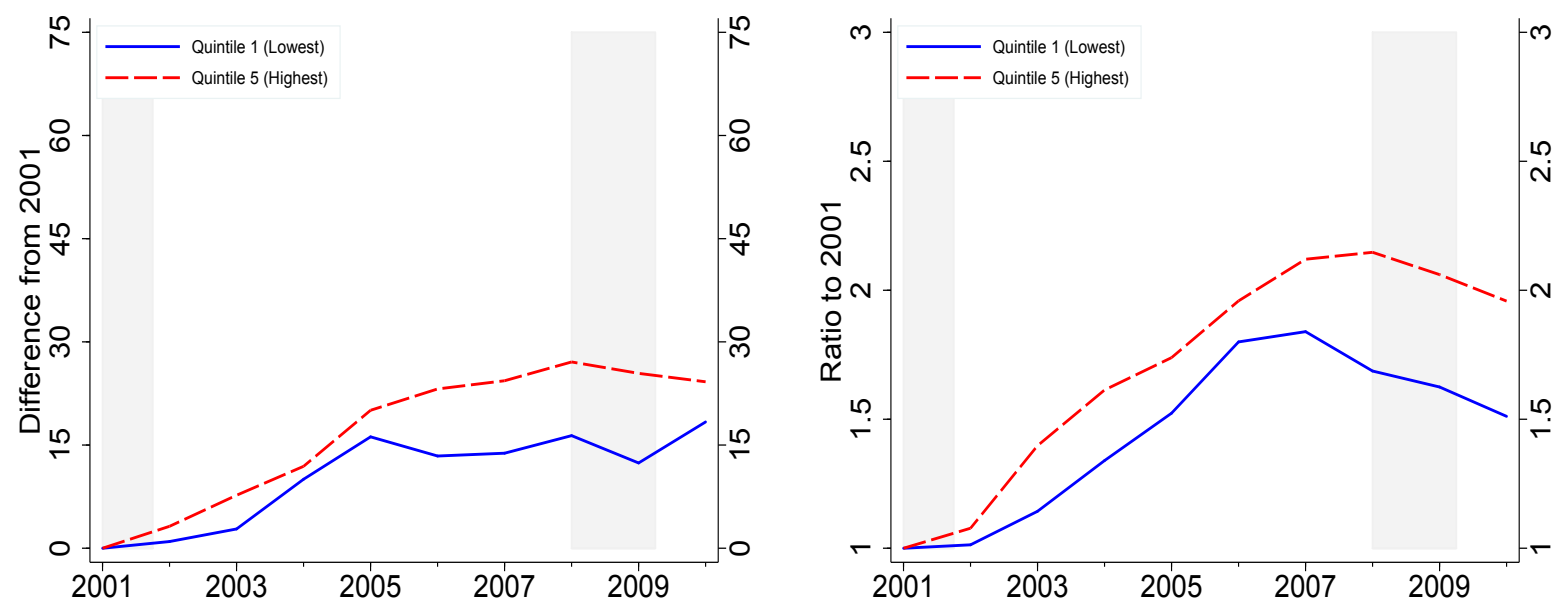

Figure 12: Equifax Risk Score and mortgage balances for 35-44 yo in 1999 by their 2009 Worknumber total annual labor income quantile. Difference with 2001 (credit score) and ratio to 2001 (balances). Source: Authors' calculations based on FRBNY CCP/Equifax Data.

CREDIT SCORE

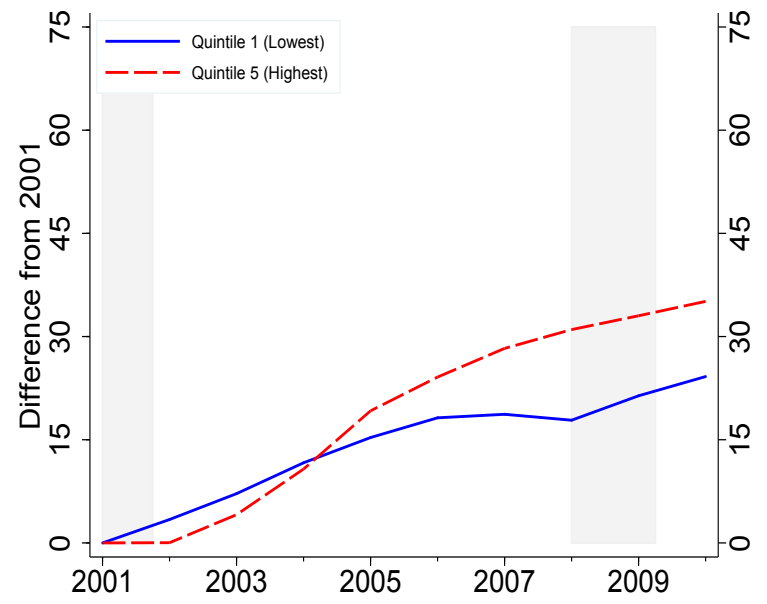

Mortgage BALANCES

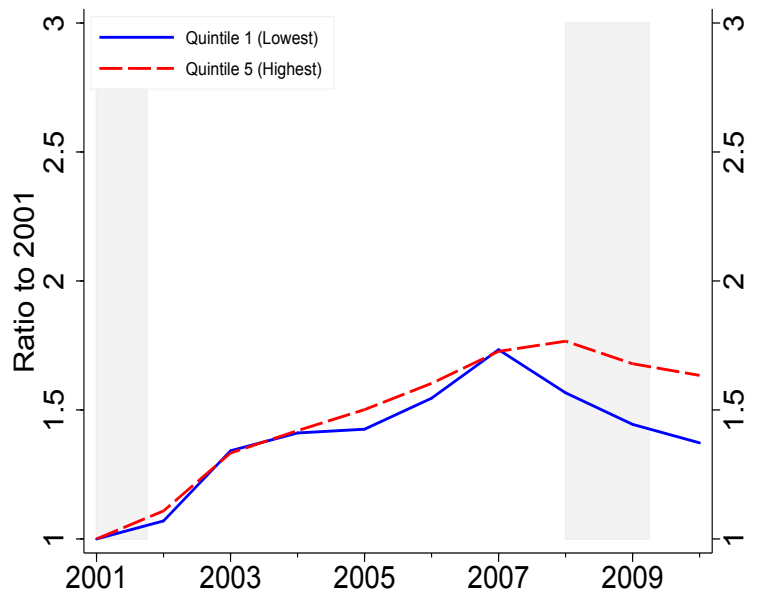

Figure 13: Equifax Risk Score and mortgage balances for 45-54 yo in 1999 by their 2009 Worknumber total annual labor income quantile. Difference with 2001 (credit score) and ratio to 2001 (balances). Source: Authors' calculations based on FRBNY CCP/Equifax Data. 
Table 1: Relation between Credit Score, Income and Debt Balances

\begin{tabular}{lllll}
\hline 2009 credit score & Quartile 1 & Quartile 2 & Quartile 3 & Quartile 4 \\
\hline Debt balances & $\$ 38 \mathrm{k}$ & $\$ 74 \mathrm{k}$ & $\$ 126 \mathrm{k}$ & $\$ 213 \mathrm{k}$ \\
Income & $\$ 39 \mathrm{k}$ & $\$ 47 \mathrm{k}$ & $\$ 57 \mathrm{k}$ & $\$ 62 \mathrm{k}$ \\
\hline
\end{tabular}

Mean income and total debt balances by 2009 Equifax Risk Score quartile for individuals in the first quartile of the 1999 Equifax Risk Score distribution. Worknumber total annual labor income for restricted Worknumber sample. Source: Authors' calculations based on FRBNY CCP/Equifax Data.

This evidence speaks directly to the relation between income and debt during the credit boom. Using zip code level data, Mian and Sufi (2009) show that during the period between 2001 and 2006, the zip codes that exhibited the largest growth in debt were those who experiences the smallest growth in income. They argue that the negative relation between debt growth and income growth at the zip code level over that period is consistent with a growth in the supply of credit to high risk borrowers. We show that this negative relation does not hold for individual data. The differences in credit growth between 2001 and 2009 are positively related to life cycle growth in income and credit scores. Moreover, debt growth for young/low credit score borrowers at the start of the boom occurs primarily for individuals who have high income by 2009, and the growth in income is associated in a growth in credit score. Older individuals in 1999 exhibit much lower subsequent debt and credit score growth, still positively related to their income in 2009. The strong correlation between recent credit scores and income suggests recent credit scores are better indicator of default risk. Appendix D reports estimates of the relation between the growth in total debt balances and total income using the PSID over the 1999-2007 period. The PSID analysis confirms the positive relation between income growth and growth in debt balances in 2001-2006.

The positive relation between income growth and debt growth during the credit boom casts doubt on the notion that there was an increase in the supply of credit, especially to high risk borrowers. Instead, it is more likely that the rise in house prices caused an increase in mortgage balances. This is confirmed by the fact that the fraction of borrowers with mortgages did not rise for any quartile of the credit score distribution, as we show in Section 6.1.1 below. 


\section{Debt and Defaults by Recent Credit Score}

We now present our approach to characterizing the distribution of debt growth during the boom and defaults during the crisis based on recent credit scores. We adopt a lender's perspective, and relate future credit growth at various horizons to a recent lagged credit score to capture the credit score at the time of borrowing. This strategy is based on the observed patterns of credit extension in the U.S. An increase in debt balances between two time periods, say one year, would arise due to either a new loan or credit line, or to an increase in the maximum balance on an outstanding loan or credit line. In most cases, the borrower would have applied for the loan or the balance increase, leading the lender to check the borrower's credit score. Given that our data is quarterly and for most types of debt such requests are processed in a matter of days, the credit score in the quarter before the increase in debt balances is the best proxy of the one that would be available to the lender at the time of application.

Lenders often may also check some other variables in an applicant's credit history, such as the number of missed payments or credit utilization in the last 1-2 years. These factors would be reflected in changes in the credit score in the corresponding period. Changes in the credit score before the application date may also be motivated by the intention to borrow. For example, individuals intending to finance a car purchase may be motivated to improve their credit score in the period leading up to their purchase or to delay the purchase until their credit score has improved- for example by paying down credit card balances- in order to secure better terms. For these reasons, we also include the change in the credit score as an explanatory variable. For most unsecured debt and auto loans, lenders would not typically verify a borrower's income. For mortgage loans, lenders typically also verify a lender's recent income history. We do not have access to income, therefore, we only use the credit score in the last quarter and the change in the score between the last quarter and some previous dates as our main explanatory variables. As we have shown, income and recent credit score are positively related, conditional on age.

Our baseline specification is:

$$
\Delta B_{t, t+h}^{i}=\sum_{j=1,2,3,4} \alpha\left(j_{-1}\right)+\eta \Delta C S_{t-1, t-1-k}^{i}+\text { time fe }+ \text { age fe }+ \text { interactions }+\varepsilon_{t}^{i}
$$

where $i$ denotes and individual, $t$ denotes a quarter, $\Delta B_{t, t+h}^{i}$ is the change in balances between quarters $t$ and $t+h$, and $h \in\{4,8,12\}$ is the horizon. The explanatory variables are $\alpha\left(j_{-1}\right)$ which is a fixed effect for the 1 quarter lagged quartile of the credit score distribution and 
$\Delta C S_{t-1, t-1-k}^{i}$, which represents the change in credit score between $t-1$ and $t-1-k$, with $k \in\{4,6\}$ length of the credit score history considered. The baseline specification includes interactions between the time effects and the 1 quarter lagged credit score quartile. In additional specifications, we also include age $\times 1$ quarter lagged credit score quartile interactions.

Our estimates show that during the boom credit growth was highest for borrowers in the middle and top quartiles of the 1 quarter lagged credit score distribution, at all horizons. We find that past changes in the credit score have virtually no effect on subsequent balance growth. Consistent with our analysis in Section 4, we find strong age effects in balance growth but only for individuals in quartile 2-4 of the 1 quarter lagged credit score distribution. We also find that the growth in delinquent balances during the crisis is concentrated in the middle of the credit score distribution.

In the rest of this section we report our findings. We complement our regression based evidence with an analysis of extensive margins, such as mortgage originations, first mortgages, foreclosures by 8 quarter lagged credit scores. We find there is no growth in the fraction with first mortgages or with new mortgage originations for borrowers in the first quartile of the 8 quarter lagged credit score distribution. Additionally, consistent with Adelino, Schoar, and Severino (2015), we find that the distribution of credit scores at originations is virtually constant throughout the boom. Further, we show that the rise in mortgage defaults and foreclosures is greatest for borrowers in quartiles 2 and 3 of the 8 quarter lagged credit score distribution.

\subsection{Debt Growth}

This section presents our regression results for mortgage balances. In Appendix E, we report results for total debt balances, as well as some robustness analysis.

Our baseline specification uses the 8 quarter ahead change in mortgage balances as the dependent variable and includes the 4 quarter change in credit score as a regressor. Table 2 reports the fixed effects estimates, and figure 14 presents the interactions between the time effects and each quartile of the 1 quarter lagged credit score distribution. The credit score quartile fixed effects show a non-monotone pattern, with quartile 2 and 3 showing estimates of the average 8 quarter ahead mortgage balance change above $\$ 9,000$, approximately three times as large as the value for the first quartile, and approximately double the value for quartile 4. The coefficients on the change in the credit score distribution are $\$ 50$ for the 4 quarter lag and $\$ 51$ for the 6 quarter lag, and highly significant. To understand the economic 
impact of this estimate, it is useful to consider how common credit events may affect the credit score over a 4 or 6 quarter period. Based on a popular credit score calculator service, a borrower with credit score of 610 (in quartile 1) with a $\$ 15,000$ balance on revolving trades (credit cards) and no mortgages can increase her credit score by 30 points over a one year period by paying down 5\% of her balance every month for 12 months. Paying her bills on time over the same period may improve her credit score by only 5 points, while taking out a mortgage would not affect her credit score. The simulated changes in credit score corresponding to these event have smaller effects for borrowers in quartile 2, and negligible effects for borrowers in quartiles 3 and 4, based on the same calculator. Forgetting to pay a bill would reduce her credit score by at least 35 points instantly, irrespective of her initial score. Based on these simulations, common positive credit events inducing a change in credit score over a 4-6 quarter period could change the predicted 8 quarter ahead change in balances by $\$ 250-1,530$ for low credit score borrowers, while a missed payment could reduce the predicted change in balances by $\$ 1,750-1,785$. The magnitudes are sizable, especially for borrowers in quartile 1 , for whom the changes are approximately equal to half of their 8 quarter ahead predicted change in balances.

Table 2: Mortgage Balance Growth

\begin{tabular}{cccccc}
\hline \multicolumn{5}{c}{ Dependent Variable: 8Q Ahead Mortgage Balance Change } \\
\hline \multicolumn{1}{c}{ 1Q lagged CS Quartile Effects } & \multicolumn{2}{c}{ Credit Score Change } \\
1 & 2 & 3 & 4 & $4 \mathrm{Q}$ & $6 \mathrm{Q}$ \\
\hline 3,182 & 9,559 & 9,291 & 4,803 & 50 & \\
4,129 & 10,164 & 9,787 & 5,173 & & 51 \\
\hline
\end{tabular}

Estimated 1Q lagged Equifax Risk Score quartile effects and coefficients for 4Q, 6Q past change from 1Q lagged score in balance change regressions, in USD. Baseline specification. All estimates significant at $1 \%$ level. Sample period 2001Q1-2011Q4. Number of obs. 64,588,488. Source: Authors' calculations based on FRBNY CCP/Equifax Data.

Figure 14 presents the estimated time effects for each quartile of the 1 quarter lagged credit score distribution, net of the averages presented in Table 2. The estimated time effects suggest little growth for quartile 1 during the boom, for which average 8 quarter ahead growth in balances hovers around $\$ 1,000$ between 2001Q3 and 2004Q1 and then peaks at $\$ 3,000$ in 2005. Quartiles 2-4 show a very similar increase in balances between 2001Q3 and 2004Q1, 
averaging approximately $\$ 3,000$ in each quarter over that period. Starting in 2004Q1, the growth rate in balances for quartiles 2 and 3 accelerates, reaching a peak of approximately $\$ 7,000$ in 2005Q4, while the growth in balances is stable over that period for quartile 4 . Starting in 2006Q1, all quartiles experience a sharp decline in the 8 quarter ahead growth in mortgage balances, which bottoms out in 2009Q1 for quartile 2-4 and in 2009Q4 for quartile 1. Figure 31 in Appendix E presents the difference between the time $\times$ quartile effect interactions for quartiles 2-4 relative to quartile 1, with $5 \%$ confidence intervals. These charts clarify that the difference in time effects across quartiles is sizable and highly significant throughout the sample period.

Summing the time effects to the quartile fixed effects in Table 2, which gives us the total change in balances, suggest that mortgage balance growth was close to zero during the 2007-2009 recession, and returns to positive, though much slower than during boom, in the recovery for quartiles 2-4. For quartile 1 borrowers, however, balance growth is negative during the crisis, ranging between $-\$ 3,000$ and $-\$ 6,000$ in each quarter, and remains around these values throughout the sample period. This finding is particularly striking, since quartile 1 borrowers experienced very modest mortgage balance growth during the boom, suggesting the the costs in terms of credit contraction were mainly borne by borrowers who reaped little benefit from the previous boom. Part of the decline in mortgage balances for quartile 1 may also be driven by charge offs by borrowers who had higher credit scores during the boom and drop into quartile 1 during and after the housing crisis as a consequence of mortgage defaults 18

The findings are very similar using the 4 quarter ahead and 12 ahead change in mortgage balances, including additional robustness results for the 8 quarter ahead change in mortgage balances. Table 11 in Appendix Esummarizes the implied cumulated mortgage debt balance change for 2002-2006 and 2007-2010 by sub period using the 4, 8 and 12 quarter ahead mortgage balance change regressions.

Role of Age Figure 15 presents the estimated age effects for the baseline specification (left panel) and for the version in which the age effects are interacted with the quartile fixed effects (right panel) 19 The common age effect estimated in the left panel is consistent with our estimates in Section 4.1, since the cumulated growth in mortgage debt balances between age 20 and age 30, which corresponds to peak growth over the life cycle, based on the 8

\footnotetext{
${ }^{18}$ This is consistent with the behavior of delinquent balances, described in Section 6.2.1.

${ }^{19}$ The estimated quartile effects and quartile time effects differ very little across these two specifications.
} 


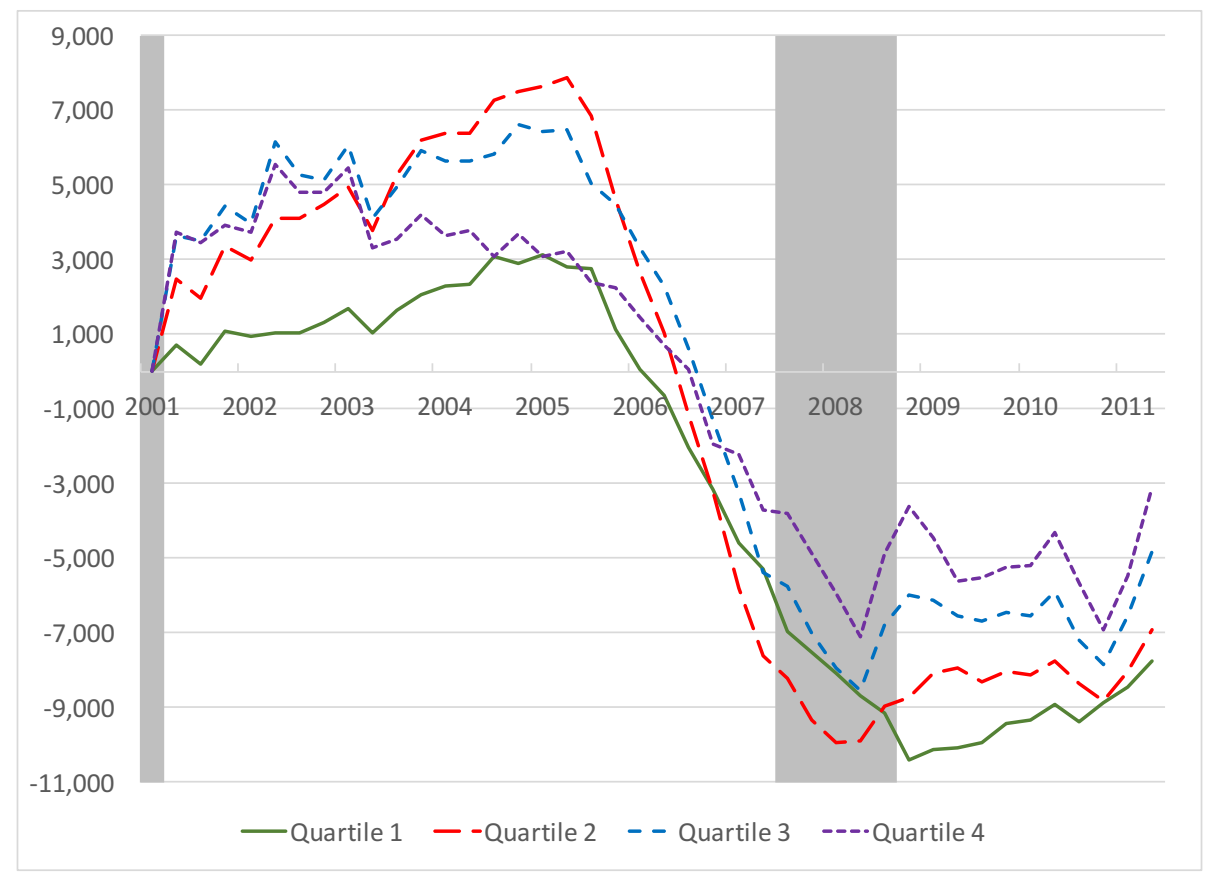

Figure 14: Estimated time effects by 1Q lagged Equifax Risk Score quartile from balance change regressions. Baseline specification. Dependent variable is the $8 \mathrm{Q}$ ahead change in per capita mortgage balances in USD. Sample period 2001Q1-2011Q4. Number of obs. (baseline) 64,588,488. Source: Authors' calculations based on FRBNY CCP/Equifax Data.

quarter ahead change is approximately $\$ 35,000\left[{ }^{20}\right.$ However, the interactions between the quartile and age effects suggest that only borrowers in quartiles 2-4 of the 1 quarter lagged credit score distribution experience a life cycle growth in mortgage balances, and the size of this growth is increasing with the credit score quartile. This result is consistent with our findings in Section 5, where we show that the life cycle growth in mortgage balances is closely related by the life cycle growth in income and credit scores.

\subsubsection{Homeownership and Originations}

To corroborate the regression analysis on mortgage balances, we also examine borrowing behavior by recent credit score on the extensive margin. Consistent with our baseline regression specification, we rank borrowers by their 8 quarter lagged credit score. Our findings are robust to alternative recent rankings, such as 4 quarter lagged credit score.

Figure 16 presents the fraction with first mortgages, which can be taken to correspond to the home ownership rate in these data, and the fraction with new originations by 8

\footnotetext{
${ }^{20}$ This estimate is obtained by averaging out the quartile fixed effects and adding them to the age effects.
} 
Age EFFECts

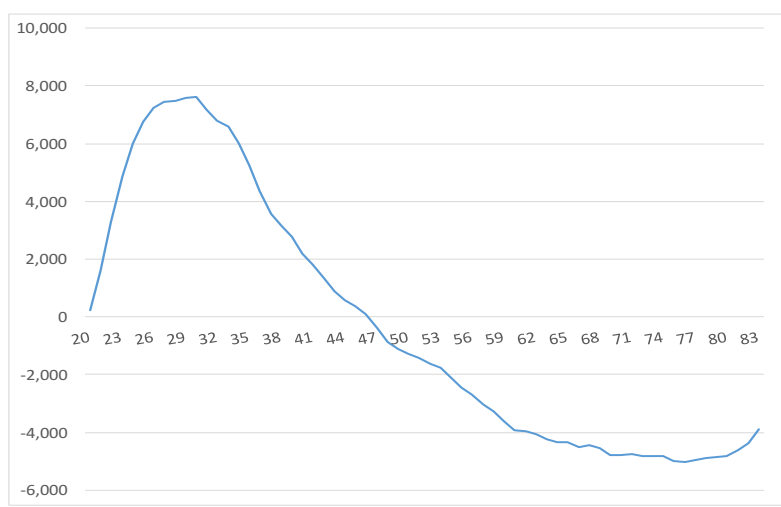

Age Effects by Quartile

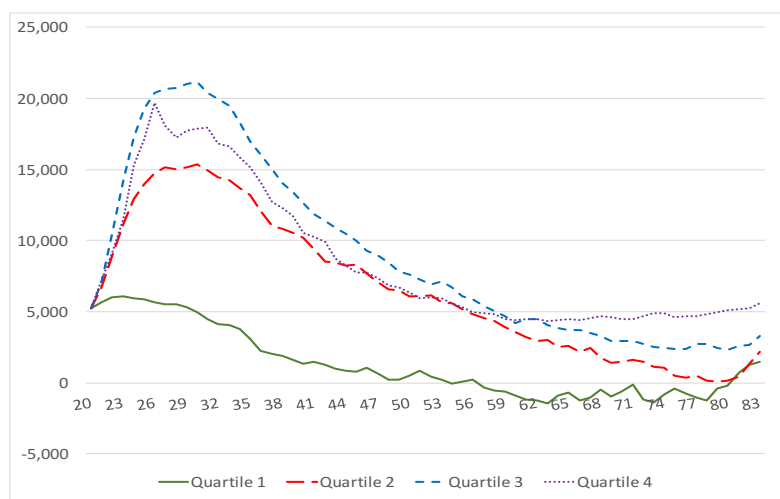

Figure 15: Estimated age effects from balance change regressions. Baseline specification (left) and specification with age $\times$ credit score quartile interactions (right). Dependent variable is the 8Q ahead change in per capita mortgage balances in USD. Sample period 2001Q32011Q4. Number of obs. (baseline) 64,588,488. Source: Authors' calculations based on FRBNY CCP/Equifax Data.

quarter lagged credit score. Both the fraction with first mortgages and the fraction with new mortgage originations are virtually constant for quartile 1 during the boom. The fraction with first mortgages grows by approximately 10 percentage points between 2001Q3 and 2007Q4 for quartiles 2 and 3, and by about 6 percentage points for quartile 4. Quartiles 2-4 experience a boom in new originations between 2001 and 2004Q1. The fraction with new mortgage originations rises from just below 20\% in 2001Q1 to 23\% and 27\% at the peak for quartiles 2 and 3, respectively. For quartile 4, it rises from 12\% in 2001 to $22 \%$ in 2004Q1. The sizable rise in mortgage originations for prime borrowers early in the boom combined with the modest rise in the fraction of borrowers with first mortgages for that period suggests that most of the originations reflect refinancing activity ${ }^{21}$ or real estate investing, as we document in Section 7.1 below. The fraction with new mortgage originations drops thereafter for quartiles 2-4, reaching lows of 6-8\% in 2009Q2, when it starts to slowly recover. For quartile 1, the fraction of borrowers with new originations declines between 2001 and 2006, reaching 8\% in 2006, and then stabilizes between 2006Q1 and 2007Q1. It then decline to close to zero by the end of 2009 .

Figure 17 presents the distribution of credit scores at originations for each quarter of our sample period. The fraction of new mortgage originations attributable to borrowers in quartiles 1 and 3 of the credit score distribution remains virtually constant throughout the

${ }^{21}$ Chen, Michaux, and Roussanov (2013) and Bhutta and Keys (2016) document the rise of refinancing activity during the credit boom and argue that in 2001-2004 it was mainly driven by lower mortgage rates. 
Fraction with First Mortgages

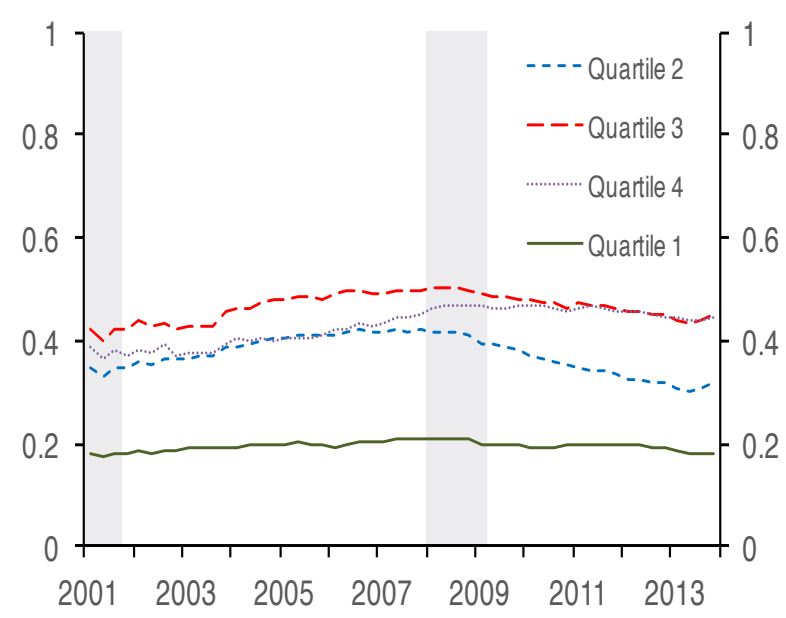

Fraction with New Originations

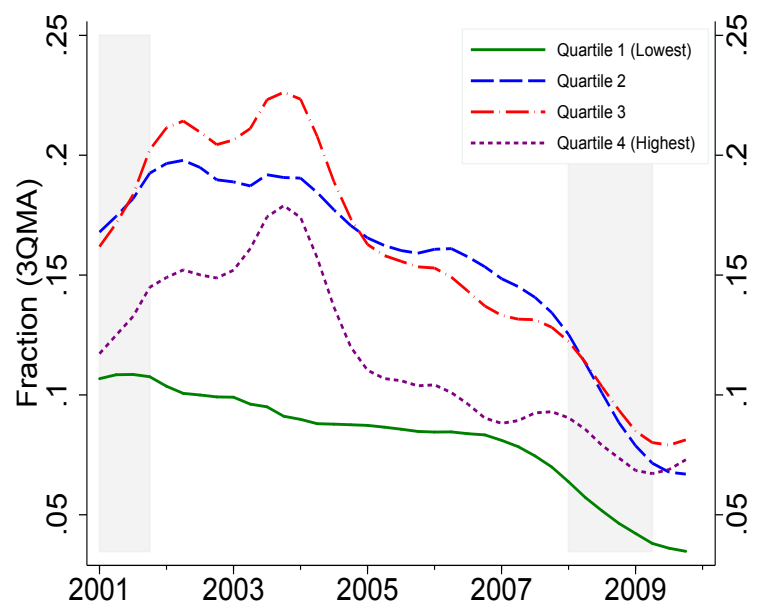

Figure 16: Fraction with first mortgages and fraction with new mortgage originations by 8Q lagged Equifax Risk Score quartile . Quartile cutoffs: 615, 720, 791, 840.

Source: Authors' calculations based on FRBNY CCP/Equifax Data.

sample period. There is a modest rise in the fraction of originations to borrowers in quartile 2, from 23\% in 2003Q4 to a peak of 30\% in 2006Q4, after which they drop to a low of $20 \%$ in 2011Q2. The fraction of new originations to borrowers in quartile 4 of the credit score distribution peaks at 28\% in 2003Q3 during the boom, but rises during the crisis from $20 \%$ in 2006Q4 to 31\% in 2011Q2 and then stabilizes. This rise reflects the tightening of lending standards during the crises. 22

\subsection{Defaults}

We now examine default activity by recent credit score. As for debt growth, we use regression analysis to examine the behavior of delinquent balances over the sample period, and then use a recent credit score ranking to the examine the distribution of mortgage delinquencies and foreclosures.

\subsubsection{Delinquent Balances}

We follow the same regression specification described in Section 6.1 for the 8 quarter ahead change in $90+$ days delinquent mortgage balances. The estimated quartile fixed effects are presented in Table 3. The average 8 quarter ahead change in delinquent balances falls with the 1 quarter lagged credit score, with the estimated effects for quartiles 3-4 about half as

\footnotetext{
${ }^{22}$ See Brown et al. (2014) for a discussion.
} 


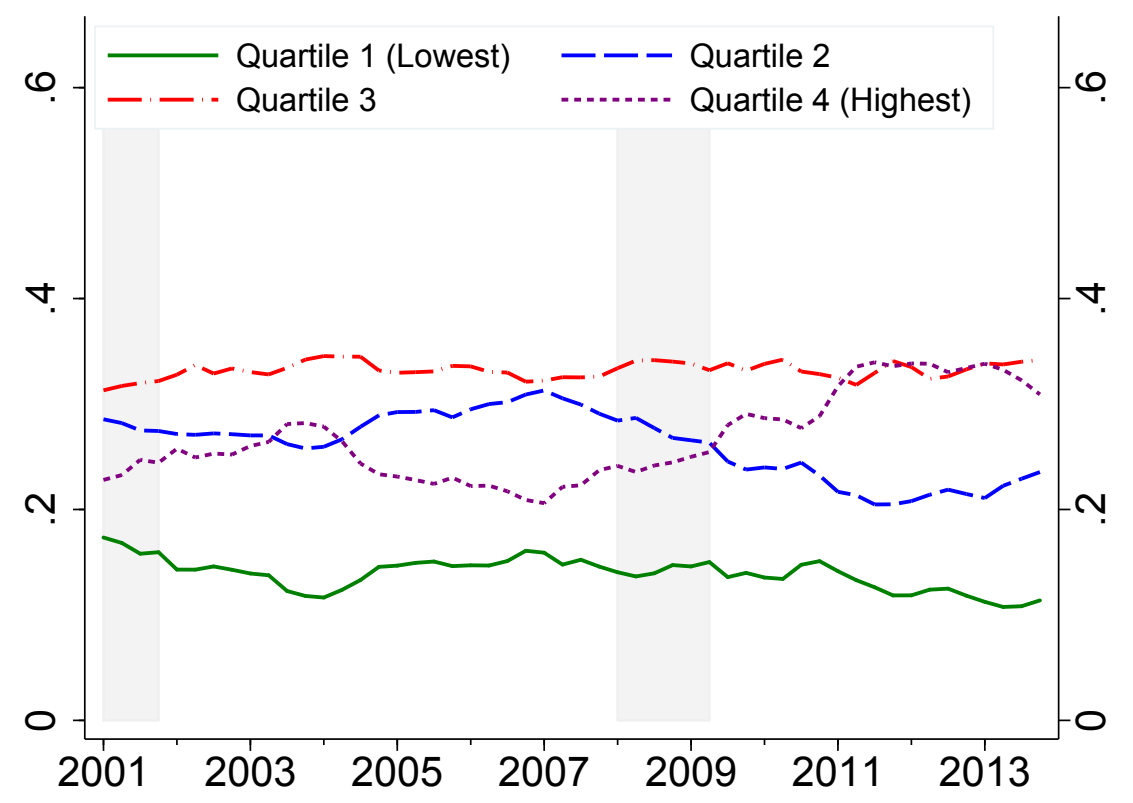

Figure 17: Individuals with a new mortgage origination. Fraction in each quartile of the 4Q lagged Equifax Risk Score distribution. Source: Authors' calculations based on FRBNY CCP/Equifax Data.

large as for quartiles 1-2. As for debt growth, the contribution of past credit score changes to the growth in delinquent balances is non negligible especially for low credit score borrowers. For example, a 30 point increase in the credit score over a 4-6 quarter period corresponds to an increase average delinquent balances of approximately $\$ 1,000$. The fact that a past increase in the credit credit score corresponds to an increase in predicted delinquent balances is due to the fact that such an increase is associated in an increase in average balances over the same horizon, as shown in Table 2 .

Figure 18 presents the balance change time effects by 1 quarter lagged credit score. There is a very large rise in the 8 quarter ahead change in delinquent balances for quartiles 2-3 starting at the end of the credit boom into the crisis. For quartile 2, the change in delinquent balances is very close to zero until 2004Q4, when it starts rising to a peak of $\$ 5,900$ in 2007Q3. For quartile 3, the growth in delinquent balances also started to pick up in 2004Q4, reaching a peak of $\$ 3,900$ in 2008Q2. Quartile 4 also experience a modest rise in the growth in delinquent balances to a peak of about $\$ 1,000$ in 2008Q2. The growth in delinquent balances declines for all borrowers during the 2007-09 recession and for about a year after. For quartiles 2-4, the growth in delinquent balances goes back to zero by 2011, 
Table 3: Growth in Delinquent Balances

\begin{tabular}{lccccc}
\hline \multicolumn{5}{c}{ Dependent Variable: 8Q } & Ahead Delinquent Balance Change \\
\hline & 1Q lagged CS Quartile Effects & \multicolumn{2}{c}{ Credit Score Change } \\
1 & 2 & 3 & 4 & $4 Q$ & $6 Q$ \\
\hline 505 & 635 & 227 & 194 & 33 & \\
993 & 856 & 404 & 318 & & 34 \\
\hline
\end{tabular}

Estimated 1Q lagged Equifax Risk Score quartile effects and coefficients for 4Q, 6Q past change from 1Q lagged Risk Score in balance change regressions, in USD. Baseline specification. All estimates significant at 1\% level. Sample period 2001Q3-2011Q4. Number of obs. 64,588,488. Source: Authors' calculations based on FRBNY CCP/Equifax Data.

whereas it hovers around $-\$ 7,000$ in 2009 and 2010 for quartile 4 . For quartile 1 , the growth in delinquent mortgage balances is close to zero until mid 2005, when it rising, reaching $\$ 1,800$ in 2007Q3. Subsequently, there is a large decline in the growth in delinquent mortgage balances for quartile 1 , to a low of $-\$ 8,200$ by 2010 Q1. This pattern is driven by the large decline in mortgage balances for borrowers in the first quartile, discussed in Section 6.1, and may in part be driven by charge offs. We find similar results for the change in delinquent balances at 4 and 12 quarter ahead horizon 23

\subsubsection{Defaults by Recent Credit Score}

We now examine default behavior on the extensive margin by recent credit score, and again we present results by 8 quarter lagged credit score as a baseline. Results are very similar for 4 quarter lagged credit score.

Figure 19 presents the distribution of new mortgage delinquencies. The fraction of borrowers with a new $90+$ days mortgage delinquency in the last 4 quarters (left panel) is highest for borrowers in quartile 1 in 2001-2004. During this period, it drops from $1.8 \%$ to $1 \%$, and by 2004Q1, the fraction with a new mortgage delinquency in quartile 1 is very similar to the fraction for quartile 2 . The delinquency rate starts rising for both quartile 1 and 2 in 2005Q2, though the rise for quartile 2 is much bigger than for quartile 1 , so that the fraction with new delinquencies peaks at 1.3\% in 2007Q2 for quartile 1 and at 1.7\% in 2009Q1 for quartile 2. The fraction with new delinquencies hovers around $0.3 \%$ for quartile

\footnotetext{
${ }^{23}$ Appendix E.2 reports additional results for delinquent balances, including the estimated age affects.
} 


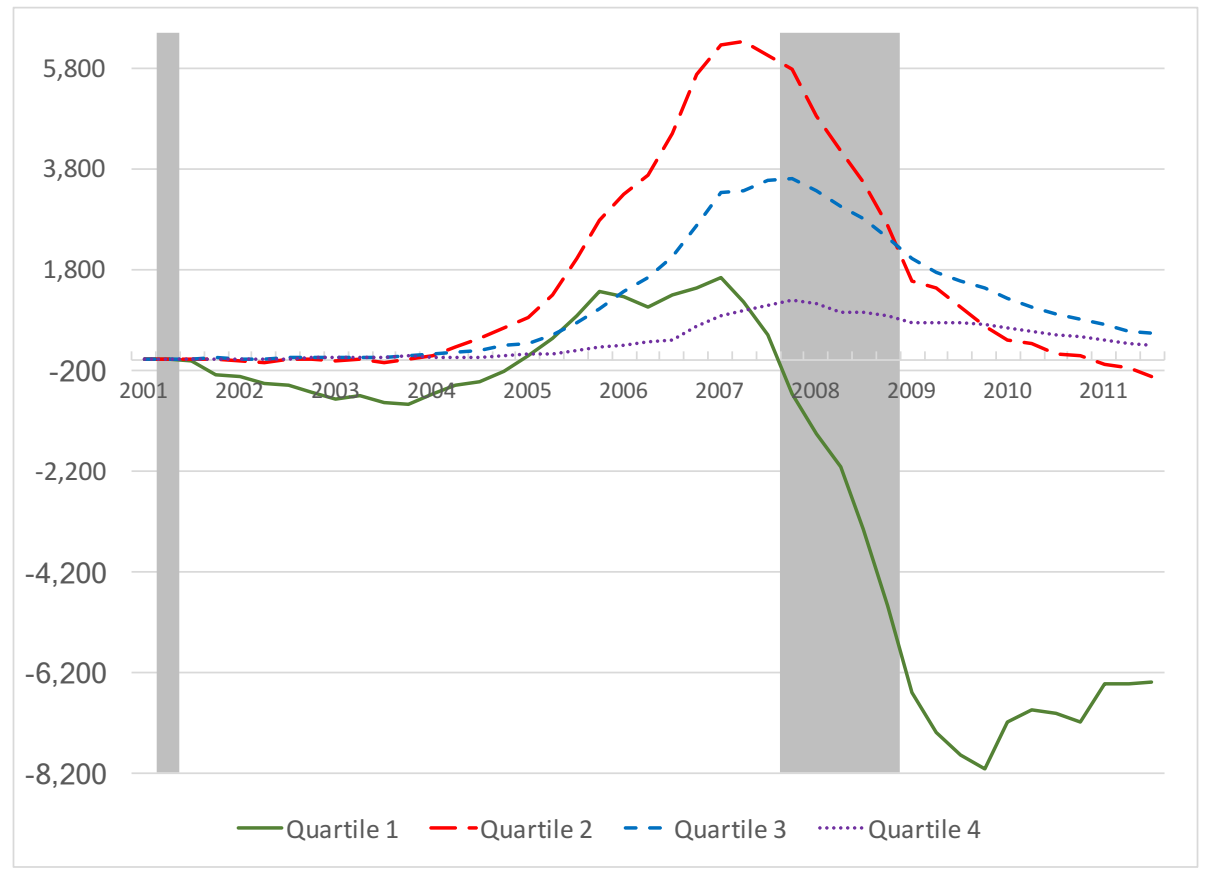

Figure 18: Estimated time effects by 1Q lagged Equifax Risk Score quartile from balance change regressions. Baseline specification. Dependent variable is the $8 \mathrm{Q}$ ahead change in per capita 90+ days delinquent debt balances in USD. Sample period 2001Q3-2011Q4. Number of obs. 64,588,488. Source: Authors' calculations based on FRBNY CCP/Equifax Data.

3 and $0.15 \%$ for quartile for during the boom. During the crisis, it rises to a peak of $0.45 \%$ in 2009Q3 for quartile 3, with a very modest rise for quartile 4 over the same period. As a result of the large rise in the fraction of new delinquencies for borrowers in quartile 2 and 3 , the quartile 1 share of new delinquencies (right panel) falls by 10 percentage points during the crisis. The share of delinquencies for quartile 2 borrowers rises by 8 percentage points during the crisis and by 11 percentage points for quartile 3 .

Figure 20 presents the same statistics for new foreclosures. The quartile 1 and 2 fraction with new foreclosures in the last 4 quarters (left panel) average to $0.26 \%$ and to $0.1 \%$, respectively, for the period ending in 2005Q2. For quartile 3 and 4, this fraction is very close to zero until 2006Q3. In mid 2006, new foreclosures start rising for all quartiles, and the rise is particularly pronounced for borrowers in quartile 2 and 3 of the 8 quarter lagged credit score distribution. As a result, the share of new foreclosures (right panel) for quartile 1 borrowers drops from $73 \%$ during the boom to a low of 39\% in 2009Q1. By contrast, the share of new foreclosures to quartile 2 borrowers rises from $21 \%$ during the boom to a peak of $38 \%$ in 2009Q1. The share of foreclosures to quartile 3 also rises noticeably from around $4 \%$ 

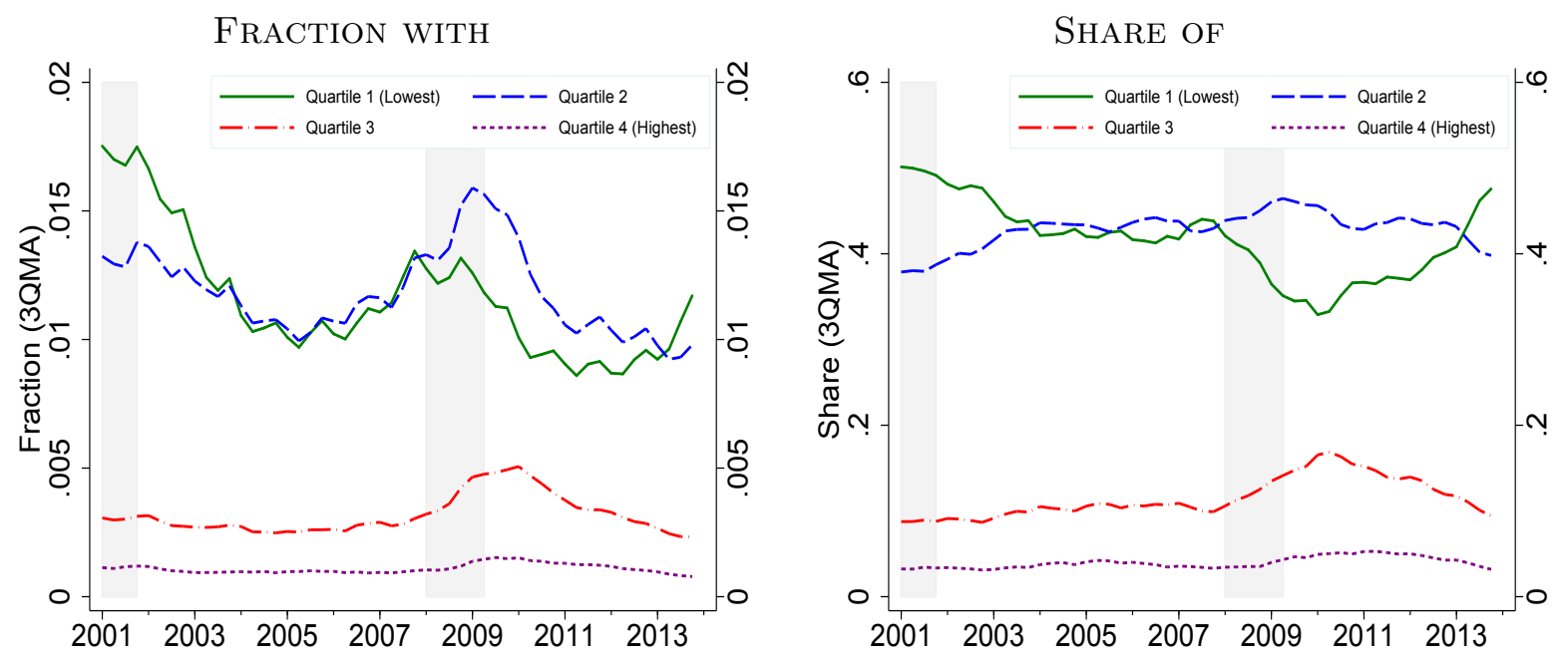

Figure 19: New 90 days+ delinquencies by credit score quartile, 8Q lagged Equifax Risk Score. Source: Authors' calculations based on FRBNY CCP/Equifax Data.

during the boom, to a peak of 13\% in 2009Q2, and the share for quartile 4 also experiences a 5 percentage point rise over the same period.

\subsection{Summary}

We conclude this section with a brief summary of our findings. As discussed in Section 4 , initial credit score rankings overstate mortgage and total debt growth for low credit scores borrowers.

Using a lender's approach based on recent credit scores, we find that credit growth during boom is concentrated in the middle and the top of the credit score distribution and that the rise in defaults during the crisis is concentrated in the middle of credit score distribution. The share of new mortgage delinquencies and foreclosures to low credit score borrowers drops considerably during the crisis, challenging the notion the increase borrowing and defaults by low credit score borrowers was the main source for the housing crisis.

\section{Explaining Defaults by Prime Borrowers}

The findings presented in the previous section are puzzling given the typically very low default rates for high credit score borrowers. It is then natural to ask why did individuals with good credit histories experience defaults during the crisis. In this section, we document 
FRACTION WITH

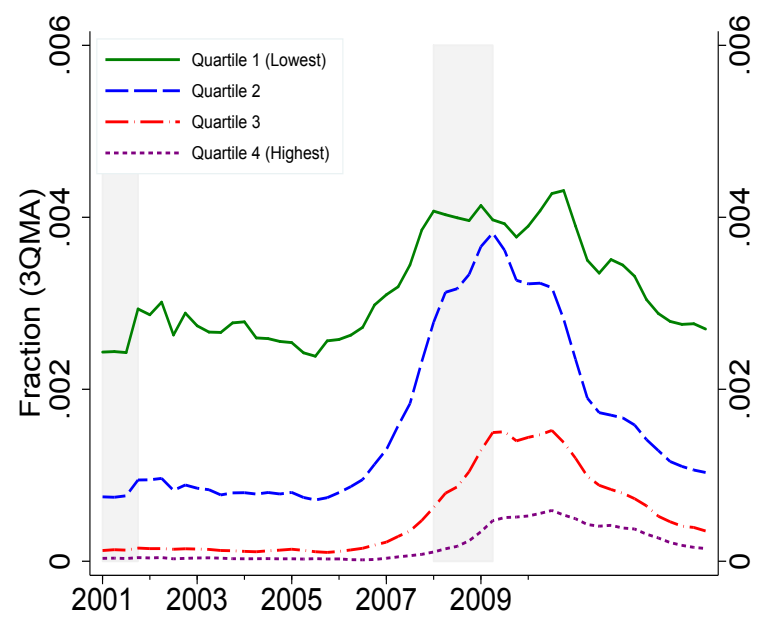

SHARE OF

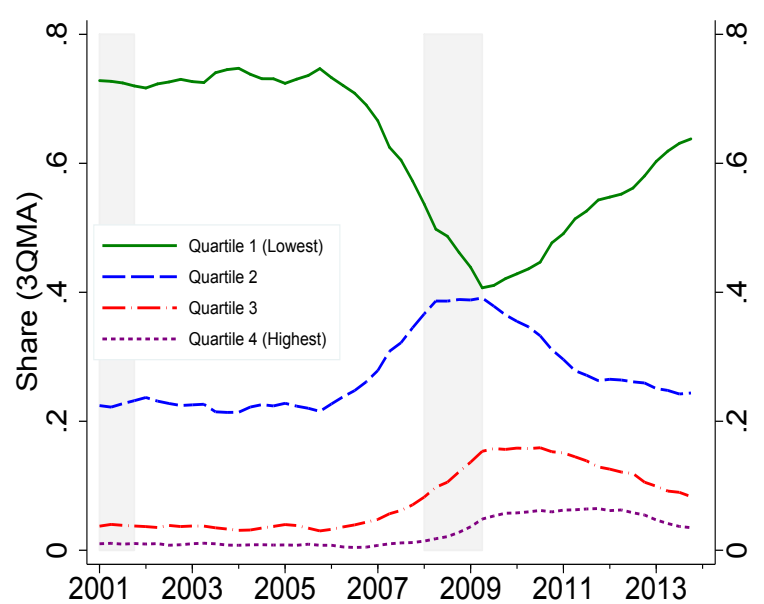

Figure 20: New foreclosures by credit score quartile, 8Q lagged Equifax Risk Score. Source: Authors' calculations based on FRBNY CCP/Equifax Data.

the rise in real estate investors in the prime segment, and we show the increase in mortgage defaults among prime borrowers is primarily driven by real estate investors. We also consider the rise in non-conforming loans. We focus specifically on jumbo loans, which are not eligible for GSE insurance. We find that jumbo loans rise modestly only for prime borrowers. ${ }^{24}$

\subsection{Role of Investors}

We follow Haughwout et al. (2011) and define investors as borrowers who hold 2 or more first mortgages. Real estate investors are particularly interesting as they may be more prone to default than mortgage borrowers who reside in the property that secures the mortgage, as we discuss below. Moreover, conventional GSE sponsored mortgages are only available for owner occupied properties, which implies investors are more likely to use alternative products, such as Alt-A mortgages, adjustable rate mortgages and other non-standard products.25

\footnotetext{
${ }^{24}$ Another possibility is that the 2007-2009 was so severe that it affected relatively high income individuals and led to a rise in mortgage defaults in populations that are not usually affected. Indeed, Foote, Gerardi, and Willen (2008) argue that negative equity is a necessary but not sufficient condition for mortgage default, and show that negative income shocks may be the ultimate trigger for defaults.

25 Keys et al. (2012) document the sizable increase of Alt-A mortgages, that have low standard for income documentation and would be particularly appropriate for real estate investors who have variable and hard to document income. Further, Foote and Willen (2016) also discuss the role of alternative mortgage products and the fact that their structure may increase the risk of default. However, Elul and Tilson (2015) present evidence of substantial misrepresentation of home purchases as primary residences, for the purpose of qualifying for GSE sponsored mortgages.
} 
Additionally, if investors are motivated by the prospect of capital gains ${ }^{26}$ they have an incentive to maximize leverage, as this strategy increases potential gains, while the potential losses are limited, especially in states in which foreclosure is non recourse.

Figure 21 presents the fraction of borrowers with 2 or more first mortgages and their share of total balances, among all first mortgage holders, by 8 quarter lagged credit score quartile. The fraction of investors (left panel) increases with credit score quartile. Most notably, quartiles 2-4 experience a 14-16 percentage point increase in the fraction of investors between early 2004 and the start of the 2007-09 recession. For quartiles 2-3, the fraction of investors drops to pre boom levels by 2011, but it settles at the 2007 peak for borrowers in quartile 4. The fraction of investors for quartile 1 is about half of the fraction for higher quartiles, and rises only modestly during the boom. ${ }^{27}$ The time path of the investor share of mortgage balances (right panel) is very similar to the path of the fraction of investors, but the share of investor balances is sizably higher than the fraction of investors, as balances per capita are substantially higher for investors. At the beginning of the sample, the share of mortgage balances held by investors is $15 \%$ for quartile 1, 25\% for quartile $2-3$ and $30 \%$ for quartile 4. This share remains mostly stable for quartile 1 borrowers throughout the sample period while it increases by approximately 15 percentage points for those in quartile 2 and 3, starting in 2004. For quartile 4 borrowers, investor mortgage balances grows steadily during the boom peaking at $43 \%$ at the start of the 2007-09 recession. During and after the recession the investor share of mortgage balances drops, reaching pre-boom levels for quartile 2, and dropping below those levels for quartiles 2 and 4. Appendix F presents the fraction of investors and the share of balances by specific number of first mortgages (only 2 , only 3 and $4+$ ), and shows that both these statistics are increasing with credit score quartile and display the same overall patterns as the combined statistics. ${ }^{28}$

Figure 22 and 23 report the fraction of borrowers with mortgage delinquencies and foreclosures, respectively, by number of first mortgages. Figure 22 reports the fraction of borrowers with a 90+ day mortgage delinquency by number of first mortgages. Between 2002 and 2006, delinquency rates are similar for investors and non investors for borrowers in quartiles 2-4, but more than twice as high for investors relative to non-investors for borrowers in quartile

\footnotetext{
$2 6 \longdiv { \text { Adelino, Schoar, and Severino (2015) } }$ argue that this is the only explanation for the high levels of borrowing towards the end of the boom.

${ }^{27}$ Ferreira and Gyourko (2015) find that the fraction of investors is very similar for prime and subprime borrowers. However, their definition of investors is restricted, and includes only businesses, and borrowers with a tax address different from their mortgage address. Chinco and Mayer (2014) also identify real estate investors using the difference between property address and tax address.

${ }^{28}$ Bhutta (2015) also finds that new mortgages to real estate investors grew markedly during the housing boom, but he does not examine the differentiation by credit score.
} 

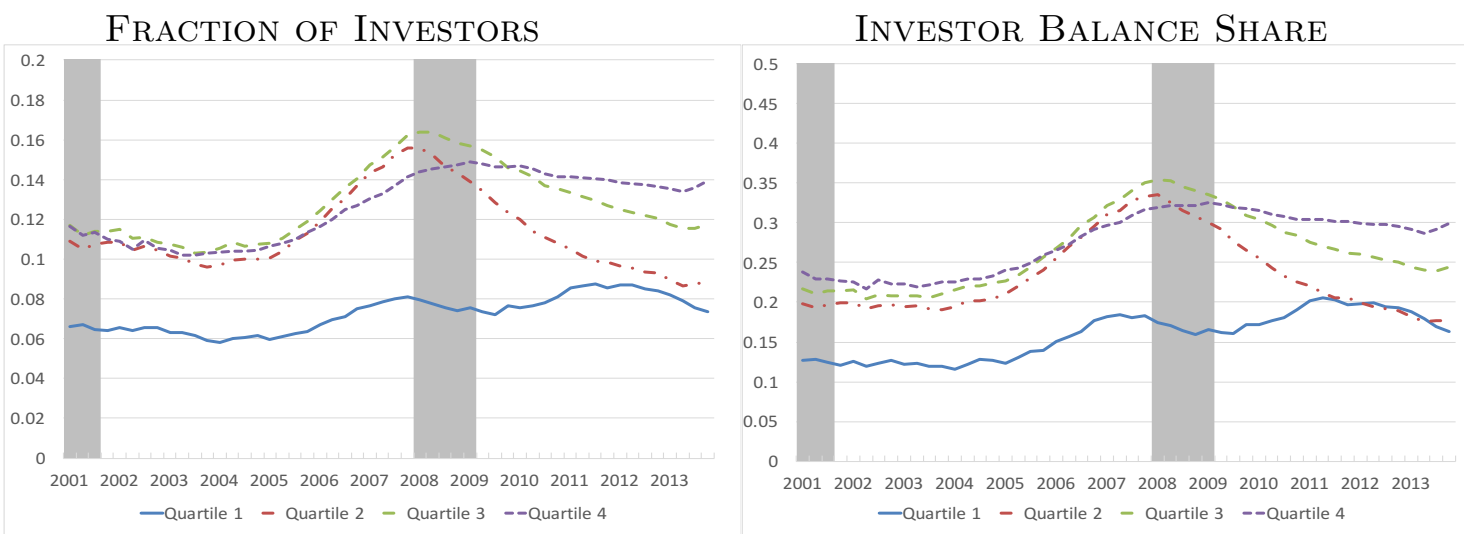

Figure 21: Borrowers with 2 or more first mortgages, fraction (left panel) and share of mortgage balances (right panel) by quartile of the 8Q lagged Equifax Risk Score. Source: Authors' calculations based on FRBNY CCP/Equifax Data.

1. For non investors, the fraction of borrowers with mortgage delinquencies approximately doubles for quartiles 1-3 of the credit score distribution, and rises very modestly for borrowers in quartile 4 from the start of 2007 until the end of 2009, returning close to pre-crisis levels rises by 2012. Strikingly, the fraction with new delinquencies rises much more strongly for investors than for non-investors over the same period. It roughly doubles for quartile 1 , and exhibits a more than 5 fold increase for higher quartiles.

2 OR MORE (INVESTORS)

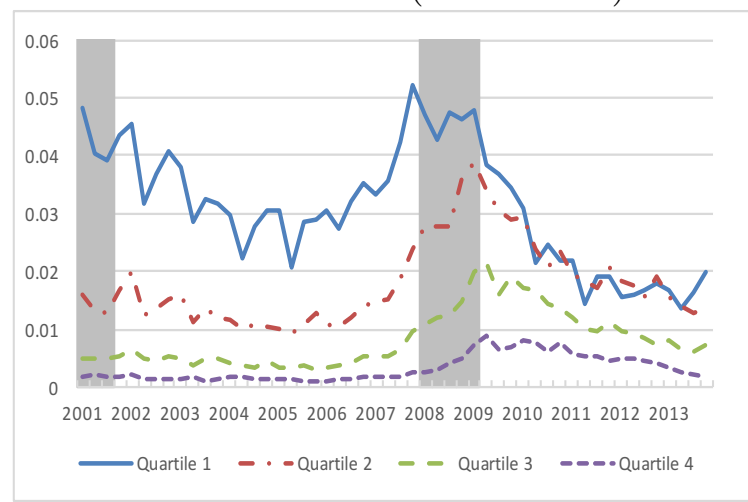

ONLY 1

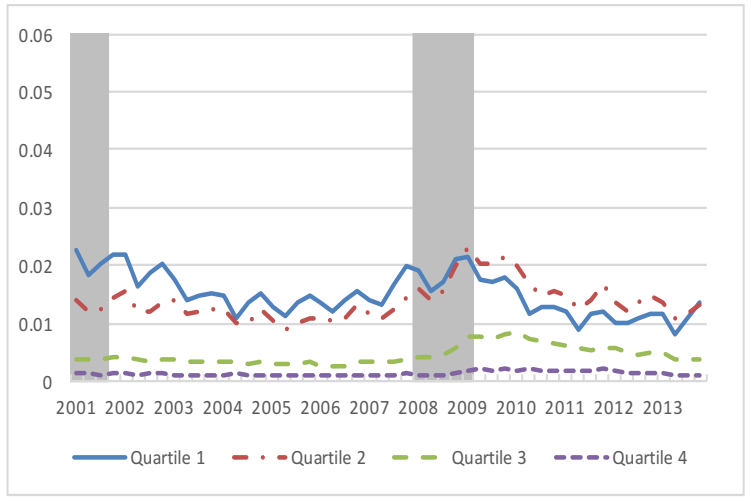

Figure 22: Fraction with new 90+ days mortgage delinquency in the last 4 quarters for borrowers with 2 or more (left panel) and only 1 (right panel) first mortgages by quartile of the 8Q lagged Equifax Risk Score. Source: Authors' calculations based on FRBNY CCP/Equifax Data.

Figure 23 presents the fraction of borrowers with new foreclosures in the last 4 quarters. During the 2002-2006 housing boom, the foreclosure rate is very similar for investors and non-investors in all quartiles. However, during the crisis a great divergence emerges, with 
investors experiencing much higher foreclosure rates than non-investors, especially for higher credit score quartiles. For investors foreclosure increases by a factor of 4 for the lowest quartile, and by more than a factor of 10 for quartiles 2-4. For non-investors, the foreclosure rate roughly doubles in quartile 1-2, and rises very modestly for quartiles 3-4. Appendix F reports delinquency and foreclosure rates by specific number of first mortgages, showing that the the rise is delinquency and foreclosure rates during the crisis is monotonically increasing in the number of first mortgages for all quartiles.

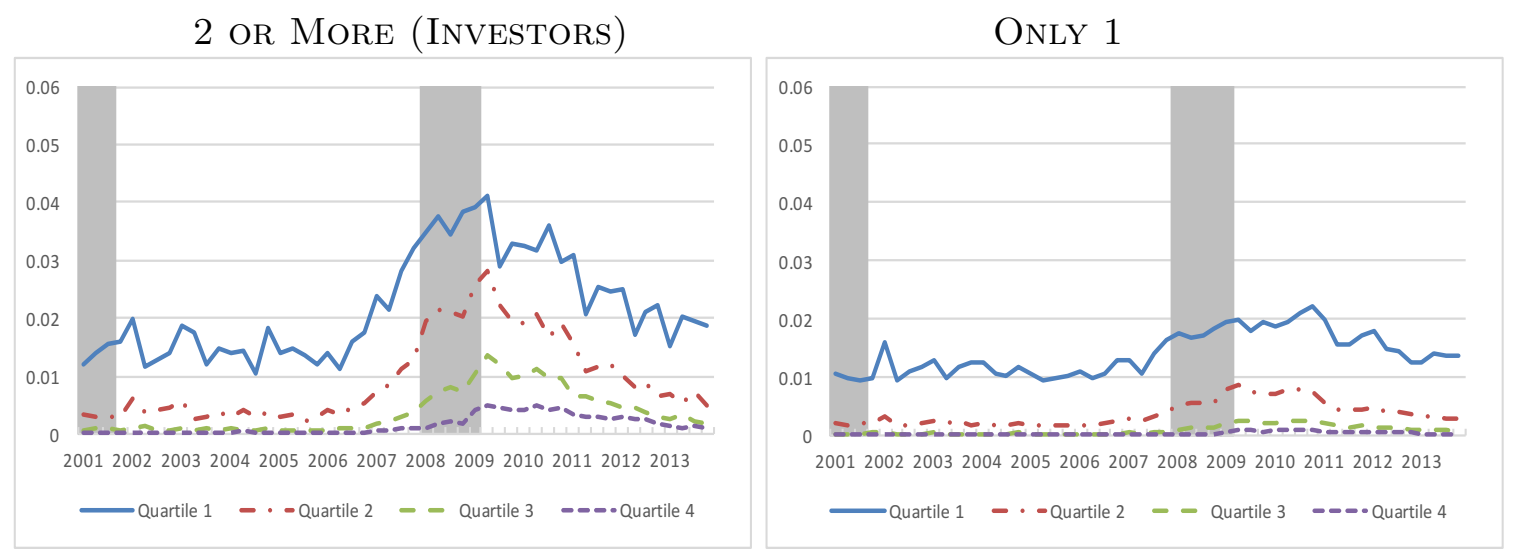

Figure 23: Foreclosure rates for 2 or more (left panel) and only 1 (right panel) first mortgages by quartile of the $8 \mathrm{Q}$ lagged Equifax Risk Score. Source: Authors' calculations based on FRBNY CCP/Equifax Data.

As a consequence of the greater rise of default rates for investors relative to non-investors, the share of investor defaults rises during the crisis. Figure 24 presents the investor share of 90+ days mortgage delinquencies and foreclosures. The delinquency share of investors is about $10 \%$ for all quartiles until mid 2006. This is similar to the share of investors for quartiles 2-4, but about twice the share of investors for quartile 1 over that period. The foreclosure share of investors is about $20 \%$ on average during the 2002-2006 boom for quartiles 2-4, which is about twice the fraction of investors for those groups, whereas the investor share of foreclosures for quartile 1 is close to $10 \%$. At the onset of the crisis, there is a sharp rise of the investor share of delinquencies, and especially foreclosures, for borrowers in quartiles 2-4 of the credit score distribution. The share of investor delinquencies rises from $10 \%$ to $17 \%$ for quartile 1, to $20 \%$ for quartile 2 , to $30 \%$ for quartile 3 and to $40 \%$ for quartile 4, with the peak for quartiles 1-3 occurring at the start of the 2007-09 recession, and the peak for quartile 4 at the end of the recession. The investor share of delinquencies subsequently declines, reaching pre-crisis levels by 2012 for quartiles 1-2, but remaining much higher relative to pre-recession levels for quartiles 3-4. The pattern is similar but more 
dramatic for foreclosures. The investor share of foreclosure rises from $20 \%$ to approximately $60 \%$ for quartiles 3 and 4, to $40 \%$ for quartile 2 and only to $15 \%$ for quartile 1 between early 2006 and the start of 2008. For quartiles 1-2, the investor share of foreclosures converges back to pre-crisis levels by the end of 2011, while it remains at more than twice the pre-crisis levels for quartiles 3-4.

DELINQUENCY SHARE

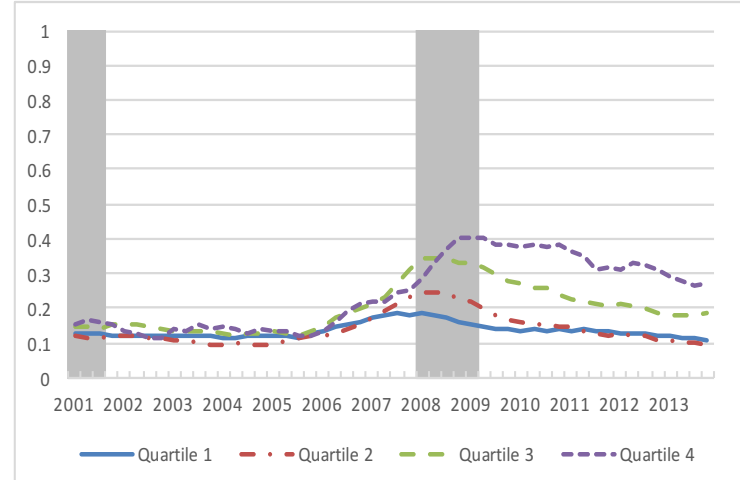

Foreclosure Share

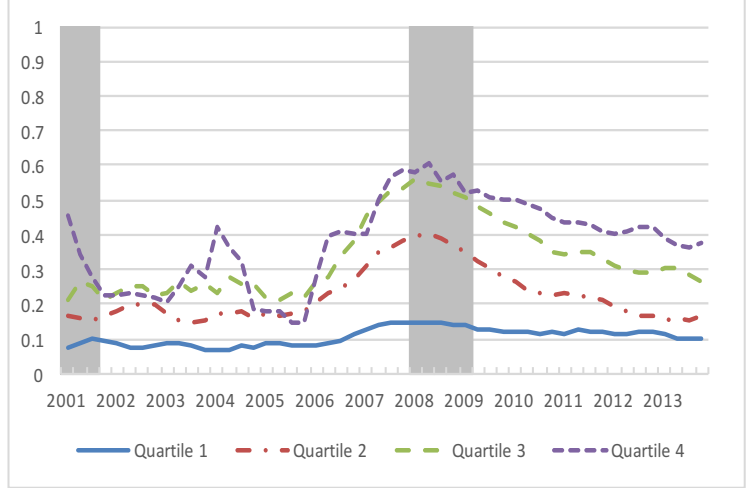

Figure 24: Investor share of 90+ days delinquencies (left panel) and foreclosures (right panel) by quartile of the $8 \mathrm{Q}$ lagged Equifax Risk Score. Source: Authors' calculations based on FRBNY CCP/Equifax Data.

To more precisely quantify the role of investors in the growth in mortgage balances and defaults, we run a number of counterfactuals presented in Table 4 . The top panel considers the growth in mortgage balances in 2001Q3-2006Q4. The first row presents the dollar change in per capita mortgage balances by quartile of the 8 quarter lagged credit score distribution over that period. The second row computes the same change in balances maintaining the distribution of the fraction of first mortgages at the 2001Q3 values, allowing balances per capita by number of first mortgages to take their historical value. Both measures are reported as a fraction of the total change ${ }^{29}$ The growth of mortgage balances per capita with a fixed distribution of number of first mortgages accounts for $77 \%$ of the total for quartile 1, $62 \%$ of the total for quartiles 2 and 3, and $69 \%$ for quartile 4 . The third row presents the growth in mortgage balances per capita keeping mortgage balances per capita constant by number

\footnotetext{
${ }^{29}$ Total balances per capita for quartile $i=1,2,34$ is $B_{t}^{i}=\sum_{j} \pi_{t}^{i, j} B_{t}^{i, j}$, where $j$ denotes the number of first mortgages $(0,1,2,3,4+)$ and $t=\{\underline{t}, \ldots, \bar{t}\}$ is the quarter. The variables $\pi_{t}^{i, j}, B_{t}^{i, j}$ are the corresponding fraction of borrowers and the per capita value of balances for that category of borrowers. In the first counterfactual, we set $\pi_{t}^{i, j}=\pi_{\underline{t}}^{i, j}$ for all periods, and in the second counterfactuals we set $B_{t}^{i, j}=B_{\underline{t}}^{i, j}$ for all periods. we then consider the change in these 3 statistics between $\underline{t}$ and $\bar{t}$, and report the ratio of the change in the counterfactual value to the total value. These two statistics need not add up to 1 as interactions are not included. The same counterfactuals are computed for delinquency and foreclosure rates, where we only include two groups $(j)$, borrowers with only 1 first mortgages or borrowers with 2 or more.
} 
of first mortgages, but allowing the distribution of the number of first mortgages to follow its historical path. The change in the distribution of the number of first mortgages accounts for only $13 \%$ of the total for quartile 1, $20 \%$ for quartiles 2 and 4, $22 \%$ for quartile 3 . This pattern confirms that the the rise in the fraction of borrowers with 2 or more first mortgages is more important for borrowers in higher quartiles.

The second and third panel of Table 4 report similar calculations for the change in delinquency and foreclosure rates in 2006Q3-2009Q4. Here, we report the log change in the rates, since the base delinquency and foreclosure rates vary substantially across quartiles ${ }^{30}$ For delinquency rates, the log change for quartile 1 is 0.12 , while it is respectively $0.32,0.54$ and 0.44 for quartiles 2, 3 and 4. The log change with fixed investor share accounts for $97 \%$ of the total change in delinquency rates for quartile 1,99\% for quartile 2, 98\% for quartile 3 and $95 \%$ for quartile 4 . The change with fixed delinquency rate for investors is $91 \%$ of the total change for quartile 1, $82 \%$ for quartile 2, $76 \%$ for quartile 3 and $63 \%$ for quartile 4. These results confirm the large role of both the rising investor delinquency rate and the rising share of investors in the increase in delinquencies for high credit score borrowers during the crisis. A similar but heightened pattern holds for foreclosures. In this case the log change in foreclosure rates is 0.27 for quartile 1, approximately 2.5 larger for quartile 2 , and approximately 5 and 6 times higher for quartiles 3 and 4, respectively. The log change in foreclosure rates with fixed investor share is $98-99 \%$ as large as the total change, while the change with constant investor foreclosure rates is $85 \%$ of the total change for quartiles 1 and 2 , and $77 \%$ and $66 \%$ of the total change for quartiles 3 and 4 , respectively. These results suggest that the increase in foreclosure rates for investors account for a much larger fraction of the total rise in foreclosure rates for higher quartiles of the credit score distribution.

Real estate investors are particularly likely to contract non-conventional mortgages that are intrinsically more risky and they are also likely to prefer highly leveraged products, as discussed above. An additional factor that may increase the default rate for investors is that only the primary residence is protected in personal bankruptcy, via the homestead exemption.Thus, a borrower who is experiencing difficulties in making payments could potentially file for Chapter 7 bankruptcy and discharge unsecured debt using non exempt assets, and avoid a mortgage delinquency. Perhaps more importantly, the financial and psychological costs of default for mortgage borrowers who reside in the home are typically quite substantial, including moving and storage costs, increased commuting costs, and so on. Our results

\footnotetext{
${ }^{30}$ Similar results obtain using the simple difference in delinquency and foreclosure rates. We select the 2006Q3-2009Q4 time period as it comprises the trough and peak of the delinquency and foreclosure rates for all quartiles of the credit score distribution.
} 
Table 4: Role of Investors in Mortgage Balance, Delinquency and Foreclosure Growth

\begin{tabular}{|c|c|c|c|c|}
\hline \multirow[b]{2}{*}{ total (USD) } & \multicolumn{4}{|c|}{ 2001Q3-2006Q4 change in mortgage balances ${ }^{a}$} \\
\hline & 8,478 & 27,608 & 28,538 & 20,063 \\
\hline $\begin{array}{l}\text { with constant distribution of number } \\
\text { of first mortgages }{ }^{c}\end{array}$ & 0.7684 & 0.61594 & 0.61554 & 0.6909 \\
\hline \multirow{3}{*}{$\begin{array}{l}\text { with constant balances by number of } \\
\text { first mortgages }{ }^{c}\end{array}$} & 0.13423 & 0.2013 & 0.2180 & 0.1961 \\
\hline & \multicolumn{4}{|c|}{ 2006Q3-2009Q4 change in delinquency rates $^{d}$} \\
\hline & Quartile 1 & Quartile 2 & Quartile 3 & Quartile 4 \\
\hline total $^{b}$ & 0.1175 & 0.3149 & 0.5426 & 0.4373 \\
\hline with constant investor share ${ }^{c}$ & 0.9706 & 0.9929 & 0.9758 & 0.9497 \\
\hline \multirow[t]{3}{*}{ with constant investor rate ${ }^{c}$} & 0.9113 & 0.8177 & 0.7634 & 0.6261 \\
\hline & \multicolumn{4}{|c|}{ 2006Q3-2009Q4 change in foreclosure rate ${ }^{d}$} \\
\hline & Quartile 1 & Quartile 2 & Quartile 3 & Quartile 4 \\
\hline total $^{b}$ & 0.2649 & 0.6338 & 1.0622 & 1.2854 \\
\hline with constant investor share ${ }^{c}$ & 0.9892 & 0.9934 & 0.9742 & 0.9676 \\
\hline with constant investor rate ${ }^{c}$ & 0.8854 & 0.8535 & 0.76535 & 0.6595 \\
\hline
\end{tabular}

Contribution of changing fraction of investors and changing behavior of investors by quartiles of the 8Q lagged Equifax Risk Score distribution. Delinquency rate is defined as fraction with new $90+$ day delinquency in last 4 quarters. Foreclosure rate is fraction with new foreclosure in last 4 quarters. Source: Authors' calculations based on FRBNY CCP/Equifax Data.

$a$. Includes all borrowers.

b. Log difference.

c. Ratio to total. Ratios need not add up to 1 as interaction terms are not reported.

$d$. Includes only borrowers with at least 1 first mortgage.

suggest that these factors may have been quite prevalent during the housing crisis.

In Appendix G, we also examine the size of the average mortgage. As house prices were rising between 2001-2007, some borrowers were taking on increasingly larger mortgages. 
Some of these mortgages satisfy the criteria of jumbo loans 31 which do not qualify for GSE insurance and therefore typically charge higher interest rates. We find a very small rise in the fraction of jumbo mortgages, for borrowers with above median credit score. The fraction of jumbo mortgages rose from $0.7 \%$ in 2001 to $1.5 \%$ in 2007 for quartile 3 borrowers, and from $1.1 \%$ to $1.9 \%$ over the same period for borrowers in quartile 4 . The rise in the fraction of jumbo loans seems too small to account for the rise in mortgage delinquencies for this group.

\section{Interpreting Zip Code Level Evidence}

Starting with the seminal work of Mian and Sufi (2009), the macroeconomic literature has used geographical variation to link mortgage debt growth to the severity of the housing crisis and of the ensuing 2007-2009 recession. As shown in figure 1, ranking zip codes by the fraction of subprime borrowers in 2001, suggests that mortgage debt growth in 2001-2007 is stronger in zip codes with high fraction of subprime borrowers at the starting date. However, there is no difference in the growth in total debt balances across quartiles of the fraction of subprime borrowers, as shown in figure 39 reported in Appendix $\mathrm{H}$. In this section, we explore the link between the fraction of subprime borrowers at the zip code level and other population characteristics.

Figure 25 presents zip code level mortgage balance growth since 2001Q3 for prime and subprime borrowers by quartile of the fraction of subprime borrowers. It is clear that prime borrowers experience much higher growth in mortgage balances during the boom relative to subprime borrowers, in all zip codes. However, in zip codes with the highest fraction of subprime borrowers, mortgage balances grow more than in other zip codes for both prime and subprime borrowers. As we show in Section 4.1, subprime borrowers are disproportionately young and have high demand for credit due to life cycle considerations. Based on this observation, we explore the role of the age distribution at the zip code level.

\subsection{The Role of Age}

Table 5 reports the age distribution by fraction of subprime borrowers. Not surprisingly, based on our results with individual data, zip codes in quartile 4 of the fraction of subprime borrowers exhibit a much larger share of borrowers younger than 35 .

\footnotetext{
${ }^{31}$ First mortgages above $\$ 417,000$ were classified as jumbo for the 2001-2007 period. The Obama administration increased this threshold for selected metropolitan areas in 2010 to adjust for regional variation in housing values.
} 
QUARTILE 1

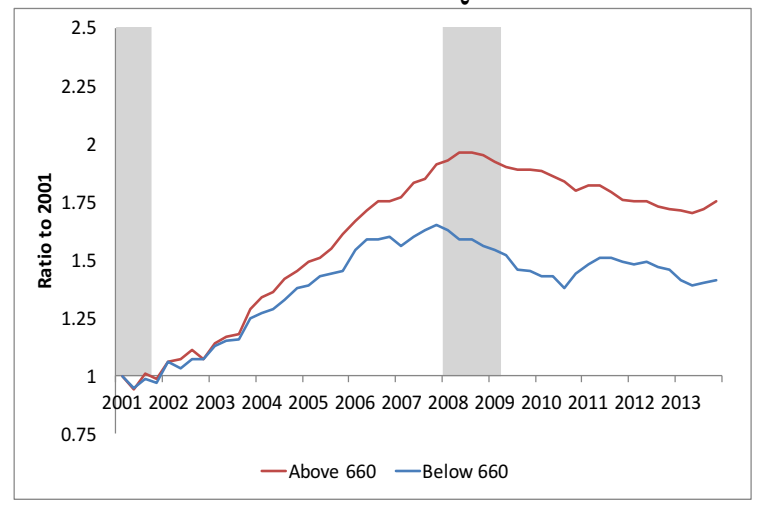

QuARTILE 3

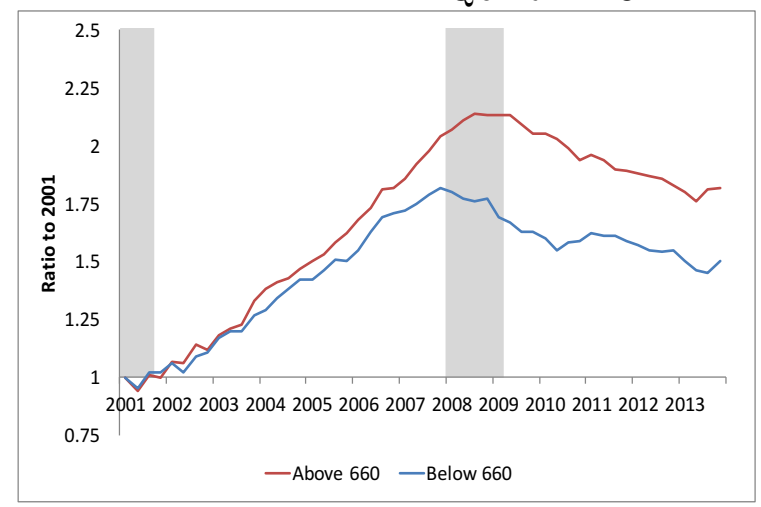

QUARTILE 2

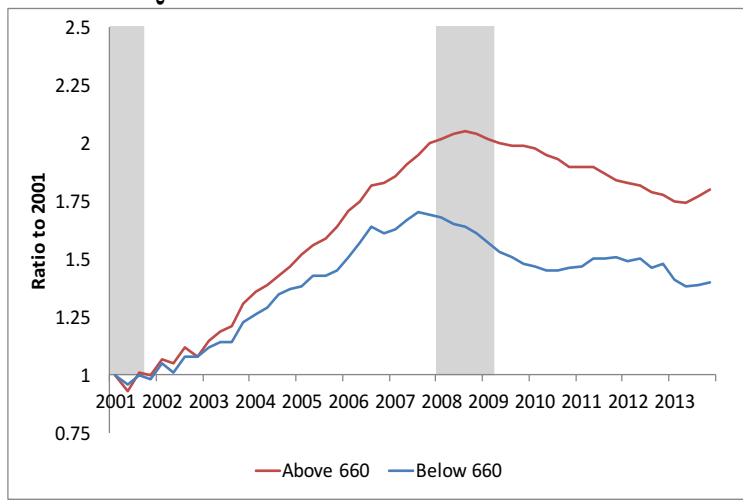

QuarTile 4

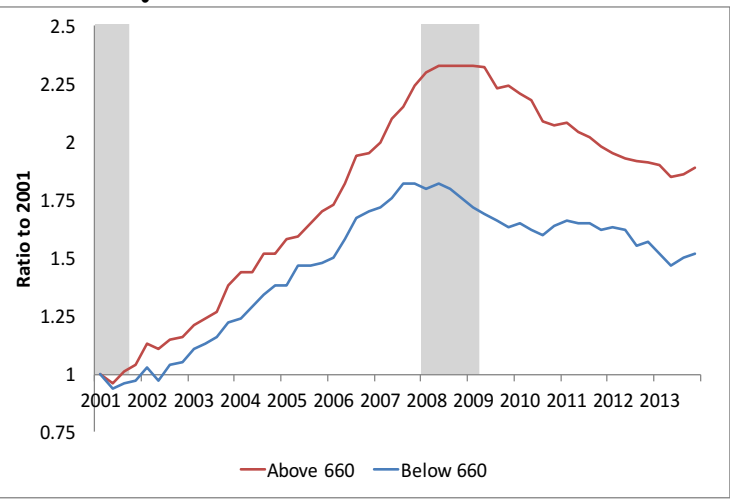

Figure 25: Zip code level per capita mortgage debt growth for prime (Equifax risk Score above 660) and subprime (Equifax risk Score below 660) borrowers by quartile of share of subprime in 2001. Based on 8Q lagged individual credit scores. Source: Authors' calculations based on FRBNY CCP/Equifax Data.

To quantify the role of the age distribution, we construct counterfactual mortgage balance growth with the age distribution set equal to the age distribution for quartile 1 for all quartiles. We then use this counterfactuals to calculate the contribution of the differences in age distribution across quartiles of the fraction of subprime borrowers to the difference in 2001Q1-2007Q4 (trough to peak) mortgage debt growth relative to quartile 1. These results are reported in Table 6. We find that for zip codes in quartiles 2 and 3 of the fraction of subprime borrowers in 2001, respectively $44 \%$ and $43 \%$ of the additional cumulative growth in mortgage debt balances relative to quartile 1 is accounted for by differences in the age distribution. This statistic is $84 \%$ for zip codes in quartile 4 . These findings suggest that even at the zip code level, the age structure is an important determinant of borrowing demand, and strongly affects the observed pattern of debt growth during the 2001-2007 credit boom. 
Table 5: Age Distribution by Fraction of Subprime Borrowers

\begin{tabular}{lcccccc}
\hline \multicolumn{7}{c}{ Fraction in each age bin, 2001Q1-2013Q4 } \\
\hline & $20-24$ & $25-34$ & $35-44$ & $45-54$ & $55-64$ & $65-85$ \\
\hline Quartile 1 & 0.063 & 0.157 & 0.200 & 0.218 & 0.171 & 0.192 \\
Quartile 2 & 0.070 & 0.184 & 0.200 & 0.205 & 0.161 & 0.181 \\
Quartile 3 & 0.074 & 0.201 & 0.206 & 0.200 & 0.152 & 0.168 \\
Quartile 4 & 0.081 & 0.212 & 0.210 & 0.199 & 0.145 & 0.153 \\
\hline
\end{tabular}

Average age distribution in 2001Q1-2013Q4 by quartile of fraction of subprime in 2001. Source: Authors' calculations based on FRBNY CCP/Equifax Data.

Table 6: Contribution of Age Distribution to Mortgage Balance Growth

\begin{tabular}{lcc}
\hline \multicolumn{3}{c}{ Mortgage Balances } \\
\hline Quartile 2 & Quartile 3 & Quartile 4 \\
\hline 0.44 & 0.43 & 0.84 \\
\hline
\end{tabular}

Contribution of differences in the age distribution to differences in mortgage balance growth 2001Q1-2007Q4. Counterfactuals computed by attributing to each quartile the age distribution of quartile 1 of the fraction of subprime borrowers in 2001. Source: Authors' calculations based on FRBNY CCP/Equifax Data.

\subsection{Defaults}

We now examine the behavior of defaults by zip code. Figure 26 presents the $90+$ mortgage delinquency rate and the foreclosure rate by quartile of fraction of subprime borrowers in 2001. Not surprisingly, zip codes with higher fraction of subprime borrowers exhibit higher delinquency and foreclosure rates, throughout the sample period, with a 2-3 percentage point difference between adjacent quartiles for most of the sample period. The delinquency rate increases modestly during the housing crisis, mostly for zip codes in quartiles 2-4 of the fraction of subprime borrowers in 2001. Foreclosure rates display a similar pattern across quartiles for the entire sample period, despite modest differences in levels. The increase in the foreclosure rate during the crisis is sizable for all quartiles. Foreclosure rates for quartiles 2-4 converge during the crisis, whereas the rate for quartile 1 remains lower, despite its increase. Figure 27 presents the share of 90+ days delinquencies and foreclosures of prime borrowers 
by quartile of the 2001 distribution of the fraction of subprime borrowers. Clearly, prime borrowers contribute more to the growth in delinquent mortgage balances and foreclosures during crisis in all zip codes. The share of prime borrowers' delinquent mortgage balances rises by approximately 30 percentage points between 2006Q2 and 2009Q4, while the share of prime borrowers' foreclosures rises approximately by 40 percentage points over the same period.

DELINQUENCIES

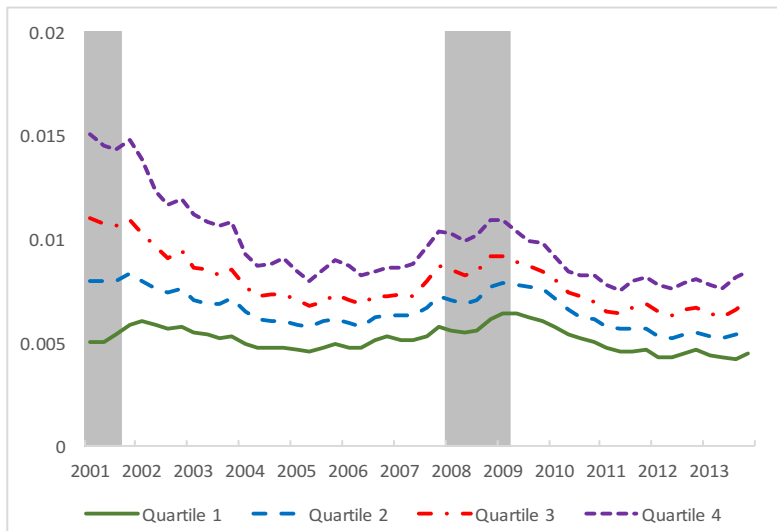

ForeClosures

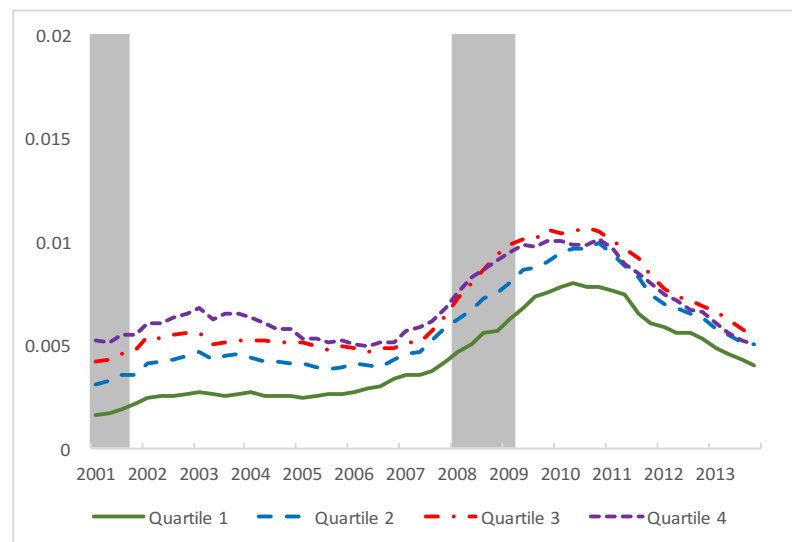

Figure 26: Fraction with 90+ days delinquencies and foreclosures. Zip code level average by quartile of the fraction of subprime share in 2001. Source: Authors' calculations based on FRBNY CCP/Equifax Data.

DELINQUENCIES

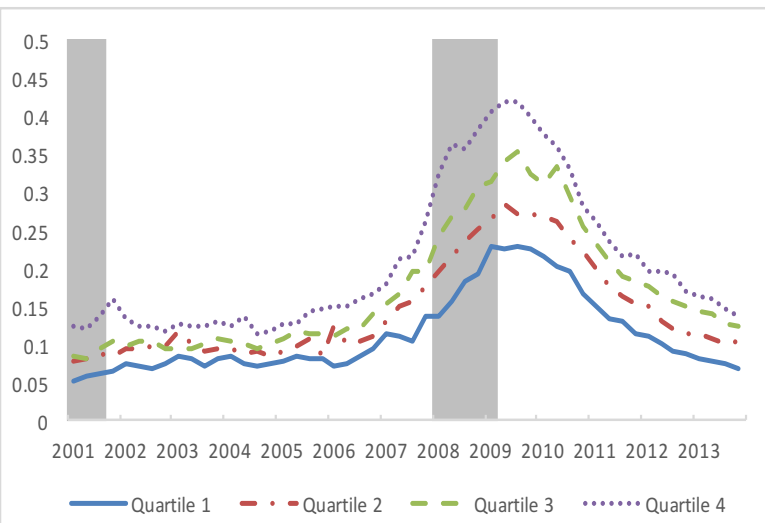

ForeClosures

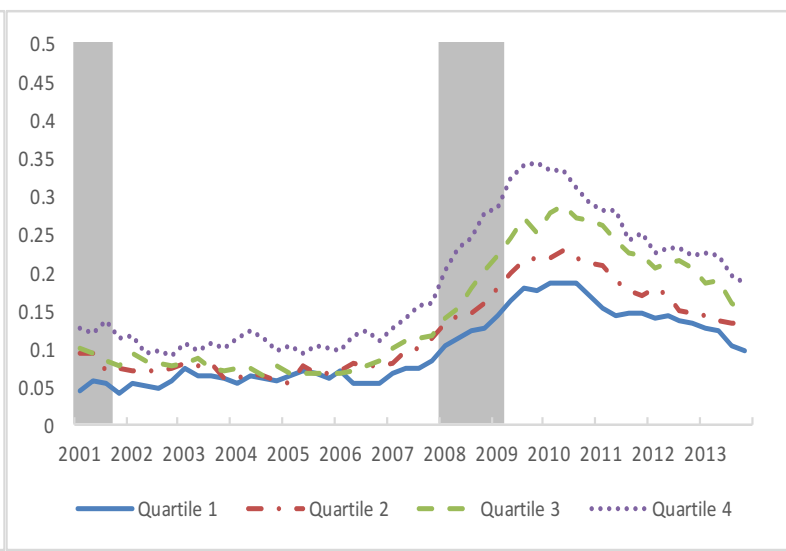

Figure 27: Share of 90+ days delinquencies and foreclosures for prime borrowers, based on 8Q lagged individual credit score. Quartiles of subprime share in 2001. Source: Authors' calculations based on FRBNY CCP/Equifax Data. 
Interestingly, the prime share of mortgage delinquencies and foreclosures are higher in zip codes with high fraction of subprime borrowers, despite the fact that prime borrowers account for a smaller fraction of the population. This suggests that prime borrowers in zip codes with high fraction of subprime borrowers are more vulnerable to financial distress. Though other zip code level characteristics may contribute to this pattern, as we discuss in Section 8.3, here we focus on the role of investors, based on our findings using individual data. Figure 28 presents the fraction of investors at the zip code level for prime and subprime borrowers. There is virtually no difference across quartiles in the fraction of investors for prime borrowers. It starts at approximately $10 \%$ in 2001, rises by 5 percentage points between 2005Q1 and 2007Q4, with the average for 2005-2007, reported in Table 7 equal to $12-13 \%$. It then drops during and after the recession, though still remaining above pre-boom levels by the end of 2013. For subprime borrowers, the fraction of investors is decreasing in the quartile of the fraction of subprime in 2001. At the beginning of the sample it is $10 \%$ for quartile 1, with a 1-3 percentage point difference across quartiles throughout the sample. The 2005Q1-2007Q4 rise in the fraction of investors is more modest for subprime borrowers, and also decreasing with the quartile of the subprime distribution in 2001. The 2005-2007 average of the fraction of investors among subprime borrowers is $11 \%$ and $10 \%$ for quartile 1 and 2 , and $8 \%$ and $7 \%$ for quartiles 3 and 4 .

PRIME BORROWERS

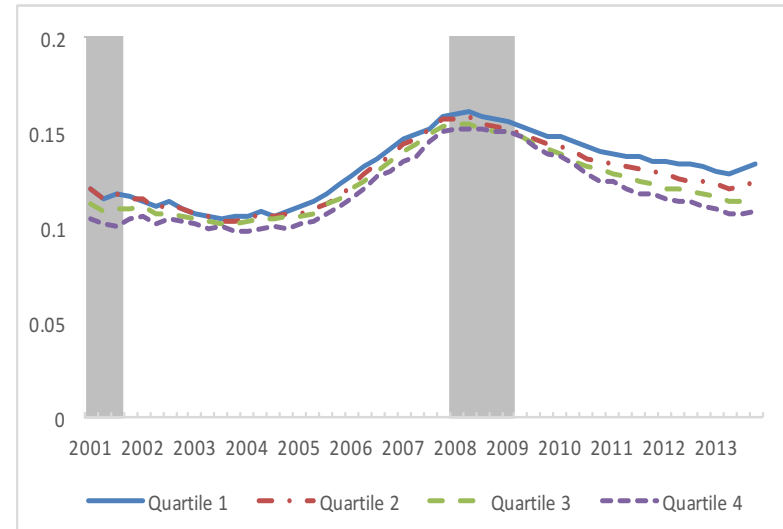

SUBPrIME BORROWERS

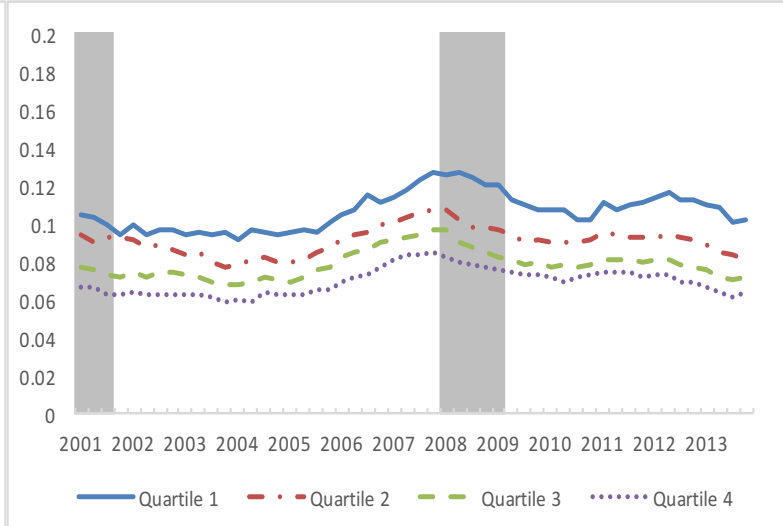

Figure 28: Fraction with 2 or more first mortgages for prime borrowers (left) and subprime borrowers (right), by quartile of fraction of subprime borrowers in 2001. Subprime/prime based on 8Q lagged credit score. Source: Authors' calculations based on FRBNY CCP/Equifax Data.

Given the large rise in the share of defaults to prime borrowers and the link between investor activity and foreclosures we established using individual data, we examine more 
detail on investor activity for prime borrowers in Table 7. The distribution of investors across the number of first mortgages is very similar across quartiles, with 79-80\% of investors holding 2 first mortgages, $13-14 \%$ holding 3 and $7-8 \%$ holding 4 or more. However, the growth in average mortgage balances per capita during the boom varies substantially by quartile, and is significantly higher in quartiles with a large fraction of subprime borrowers, especially for investors (those with 2 or more first mortgages). The growth in per capita mortgage balances for investors is around 20 percentage points higher for prime borrowers in quartile 4 relative to quartile 1 . The growth in mortgage balances for investors with 4 or more first mortgages is particularly high in quartiles $2-4$, ranging from $122 \%$ to $133 \%$. Turning to defaults, we see that foreclosure rates are sizably higher for investors relative to non-investors, as we found in the individual data. This difference is increasing in the fraction of subprime borrowers. The rise in the foreclosure rate during the crisis for investors in quartiles 3-4 is nearly double the rise in quartiles 1-2, reaching a high of $15 \%$ for investors with 4 or more first mortgages in quartile 4.

This pattern in investor borrowing and default behavior may explain why despite large regional variation in predictable default risk, GSE mortgage rates for otherwise identical loans do not vary spatially, while the private market does set interest rates that vary with local risk, as shown in Hurst et al. (2016). GSE mortgages are only available for the primary residence and default rates among borrowers with only one first mortgage are low in all zip codes. By contrast, default rates on private market products would reflect the geographical variation in investor activity, and corresponding default propensity.

Summarizing, though the fraction of investors with prime credit score is very similar across quartiles, in quartiles with high share of subprime, investors exhibit larger increases in mortgage balances during the boom and a more severe increase in foreclosures during the crisis. This difference in behavior for prime investors may be driven by the behavior of real estate values. As reported in Table 8, the average growth house price index in 2001-2007 varies from $29 \%$ in quartile 1 to $47 \%$ in quartile 4 . The total decline in housing values in 2007-2010 is also increasing in the fraction of subprime, ranging from $21 \%$ in quartile 1 to $36 \%$ in quartile 4 . This suggests that investor activity by prime borrowers is associated with a more pronounced house price boom and bust and a more severe foreclosure crisis.

\subsection{Zip Code Characteristics}

Several studies find a positive relation between the size of the increase in mortgage debt growth or house price debt growth during the 2001-2006 credit boom, often instrumented 
Table 7: Investor Activity

\begin{tabular}{|c|c|c|c|c|}
\hline & \multicolumn{4}{|c|}{ 2005-2007 fraction of investors } \\
\hline & Quartile 1 & Quartile 2 & Quartile 3 & Quartile 4 \\
\hline \multirow{4}{*}{$\begin{array}{l}\text { prime borrowers } \\
\text { subprime borrowers }\end{array}$} & $13 \%$ & $13 \%$ & $13 \%$ & $12 \%$ \\
\hline & $11 \%$ & $10 \%$ & $8 \%$ & $7 \%$ \\
\hline & \multicolumn{4}{|c|}{ Prime Borrowers } \\
\hline & Quartile 1 & Quartile 2 & Quartile 3 & Quartile 4 \\
\hline \multicolumn{5}{|c|}{ 2007Q4 fraction of investors with } \\
\hline 2 first mortgages & $80 \%$ & $80 \%$ & $80 \%$ & $79 \%$ \\
\hline 3 first mortgages & $13 \%$ & $13 \%$ & $14 \%$ & $14 \%$ \\
\hline $4+$ first mortgages & $7 \%$ & $7 \%$ & $7 \%$ & $8 \%$ \\
\hline \multicolumn{5}{|c|}{$\begin{array}{l}\text { 2001Q3-2007Q4 mortgage balance } \\
\text { growth }\end{array}$} \\
\hline 1 first mortgage & $59 \%$ & $62 \%$ & $66 \%$ & $69 \%$ \\
\hline 2 first mortgages & $86 \%$ & $85 \%$ & $97 \%$ & $104 \%$ \\
\hline 3 first mortgages & $94 \%$ & $104 \%$ & $117 \%$ & $118 \%$ \\
\hline $4+$ first mortgages & $102 \%$ & $122 \%$ & $133 \%$ & $125 \%$ \\
\hline \multicolumn{5}{|c|}{$\begin{array}{l}\text { boom average-peak change in fore- } \\
\text { closure rate }\end{array}$} \\
\hline 1 first mortgage & 0.008 & 0.012 & 0.016 & 0.017 \\
\hline 2 first mortgages & 0.023 & 0.027 & 0.045 & 0.053 \\
\hline 3 first mortgages & 0.040 & 0.063 & 0.087 & 0.115 \\
\hline $4+$ first mortgages & 0.076 & 0.096 & 0.123 & 0.151 \\
\hline
\end{tabular}

Selected zip code level indicators of investor activity by quartile of the fraction of subprime borrowers in 2001. The boom average for the foreclosure rate corresponds to the 2002Q1-2005Q4 average. The peak of the foreclosure rate varies by group, with 2007Q4 the most common date. Source: Authors' calculations based on FRBNY CCP/Equifax Data, IPUMS, IRS, BLS, ACS data.

with Saiz (2010) house price elasticities, and the severity of the 2007-2009 recession ${ }^{32}$ These

\footnotetext{
${ }^{32}$ For example, Mian, Sufi, and Trebbi (2015) find that states with higher foreclosure rates experienced a larger decline in consumption, while Mian and Sufi (2014) use county level data and show that a larger decline in household net worth during the crisis experience a more pronounced decline in non-tradable employment. Mian, Rao, and Sufi (2013) exploit geographic variation in house price declines over the period 2006-2009 and household balance sheets in 2006, to estimate the elasticity of consumption expenditures to changes in the housing share of household net worth, and find a positive and sizable elasticity. Kaplan, Mitman, and Violante (2016) refine this analysis and find that, once the direct effect of the fall in local house prices has been controlled for, household balance sheets do not have an effect on durable consumption.
} 
studies attribute this correlation to the tightening of collateral constraints during the crisis, driven by mortgage defaults and the resulting decline in housing values ${ }^{33}$ Since this causal mechanism is not consistent with our findings, we explore additional economic indicators at the zip code level to shed light on this correlation.

Table 8 reports several economic indicators by quartile of the fraction of subprime borrowers in 2001. Several indicators that are critical to business cycle sensitivity are systematically related to the fraction of subprime borrowers. Zip codes with higher fraction of subprime borrowers are younger, as previously noted, have lower levels of educational attainment and have a disproportionately large minority and African American share in the population. It is well known that younger, less educated, minority workers suffer larger employment loss during recessions.

Zip codes with a large fraction of subprime borrowers also exhibit lower per capita income levels in both the boom and the recession. In 2001-2007, the average real per capita income was $\$ 41,045$ in quartile 1 and only $\$ 21,019$ in quartile 4 , whereas in 2007-2010 it was $\$ 46,341$ for quartile 1 and $\$ 21,898$ for quartile 4. Consistent with Mian and Sufi (2009), income growth during the boom was lower in zip codes with higher fraction of subprime. Average per capita income grew by 35\% between 2001 and 2007 for quartile 1 and only 4\% for quartile 4. Similarly, zip codes with large subprime population have higher unemployment rates both during the boom and during the crisis. The average unemployment rate for 2001-2007 was 4.94\% in quartile 1 and 5.72\% in quartile 4. In 2007-2010, the average unemployment rate rose to $6.93 \%$ in quartile 1 and $7.81 \%$ in quartile 4 . Zip codes with a large subprime population also exhibit higher income inequality. We measure this with the ratio of average income for individuals with incomes above $\$ 200,000$ over average income for the entire population, based on IRS data. Higher inequality implies that the aggregation bias generated by the fact within each zip code prime borrowers experience more credit growth than subprime borrowers is accentuated.

Zip codes with high fraction of subprime borrowers experience higher house price growth in 2001-2007, as previously noted. This may be related to the their higher population density, suggesting the prevalence of urban areas for this group. Endogenous gentrification, as described in Guerrieri, Hartley, and Hurst (2013), exerted particularly high pressure on housing values in urban areas over this period, and may have encouraged real estate investor

\footnotetext{
${ }^{33}$ However, Ferreira and Gyourko (2011) show that local income is the only potential demand shifter found that also had an economically and statistically significant change around the time that local housing booms began. Liebersohn (2017) also shows that the share of growing industries drives the size of housing demand shocks, the magnitude of the housing price increase and household consumption variation between $2000-2006$.
} 
activity ${ }^{34}$ The distribution of zip codes with low housing supply elasticity, as captured by the Saiz (2010) index, is fairly even across quartiles. However, $16 \%$ of zip codes in quartiles

3 and 4 are in sand states 35 , whereas only $11 \%$ and $13 \%$ of zip codes in quartiles 1 and 2 are in those states.

The distribution of the fraction of subprime borrowers is quite stable at the zip code level, and this is also true for other characteristics salient to business cycle sensitivity, as we show in Appendix $\mathrm{H}$. Therefore, the timing of the ranking by fraction of subprime does not change the patterns at the zip code level. However, some aggregate trends, such as the historical decline in wages, labor force participation and employment rates for unskilled, young and minority workers, and the rise in income inequality may influence economic outcomes at the zip code level over time. One motivation for considering zip code level evidence is the scarcity of information on individual borrowers in credit file data. Geographical aggregation provides access to a number of additional indicators, such as income, housing values and so on. Very often, geographical patterns are interpreted as reflecting individual behavior. For example, differences in debt growth across two zip codes with different fraction of subprime borrowers are assumed to be similar to differences in debt growth across individuals with different credit scores. Our findings suggest that using geographically aggregated data does not provide an accurate account of the patterns of borrowing at the individual level. Moreover, the positive correlation between credit growth during the boom and the depth of the recession may be due to other characteristics at the zip code level, such as the prevalence of young, minority or low education workers.

\section{Conclusion}

Our analysis suggests a reassessment of the role of growth in the supply of subprime credit in the 2001-2006 housing boom and in the 2007-2009 financial crisis. We find that most of the increase in mortgage debt during the boom and of mortgage delinquencies during the crisis is driven by mid to high credit score borrowers, and it is these borrowers who disproportionately default on their mortgages during the crisis. The growth in defaults is mostly accounted for

\footnotetext{
${ }^{34}$ However, the more sizable housing boom in some zip codes with large subprime population may have masked negative employment growth over this period, as shown by Hurst et al. (2016), and increased income and reduced unemployment rates in those areas above what would have been consistent with their industry and demographic composition.

${ }^{35}$ These are Arizona, California, Colorado, Florida, and Nevada. These states exhibit the largest swings in housing values during the housing boom and the subsequent foreclosure crisis. Chinco and Mayer (2014) show that in Phoenix, Las Vegas and Miami out of town second home buyers may have contributed to an inflation in housing values.
} 
Table 8: Zip Code Level Indicators

\begin{tabular}{|c|c|c|c|c|}
\hline & \multicolumn{4}{|c|}{ Demographics } \\
\hline & Quartile 1 & Quartile 2 & Quartile 3 & Quartile 4 \\
\hline Median age & 50 & 49 & 48 & 46 \\
\hline Associate+ degree (2012) & $45 \%$ & $31 \%$ & $23 \%$ & $17 \%$ \\
\hline Percent white & $93 \%$ & $90 \%$ & $83 \%$ & $63 \%$ \\
\hline \multirow[t]{3}{*}{ Percent black } & $1.7 \%$ & $3.6 \%$ & $7.6 \%$ & $24.6 \%$ \\
\hline & \multicolumn{4}{|c|}{ Economy } \\
\hline & Quartile 1 & Quartile 2 & Quartile 3 & Quartile 4 \\
\hline Average UR 2001-2007 & $4.94 \%$ & $5.19 \%$ & $5.38 \%$ & $5.72 \%$ \\
\hline Average UR 2007-2010 & $6.93 \%$ & $7.30 \%$ & $7.51 \%$ & $7.81 \%$ \\
\hline Average PDI 2001-2007 & $\$ 41,045$ & $\$ 30,442$ & $\$ 25,692$ & $\$ 21,019$ \\
\hline Average PDI 2007-2010 & $\$ 46,341$ & $\$ 33,224$ & $\$ 27,491$ & $\$ 21,898$ \\
\hline PDI Growth 2001-2007 & $25 \%$ & $16 \%$ & $10 \%$ & $4 \%$ \\
\hline PDI Growth 2007-2010 & $10 \%$ & $10 \%$ & $11 \%$ & $10 \%$ \\
\hline \multirow[t]{3}{*}{$\frac{\text { Mean Income } \geq \$ 200 K}{\text { Mean Income }}$} & 6.4 & 7.9 & 9.4 & 11.8 \\
\hline & \multicolumn{4}{|c|}{ Mortgage Markets } \\
\hline & Quartile 1 & Quartile 2 & Quartile 3 & Quartile 4 \\
\hline 2001 fraction subprime (med) & $19 \%$ & $32 \%$ & $44 \%$ & $60 \%$ \\
\hline HPI Growth 2001-2007 & $29 \%$ & $37 \%$ & $42 \%$ & $47 \%$ \\
\hline HPI Growth 2007-2010 & $-21 \%$ & $-30 \%$ & $-27 \%$ & $-36 \%$ \\
\hline \multirow[t]{3}{*}{ Low Saiz elasticity } & $17 \%$ & $13 \%$ & $11 \%$ & $12 \%$ \\
\hline & \multicolumn{4}{|c|}{ Geography } \\
\hline & Quartile 1 & Quartile 2 & Quartile 3 & Quartile 4 \\
\hline In sand states & $11 \%$ & $13 \%$ & $16 \%$ & $16 \%$ \\
\hline Pop per sq mile & 1214 & 1380 & 1386 & 2322 \\
\hline Percent never moved & $53 \%$ & $53 \%$ & $51 \%$ & $51 \%$ \\
\hline
\end{tabular}

Selected zip code level indicators by quartile of the fraction of subprime borrowers in 2001. PDI (personal disposable income) and HPI (housing price index) expressed in 2012 USD, adjusted by CPI-U. UR (unemployment rate) is the U3 official rate. Source: Authors' calculations based on FRBNY CCP/Equifax Data, IPUMS, IRS, BLS, ACS data.

by real estate investors. Moreover, we show that at the zip code level, prime borrowers experience a larger rise in debt and defaults than subprime borrowers, irrespective of the 
size of the subprime population in the zip code. Zip codes with a large share of subprime borrowers have a young, low education, high minority population that may be particularly sensitive to business cycle shocks. These new findings should inform discussions of the causes and consequences of the 2007-2009 financial crisis and of the appropriate policy responses.

\section{References}

Adelino, Manuel, Antoinette Schoar, and Felipe Severino. 2015. "Loan Originations and Defaults in the Mortgage Crisis: The Role of the Middle Class." Working paper 20848, National Bureau of Economic Research.

—. 2017. "Dynamics of Housing Debt in the Recent Boom and Great Recession." Working paper 23502, National Bureau of Economic Research.

Agarwal, Sumit, Gene Amromin, Itzhak Ben-David, and Douglas D. Evanoff. 2016, September. "Loan Product Steering in Mortgage Markets." Working paper 22696, National Bureau of Economic Research.

Albanesi, Stefania, and Jaromir Nosal. 2015. "Insolvency After the 2005 Bankruptcy Reform." Cepr discussion papers 10533, CEPR Discussion Papers.

Bazikyan, Armine. 2009. "Renters: The Innocent Victims of the Foreclosure Mortgage Crisis." Sw. L. Rev. 39:339.

Berger, David, Veronica Guerrieri, Guido Lorenzoni, and Joseph Vavra. 2015, October. "House Prices and Consumer Spending." Working paper 21667, National Bureau of Economic Research.

Bhutta, Neil. 2015. "The ins and outs of mortgage debt during the housing boom and bust." Journal of Monetary Economics 76:284 - 298.

Bhutta, Neil, and Benjamin J Keys. 2016. "Interest rates and equity extraction during the housing boom." The American Economic Review 106 (7): 1742-1774.

Brown, Meta, Andrew Haughwout, Donghoon Lee, and Wilbert van der Klaauw. 2014. "The Financial Crisis at the Kitchen Table: Trends in Household Debt and Credit." Current Issues in Economics and Finance 19, no. 2.

Case, Karl E., Robert J. Shiller, and Anne Thompson. 2012, September. "What Have They Been Thinking? Home Buyer Behavior in Hot and Cold Markets." Working paper 18400, National Bureau of Economic Research. 
Chen, Hui, Michael Michaux, and Nikolai Roussanov. 2013, September. "Houses as ATMs? Mortgage Refinancing and Macroeconomic Uncertainty." Working paper 19421, National Bureau of Economic Research.

Chinco, Alex, and Christopher Mayer. 2014, January. "Misinformed Speculators and Mispricing in the Housing Market." Working paper 19817, National Bureau of Economic Research.

Corbae, Dean, and Erwan Quintin. 2015. "Leverage and the Foreclosure Crisis." Journal of Political Economy 123 (1): 1-65.

Elul, Ronel, and Sebastian G Tilson. 2015. "Owner occupancy fraud and mortgage performance."

Ferreira, Fernando, and Joseph Gyourko. 2011, August. "Anatomy of the Beginning of the Housing Boom: U.S. Neighborhoods and Metropolitan Areas, 1993-2009." Working paper 17374, National Bureau of Economic Research.

—. 2015, June. "A New Look at the U.S. Foreclosure Crisis: Panel Data Evidence of Prime and Subprime Borrowers from 1997 to 2012." Working paper 21261, National Bureau of Economic Research.

Foote, Christopher L., Kristopher S. Gerardi, and Paul S. Willen. 2012, May. "Why Did So Many People Make So Many Ex Post Bad Decisions? The Causes of the Foreclosure Crisis." Working paper 18082, National Bureau of Economic Research.

Foote, Christopher L., Lara Loewenstein, and Paul S. Willen. 2016. "Cross-sectional patterns of mortgage debt during the housing boom: evidence and implications." Technical Report 22985, National Bureau of Economic Research.

Foote, Christopher L., and Paul S. Willen. 2016. "The Subprime Mortgage Crisis." In Banking Crises, 324-336. Springer.

Foote, Christopher L, Kristopher Gerardi, and Paul S Willen. 2008. "Negative equity and foreclosure: Theory and evidence." Journal of Urban Economics 64 (2): 234-245.

Ghent, Andra C, and Marianna Kudlyak. 2011. "Recourse and residential mortgage default: evidence from US states." Review of Financial Studies, p. hhr055.

Guerrieri, Veronica, Daniel Hartley, and Erik Hurst. 2013. "Endogenous gentrification and housing price dynamics." Journal of Public Economics 100:45-60.

Guerrieri, Veronica, and Guido Lorenzoni. 2011. "Credit crises, precautionary savings, and the liquidity trap." Technical Report 17583, National Bureau of Economic Research. 
Haughwout, Andrew, Donghoon Lee, Joseph S Tracy, and Wilbert Van der Klaauw. 2011. "Real estate investors, the leverage cycle, and the housing market crisis." Federal Reserve Bank of New York Staff Reports, no. 514.

Hurst, Erik, Benjamin J. Keys, Amit Seru, and Joseph Vavra. 2016. "Regional Redistribution through the US Mortgage Market." American Economic Review 106 (10): 2982-3028 (October).

Iacoviello, Matteo. 2004. "Consumption, house prices, and collateral constraints: a structural econometric analysis." Journal of Housing Economics 13 (4): 304-320.

Justiniano, Alejandro, Giorgio E Primiceri, and Andrea Tambalotti. 2016. "Quantitative Modeling of the Financial Crisis A Simple Model of Subprime Borrowers and Credit Growth." The American Economic Review 106 (5): 543-547.

Kaplan, Greg, Kurt Mitman, and Giovanni L. Violante. 2016, May. "Non-durable Consumption and Housing Net Worth in the Great Recession: Evidence from Easily Accessible Data." Working paper 22232, National Bureau of Economic Research.

—. 2017, August. "The Housing Boom and Bust: Model Meets Evidence." Working paper 23694, National Bureau of Economic Research.

Kehoe, Patrick, Elena Pastorino, and Virgiliu Midrigan. 2016. "Debt constraints and employment." Technical Report, National Bureau of Economic Research.

Keys, Benjamin J, Tomasz Piskorski, Amit Seru, and Vikrant Vig. 2012. "Mortgage financing in the housing boom and bust." In Housing and the Financial Crisis, 143204. University of Chicago Press.

Keys, Benjamin J, Tomasz Piskorski, Amit Seru, and Vincent Yao. 2014. "Mortgage rates, household balance sheets, and the real economy." Technical Report, National Bureau of Economic Research.

Kiyotaki, Nobuhiro, and John Moore. 1997. "Credit Cycles." Journal of Political Economy, no. 2:211-248.

Lee, Donghoon, and Wilbert van der Klaauw. 2010. "An Introduction to the FRBNY Consumer Credit Panel." FRBNY Staff Report 479.

Li, Wenli. 2009. "Residential housing and personal bankruptcy." Business Review 2:19-29. Liebersohn, Jack. 2017. "Housing Demand, Regional House Prices and Consumption." Manuscript, MIT. 
Mian, Atif, Kamalesh Rao, and Amir Sufi. 2013. "Household Balance Sheets, Consumption, and the Economic Slump." The Quarterly Journal of Economics 128 (4): 1687-1726.

Mian, Atif, and Amir Sufi. 2009. "The Consequences of Mortgage Credit Expansion: Evidence from the U.S. Mortgage Default Crisis." The Quarterly Journal of Economics 124 (4): 1449-1496.

—. 2010. "The Great Recession: Lessons from Microeconomic Data." The American Economic Review 100 (2): 51-56.

—. 2011. "House Prices, Home Equity-Based Borrowing, and the US Household Leverage Crisis." The American Economic Review 101 (5): 2132-2156.

—. 2014. "What explains the 2007-2009 drop in employment?" Econometrica 82 (6): $2197-2223$

Mian, Atif, Amir Sufi, and Francesco Trebbi. 2015. "Foreclosures, house prices, and the real economy." The Journal of Finance 70 (6): 2587-2634.

Mian, Atif R, and Amir Sufi. 2016. "Household debt and defaults from 2000 to 2010: The credit supply view." Manuscript.

Midrigan, Virgiliu, and Thomas Philippon. 2011. "Household Leverage and the Recession." NBER Working Paper 16965.

Mincer, Jacob. 1991. "Education and unemployment." Technical Report, National Bureau of Economic Research.

Mitman, Kurt. 2016. "Macroeconomic effects of bankruptcy and foreclosure policies." The American Economic Review 106 (8): 2219-2255.

Saiz, Albert. 2010. "The geographic determinants of housing supply." The Quarterly Journal of Economics 125 (3): 1253-1296.

Shimer, Robert. 1998. "Why is the US unemployment rate so much lower?" NBER Macroeconomics Annual 13:11-61. 


\section{A Consumer Credit Panel Data and Variables}

We describe in detail the definitions of delinquency and foreclosure used in the analysis.

90+ Days Delinquent: An individual is delinquent if they have at least one loan in their CCP report in that quarter that is $90+$ days past due, severely derogatory, or bankrupt (crtr_attr16, crtr_attr17, or crtr_attr18). Also, at least one of crtr_attr16, crtr_attr17, or crtr_attr18 must be non-missing.

Foreclosure: There are two scenarios in which an individual is marked as being in the state of foreclosure. First, if the individual forecloses on a home (that is, if cma_attr3905 switches from off ("0") to on (" 1 " or "7")), then that individual is marked as being in a state of foreclosure for seven years after the date of their foreclosure. Second, if the individual enters the dataset for the first time while under foreclosure (which almost exclusively occurs at the dataset's 1999 Q1 truncation), that individual is marked as being in the state of foreclosure until the flag (which is supposed to stay on for seven years after the date of the foreclosure) turns off.

\section{B Initial Credit Score Ranking: Additional Results}

Figure 29 displays the fraction with first mortgages by 1999 credit score ranking for individuals (left panel) and by fraction of subprime borrowers in 2001 for zip codes (right panel). Based on the individual level data, the fraction with first mortgages growth by 10-13 percentage points between 2001Q3 and the start of the recession for quartiles 1-3, and only by 2 percentage points for borrowers in quartile 4. At the zip code level, there is little difference in the change in the fraction with first mortgages across zip codes during the boom, though the decline during and after the recession is more pronounced for lower quartiles.

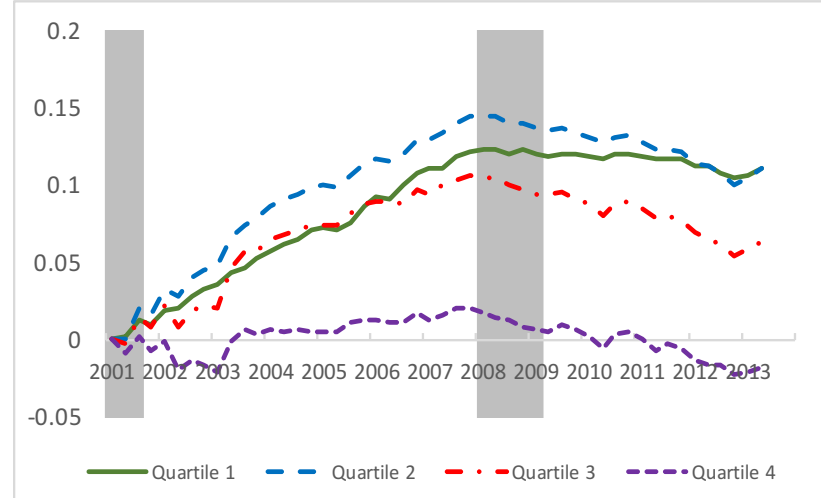

(a) Individuals: Ranked by 1999 Equifax Risk Score

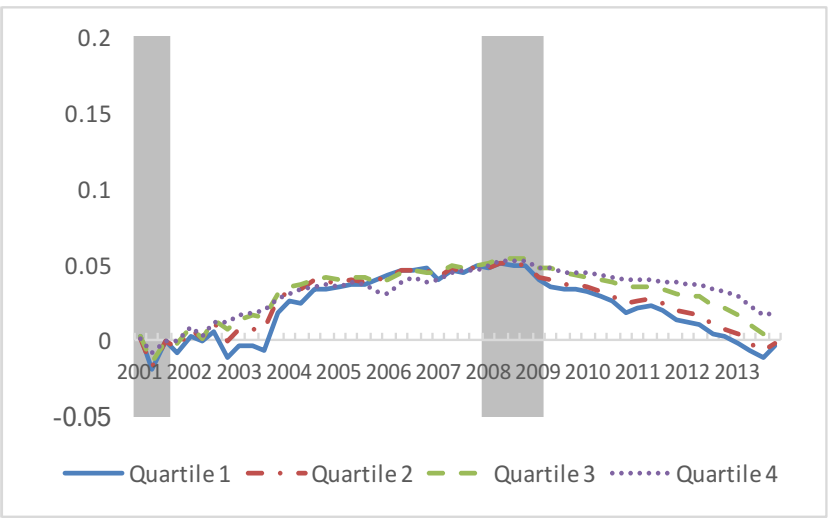

(b) Zip Codes: Ranked by Fraction of Subprime in 2001

Figure 29: Fraction with first mortgages, difference from 2001Q3. Source: Authors' calculation based on Federal Reserve Bank of New York's Consumer Credit Panel/Equifax Data. 
Figure 30 displays the fraction with new mortgage originations. Even with the 1999 quartile ranking, borrowers in quartile 1 do not exhibit any growth in new mortgage originations during the boom, and most of the growth in new mortgage originations occurs between 2001 and 2004 for borrowers in quartiles 2-4 (left panel). At the zip code level (right panel), zip codes with the lowest fraction of subprime borrowers exhibit stronger growth in mortgage originations between 2001 and 2004, and this fraction declines for all quartiles after 2004.

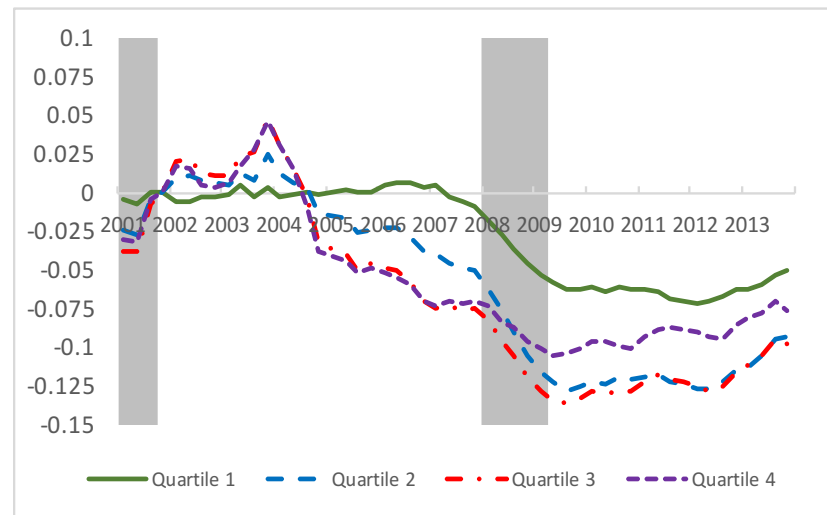

(a) Individuals: Ranked by 1999 Equifax Risk Score

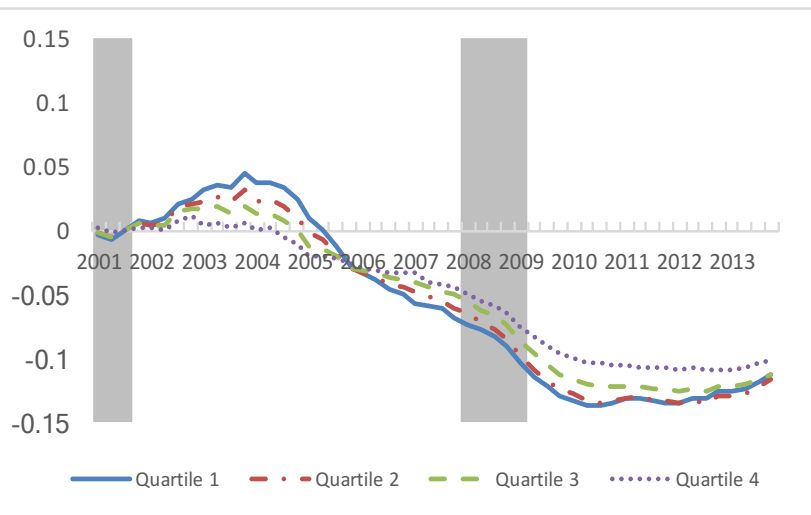

(b) Zip Codes: Ranked by Fraction of Subprime in 2001

Figure 30: Fraction with new mortgage originations in the last 4 quarters, difference from 2001Q3. Source: Authors' calculation based on Federal Reserve Bank of New York's Consumer Credit Panel/Equifax Data.

\section{Income Data}

In this section, we describe the supplementary payroll data used for the income imputation procedure. This data is merged with our credit panel data, allowing us to map individuals' incomes for 2009 to their credit files.

The Equifax Workforce Solutions data provided by Equifax is a nationally-representative random sample of individuals containing employment and payroll verification information provided directly from the employers. The information provided for each employee includes the last three years of total income, the date of first hire, tenure, and for the current year status (part time/full time), weekly hours, pay rate and pay frequency.

Income Measure Description There are various income measures provided in the Worknumber dataset. For each year of data available variables are given for the total 12month base, bonus, overtime, and commission compensation in year $t, t-1$, and $t-2$. This information however is only available for a little over $\frac{1}{3}$ of the sample. The other measure of income, which is widely available across the sample, is rate of pay and pay frequency. We therefore impute total income using a simple rate $\times$ frequency approach to account for 
the lack of representation found in the sample regarding the total 12-month income variables. This yields about 11,000 observations for 2009. The sample of records is nationally representative, both in terms of geographical and age distribution.

Comparison with the CPS To gauge the accuracy of the imputed income measure in our data, we performed a simple comparison with the income levels reported in the Consumer Population Survey. We present results based on income quintiles below.

Table 9: Income Distribution Comparison by Quintile

\begin{tabular}{lcccccc}
\hline Calculation & Dataset & 1 & 2 & 3 & 4 & 5 \\
Mean & CPS & 11058.67 & 24791.32 & 36584.61 & 51872.45 & 110192.2 \\
\multirow{4}{*}{ Median } & Worknumber & 17078.07 & 26565.46 & 39589.76 & 58510.22 & 117260.1 \\
& CPS & 12000 & 25000 & 36000 & 50000 & 85000 \\
& Worknumber & 16640 & 27040 & 39520 & 57512 & 99990 \\
\hline
\end{tabular}

Source: IPUMS, Equifax Worknumber. Worknumber income calculations made using proxied income from pay periods and pay rate. CPS income calculations made using total wage and salary income.

We conduct a similar analysis, comparing the distribution of income and age by state in the Worknumber sample and compare it to the American Community Survey. We also find that the sample is consistent with this survey. These results are available upon request.

\section{PSID Evidence on Income and Debt}

To assess the generality of the relation between income, age and debt described in Section 5.1. we use the PSID to estimate the relation between debt growth and income during the boom period. Using zip code level data, Mian and Sufi (2009) show that during the period between 2001 and 2006, the zip codes that exhibited the largest growth in debt were those who experiences the smallest growth in income. They argue that the negative relation between debt growth and income growth at the zip code level over that period is consistent with a growth in the supply of credit, via a relaxation of lending standards. Using the panel stricture of the PSID, we can directly assess the relation between income and debt growth at the individual data. While debt is poorly measured in the PSID relative to the Consumer Credit Panel that we use for our main analysis, we have income at a yearly or bi-yearly frequency.

The estimates for various specifications are displayed in Table10. The dependent variable is the change in real log total debt between 2007 and 1999, and the baseline specification includes the change in log income over the same period as a dependent variable. The coefficient is positive and highly significant, with a 1 log point change in income corresponding to a $0.066 \log$ point increase in the change in debt over the period. This coefficient implies that 1 10,000\$ increase in income from a value of 50,000\$ in 1999 is associated with a $1 \$$ 
increase in debt. The second column includes 1999 age and 1999 age squared. The coefficient on the change in income changes little, and the coefficient on age is negative and significant, consistent with our previous finding on the fact that debt accumulation slows with age, and debt accumulation is strongest for borrowers who are young in 1999. The third column includes a an interaction between 1999 age and the change in income, log income in 1999 and no squared age term. In this case the coefficient on the change in log income is positive but much smaller and not significant, while the coefficient on age is still negative and significant, but smaller in magnitude. The coefficient on log income in 1999 is positive but not significant. The last column also adds an interaction between log income in 1999 and age in 1999. In this case the coefficient on the change in income is positive and larger in magnitude relative to previous specifications, but not significant. The other coefficients are similar, with a larger magnitude of the negative coefficient on age. The interaction between age and log income in 1999 is positive and significant, suggesting that higher initial income is associated with larger growth in debt conditional on age. These results confirm our findings based on the Equifax data, suggesting that income growth and debt growth are positively related over the 2001-2006 boom.

Table 10: Relation Between Debt Growth and Income Growth

\begin{tabular}{|c|c|c|c|c|}
\hline \multicolumn{5}{|c|}{ Dependent Variable: 2007-1999 change in log total debt (real USD) } \\
\hline$\Delta \log ($ income $)$ & $0.066^{* *}$ & $0.068^{* *}$ & 0.21 & 0.081 \\
\hline 1999 age & & $-0.064^{* * *}$ & $-0.01^{* * *}$ & $-0.070 * *$ \\
\hline 1999 age sq & & $0.001^{* * *}$ & & \\
\hline 1999 age $\times \Delta \log ($ income $)$ & & & -0.003 & -0.001 \\
\hline $\log \left(\right.$ income $\left._{1999}\right)$ & & & 0.001 & -0.270 \\
\hline 1999 age $\times \log \left(\right.$ income $\left._{1999}\right)$ & & & & $0.006^{*}$ \\
\hline
\end{tabular}

*** $p<0.01,{ }^{* *} p<0.05,{ }^{*} p<0.1$ No. obs. 1,395. Source: Authors' calculations based on PSID Data. 


\section{E Balance Change Regressions: Additional Results}

\section{E.1 Mortgage Balances}

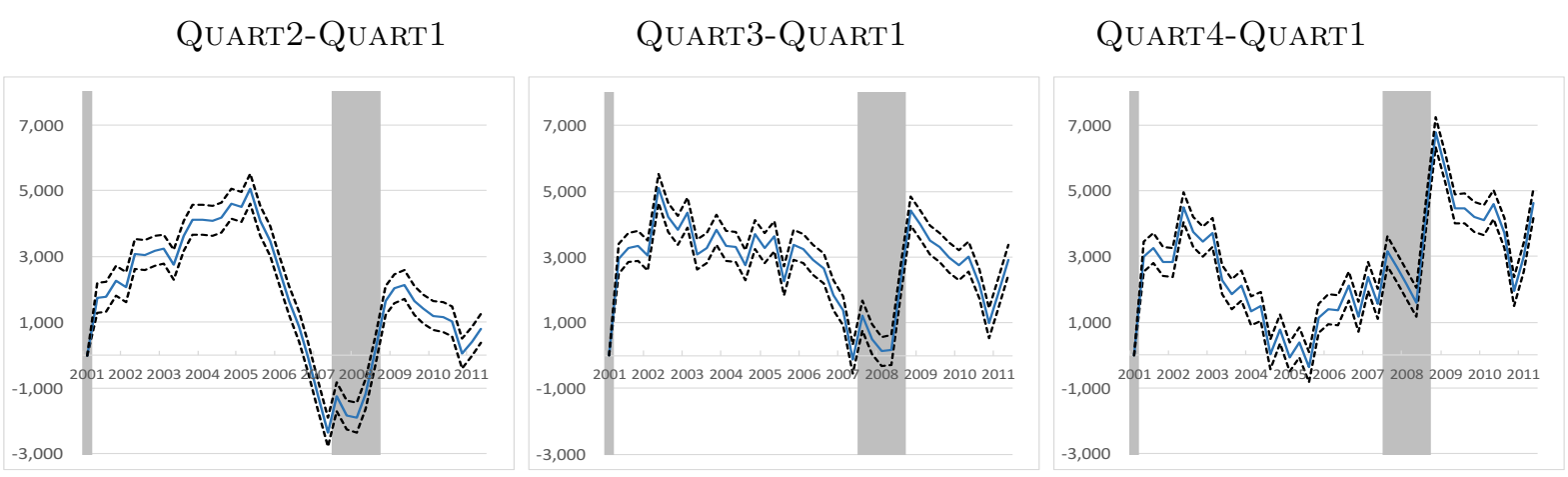

Figure 31: Estimated time effects by 1Q lagged Equifax Risk Score quartile from balance change regressions. Baseline specification. Dependent variable is the $8 \mathrm{Q}$ ahead change in per capita mortgage balances in USD. Dashed lines denote $5 \%$ confidence intervals. Sample period 2001Q3-2011Q4. Number of obs. (baseline) 64,588,488. Source: Authors' calculations based on FRBNY CCP/Equifax Data.

Figure 32 displays some robustness analysis. The left panel plots the estimated age effects for the baseline specification, as well as the specifications that include the past changes in the credit score. The estimated age effects are very similar across specifications, consistent with the notion that changes in past credit scores exert negligible impact on credit growth. The right panel reports the estimated interaction between the 4 quarter past change in the credit score from its 1 quarter lagged value and the time effect, for the specification that includes these two variables. The estimated averages and time effects by credit score quartile are very similar to those in the baseline specification. The effect of the 4 quarter past change in credit score is more sizable during crisis, but still economically negligible.

Table 11

\section{E.2 Delinquent balances}

We report additional results for the estimates for delinquent balances described in Section 6.2.1. Figure 33 reports the differences in the estimated time effects for quartiles 2-4 relative to quartile 1. As for debt balances, there is a sizable and highly significant difference in time effects across quartiles. Figure 34 reports the estimated age effects. The age effects for dellinquent balances largely reflect the age pattern of total debt balances.

\section{F Investors}

We report additional detail about investor activity. Figure 35 report the fraction of borrowers with only 2 , only 3 and 4 or more first mortgages among all borrowers with first mortgages, 
Age Effects By Specification

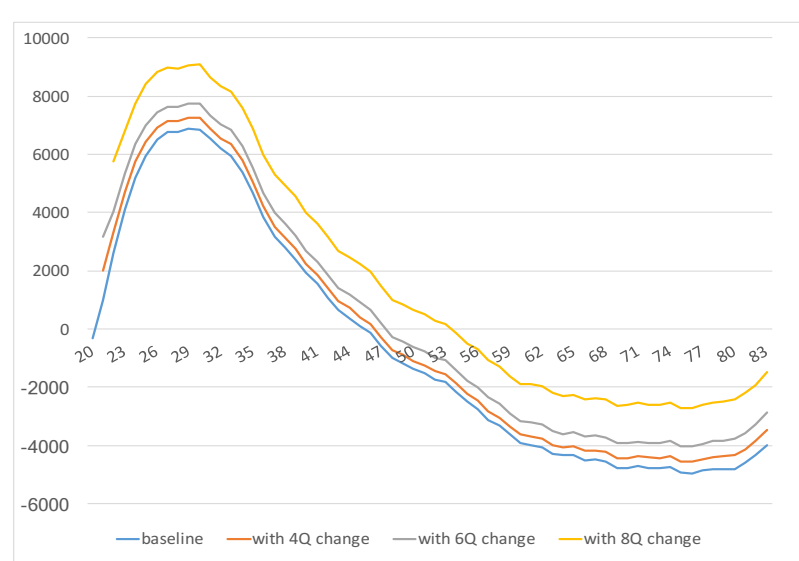

$\Delta_{4 Q} C S_{-1} \times \mathrm{T}$

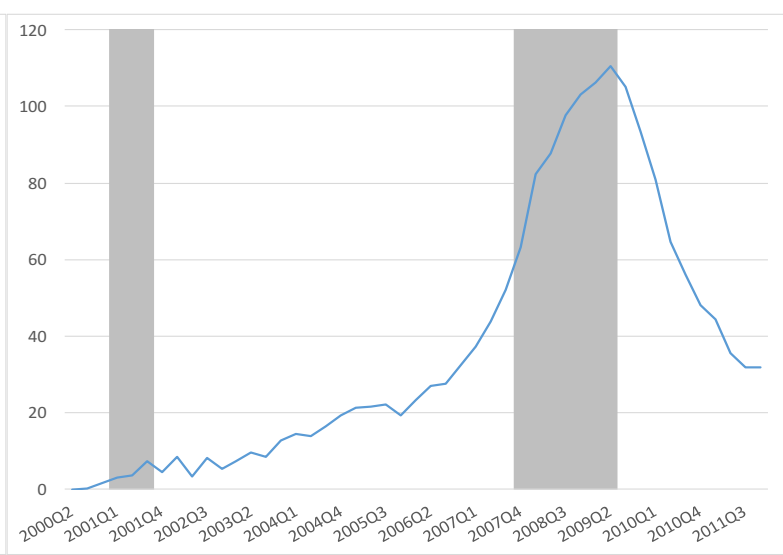

Figure 32: Robustness analysis. Left panel: Estimated age effects from balance change regressions. Baseline specification, plus variant with $4 \mathrm{Q}, 6 \mathrm{Q}, 8 \mathrm{Q}$ past change from $1 \mathrm{Q}$ lagged score. Right panel: Interaction of $4 \mathrm{Q}$ past change from $1 \mathrm{Q}$ lagged score with time effect. Dependent variable is $8 \mathrm{Q}$ ahead change in mortgage balances per capita in USD. Sample period 1999Q2-2012Q4. Number of obs. (baseline) 77,943,776. Source: Authors' calculations based on FRBNY CCP/Equifax Data.

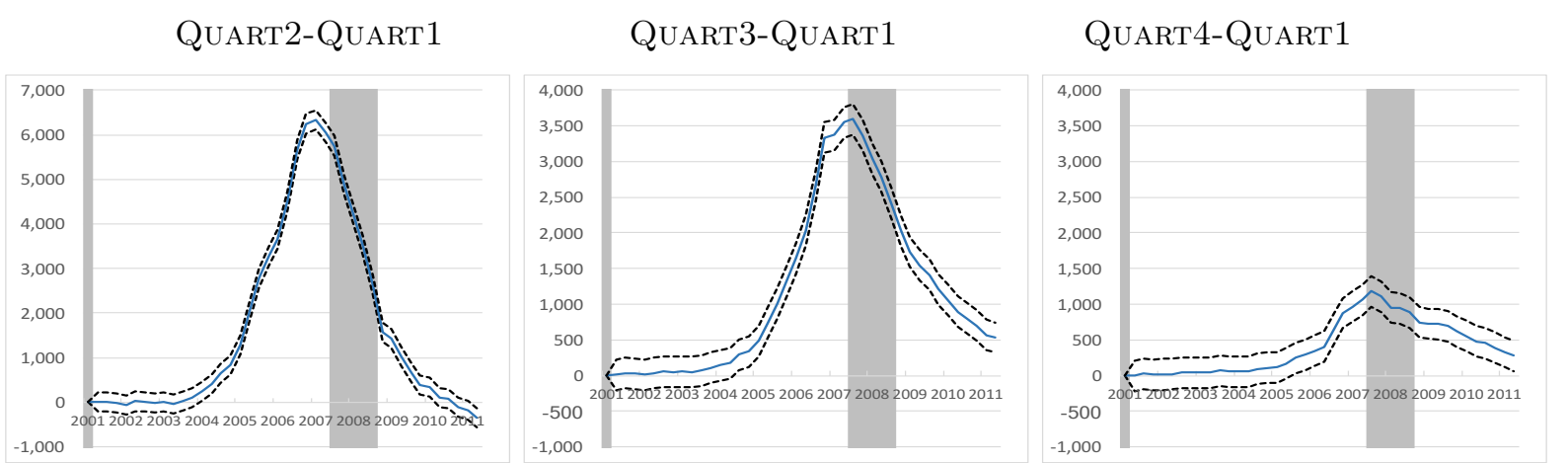

Figure 33: Difference in estimated time effects by 1Q lagged Equifax Risk Score quartile relative to quartile 1. Baseline specification. Dependent variable is the $8 \mathrm{Q}$ ahead change in per capita 90+ days delinquent debt balances in USD. Sample period 2001Q3-2011Q4. Number of obs. 64,588,488. Dashed lines denote 5\% confidence intervals. Source: Authors' calculations based on FRBNY CCP/Equifax Data.

by quartile of the 8 quarter lagged credit score distribution. These fractions are lowest for quartile 1 for all categories. There is modest rise is fraction with two mortgages in 2005-2007 for quartile 1, whereas the fraction with 3 or $4+$ are stable throughout the period for this quartile. Quartiles 2-4 exhibit strong rise in the number of first mortgages, as previously noted. The fraction with 2 rises by about a third of the 2004 value, the fraction with 3 and 4 or more than double, though they start from a much lower level. For quartiles 2-3, these fractions return to pre-boom levels in the aftermath of the recession, while they remain 
Table 11: Mortgage Balances: Summary Regression Results

\begin{tabular}{|c|c|c|c|c|}
\hline & \multicolumn{4}{|c|}{ Average 4 Quarter Ahead Change in Mortgage Balances } \\
\hline & Quartile 1 & Quartile 2 & Quartile 3 & Quartile 4 \\
\hline 2002-03 & -206 & 1,998 & 2,329 & 1,269 \\
\hline 2003-04 & 235 & 3,622 & 4,355 & 3,182 \\
\hline 2004-05 & 173 & 3,173 & 3,150 & 1,702 \\
\hline $2005-06$ & 936 & 5,316 & 4,996 & 2,209 \\
\hline 2006-07 & 798 & 4,937 & 3,854 & 1,115 \\
\hline $2007-08$ & $-1,700$ & 1,732 & 2,505 & 818 \\
\hline 2008-09 & $-4,690$ & $-2,691$ & $-1,724$ & $-2,355$ \\
\hline 2009-10 & $-6,463$ & $-3,075$ & $-1,964$ & $-2,369$ \\
\hline 2010-11 & $-5,538$ & $-2,670$ & $-1,269$ & $-1,591$ \\
\hline 2011-12 & $-5,189$ & $-3,020$ & $-2,281$ & $-2,921$ \\
\hline $2002-2006$ & 1,138 & 14,108 & 14,831 & 8,361 \\
\hline \multirow[t]{3}{*}{$2007-2010$} & $-12,853$ & $-4,035$ & $-1,183$ & $-3,905$ \\
\hline & \multicolumn{4}{|c|}{ Average 8 Quarter Ahead Change in Mortgage Balances } \\
\hline & Quartile 1 & Quartile 2 & Quartile 3 & Quartile 4 \\
\hline 2002-04 & 1,202 & 7,760 & 9,663 & 6,745 \\
\hline 2004-06 & 2,449 & 10,696 & 10,657 & 6,351 \\
\hline 2006-08 & 1,175 & 8,397 & 8,896 & 4,260 \\
\hline 2008-10 & $-7,459$ & $-4,732$ & $-2,192$ & $-2,864$ \\
\hline 2010-12 & $-9,053$ & $-3,413$ & $-1,276$ & $-2,515$ \\
\hline 2002-2006 & 5,304 & 27,419 & 30,604 & 20,248 \\
\hline \multirow[t]{3}{*}{$2007-2010$} & $-9,689$ & 3,835 & 9,500 & 2,002 \\
\hline & \multicolumn{4}{|c|}{ Average 12 Quarter Ahead Change in Mortgage Balances } \\
\hline & Quartile 1 & Quartile 2 & Quartile 3 & Quartile 4 \\
\hline 2002-05 & 2,073 & 9,390 & 10,605 & 7,132 \\
\hline 2005-08 & 3,256 & 12,123 & 11,470 & 5,417 \\
\hline $2008-11$ & $-10,039$ & $-9,680$ & $-7,010$ & $-6,390$ \\
\hline 2002-2006 & 5,589 & 22,032 & 23,454 & 15,411 \\
\hline $2007-2010$ & $-3,583$ & 8,870 & 12,561 & 2,476 \\
\hline
\end{tabular}

Cumulative change in mortgage balances at various horizons in USD. Based on 1 quarter lagged credit score quartile fixed effects and time effect from balance change regressions. Source: Authors' calculations based on FRBNY CCP/Equifax Data. 


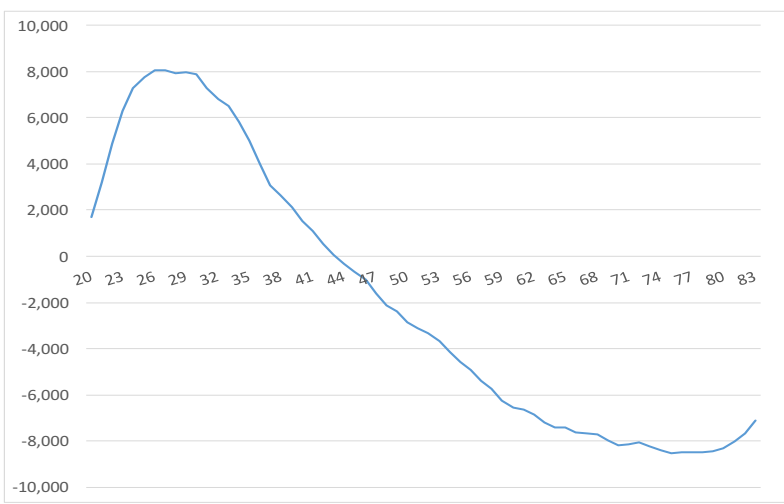

Figure 34: Estimated age effects from balance change regressions. Baseline specification. Dependent variable is the $8 \mathrm{Q}$ ahead change in per capita $90+$ days delinquent debt balances in USD. Sample period 2001Q3-2011Q4. Number of obs. 64,588,488. Source: Authors' calculations based on FRBNY CCP/Equifax Data.

at peak levels for borrowers in quartile 4 . Figure 36 reports the share of balances held by borrowers with only 2 , only 3 and 4 or more first mortgages. The behavior of balances broadly reflects the pattern of the fractions.

ONLY 2

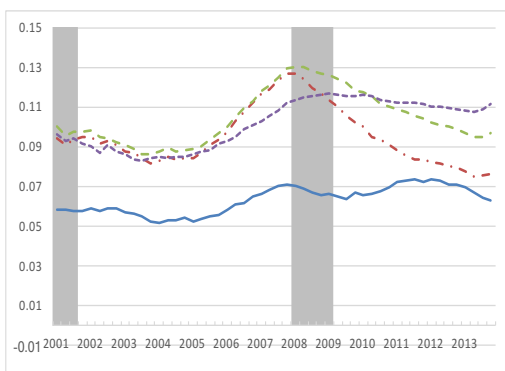

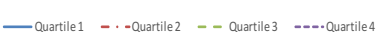

ONLY 3

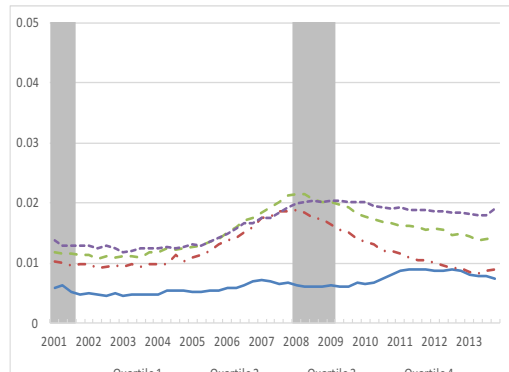

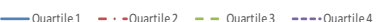

4 OR MORE

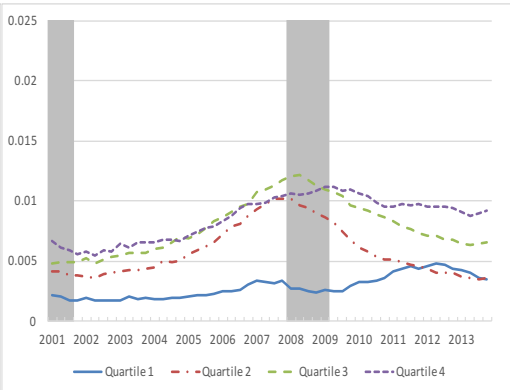

Figure 35: Fraction of borrowers with only 2 (left), only 3 (center) and 4 or more (right) first mortgages by quartile of the 8Q lagged Equifax Risk Score. Source: Authors' calculations based on FRBNY CCP/Equifax Data.

Figure 37 reports the fraction with a new 90+ days mortgage delinquency in the last 4 quarters by number of first mortgages, whereas figure 38 presents the fraction with a new foreclosure in the last 4 quarters by number of first mortgages. There is a sharp rise in the delinquency and foreclosure rates for borrowers with 2 or more first mortgages, with the rates increasing in the number of firts mortgages. This is true for all quartiles of the 8 quarter lagged credit score distribution, though for delinquencies the rise is particular sharp for borrowers in quartiles 2 and 4, compared to both the pre-crisis rates and the rates of borrowers with only first mortgage in the same quartiles. The maximum delinquency rate is registered for borrowers with 4 or more first mortgages in quartile 3 of the credit score 
ONLY 2

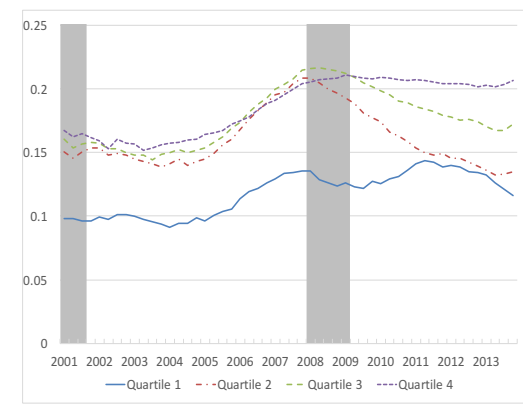

ONLY 3

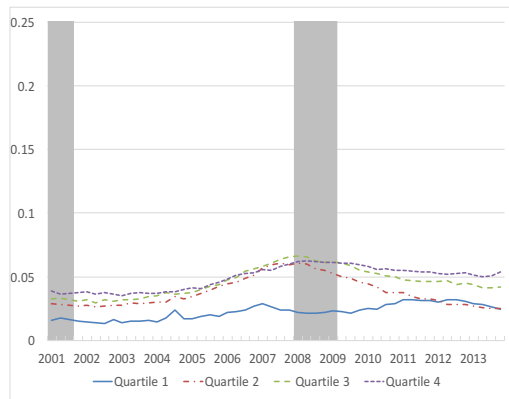

4 OR MORE

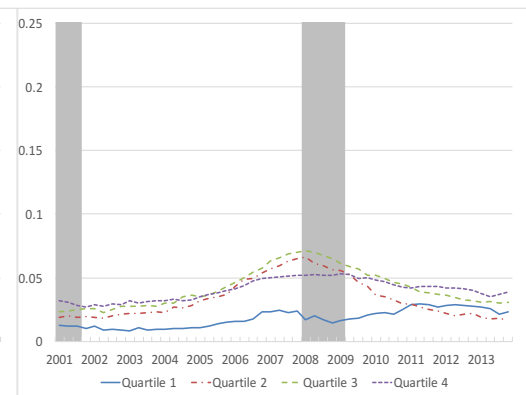

Figure 36: Share of mortgage balances held by borrowers with only 2 (left), only 3 (center) and 4 or more (right) first mortgages by quartile of the 8Q lagged Equifax Risk Score. Source: Authors' calculations based on FRBNY CCP/Equifax Data.

distribution, which reaches a rate of 3.5\% in 2009Q2. For foreclosures, there is a sharp rise for all quartiles, and again the increase in rates is increasing in the number of first mortgages, with the maximum foreclosure rate attained by borrowers with 4 or more first mortgages in quartile 3 of the credit score distribution, at 3\% in 2009Q3.

\section{G Non Conforming Mortgages}

We also examine the size of the average mortgage. As house prices were rising during between 2001-2007, some borrowers were taking on increasingly larger mortgages. Some of these mortgages satisfy the criteria of jumbo loans, which do not qualify for GSE insurance and therefore typically display higher rates.

The distribution of jumbo loans by quartile of the credit score distribution in reported in Table 12 between 2001 and 2007 ${ }^{36}$ There is a small rise in the fraction of jumbo mortgages, but only for borrowers in the top quartile of the credit score distribution.

\section{H Additional Zip Code Level Evidence}

In this section, we report additional results for the zip code level analysis. We start by plotting the gross level of total debt balances per capita as a ratio to 2001Q3 by fraction of subprime borrowers in 2001. While for mortgage balances, zip codes in quartile 4 exhibit faster growth in debt balances, relative to those in lower quartiles, there is virtually no difference across quartiles for total debt balances. While total balance growth is more pronounced for prime borrowers in zip codes with the highest fraction of subprime, there is virtually no difference in debt growth for subprime borrowers across quartiles.

\footnotetext{
${ }^{36}$ In 2008, the Obama Administration increased the thresholds for jumbo loans in the major metropolitan areas that exhibited the largest house price increases.
} 
QUARTILE 1

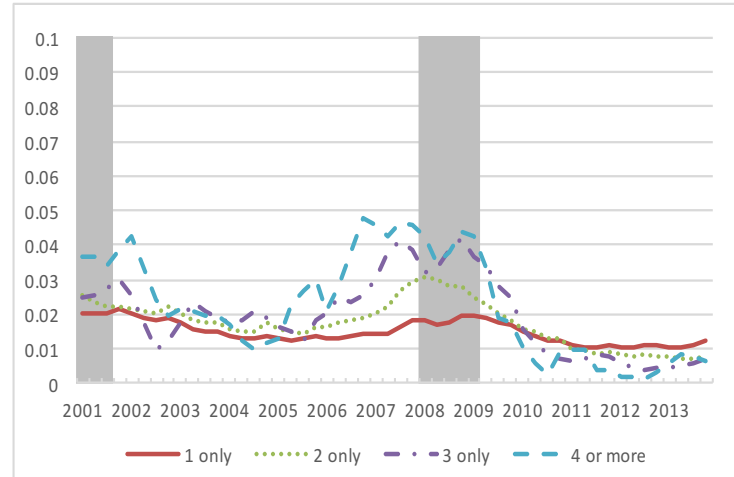

QUARTILE 3

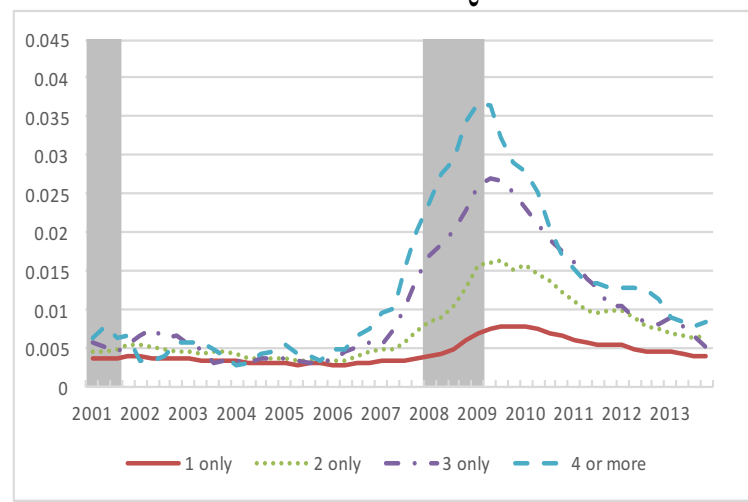

QUARTILE 2

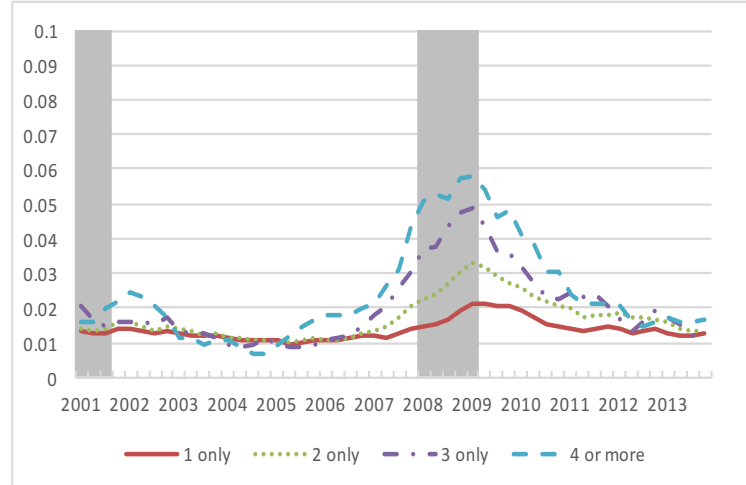

QUARTILE 4

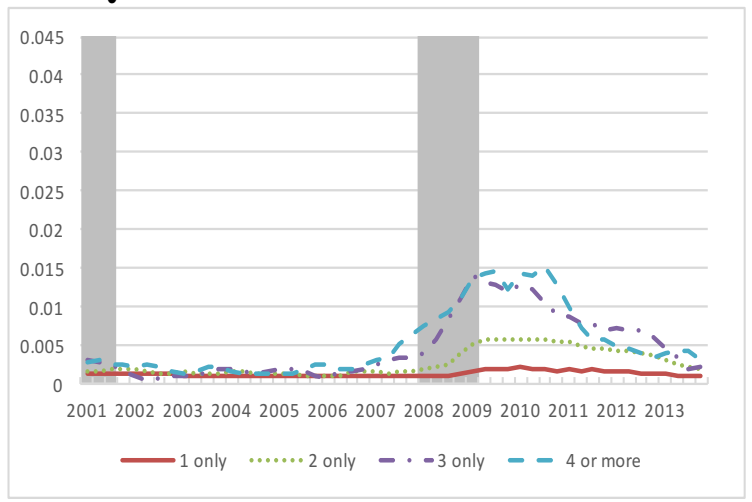

Figure 37: 90+ days mortgage delinquency rates by quartile of 8Q lag Equifax Risk Score quartile by number of first mortgages. Source: Authors' calculations based on FRBNY CCP/Equifax Data.

Table 12: Fraction of Jumbo Mortgages

\begin{tabular}{lllll}
\hline quartile & 1 & 2 & 3 & 4 \\
\hline 2001Q1 & $0.1 \%$ & $0.4 \%$ & $0.7 \%$ & $1.1 \%$ \\
2003Q1 & $0.1 \%$ & $0.5 \%$ & $1.1 \%$ & $1.4 \%$ \\
2005Q1 & $0.1 \%$ & $0.7 \%$ & $1.5 \%$ & $1.7 \%$ \\
2007Q1 & $0.2 \%$ & $0.7 \%$ & $1.5 \%$ & $1.9 \%$ \\
2009Q1 & $0.1 \%$ & $0.3 \%$ & $0.3 \%$ & $0.7 \%$ \\
\hline
\end{tabular}

Fraction with non-conforming mortgages by $8 \mathrm{Q}$ lagged Equifax Risk Score ranking. Mortgages with values above $\$ 470,000$ were classified as non-conforming until 2009. Source: Authors' calculations based on FRBNY $\mathrm{CCP} /$ Equifax Data. 
QUARTILE 1

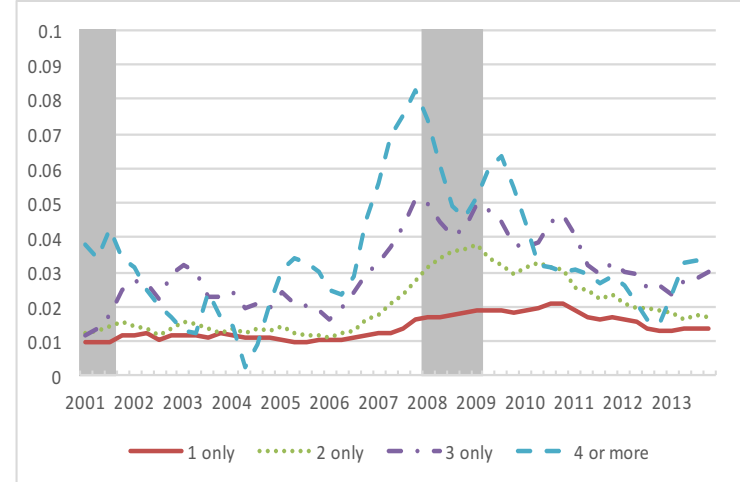

QUARTILE 3

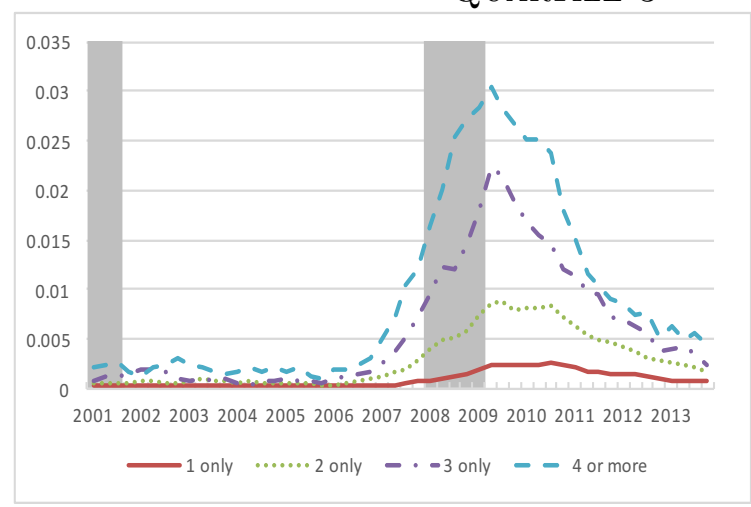

QUARTILE 2

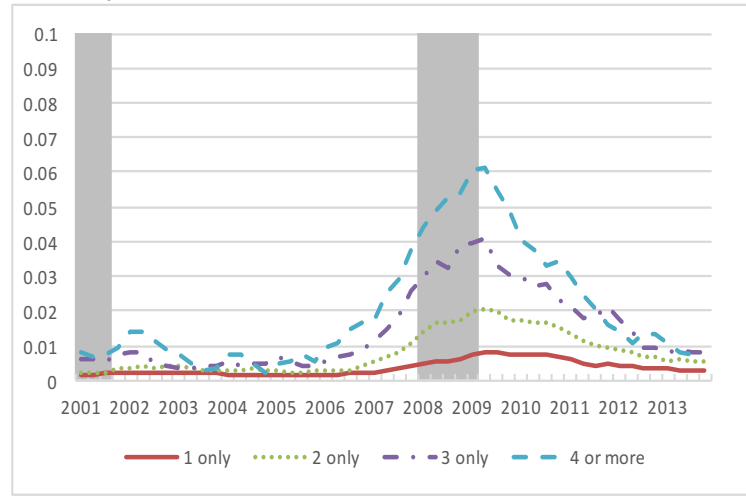

QUARTILE 4

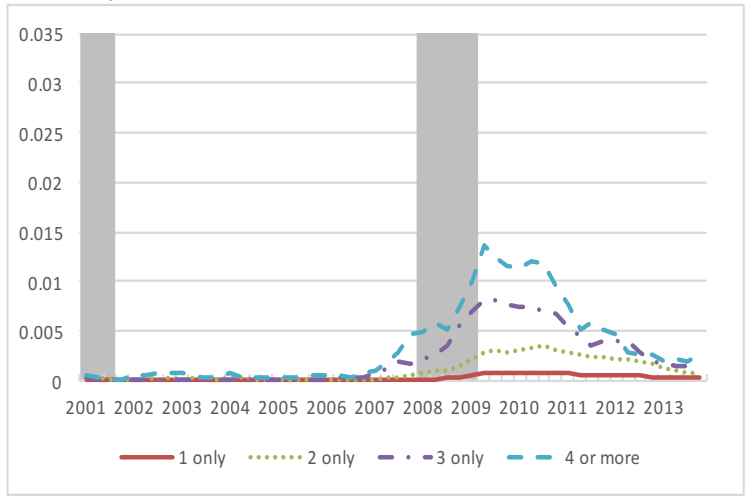

Figure 38: Foreclosure rates by quartile of 8Q lag Equifax Risk Score quartile by number of first mortgages. Source: Authors' calculations based on FRBNY CCP/Equifax Data.

\section{H.1 Stability and Consistency of Zip Code Rankings}

Mian and Sufi (2009) ranks zip codes by the fraction of subprime in 1996. Mian and Sufi (2011) ranks zip codes by initial personal disposable income or initial leverage, which they define as total debt balances per capita over average personal disposable income. Mian and Sufi (2014) rank counties by the decline in household net worth during the crisis, which is instrumented by the Saiz (2010) house prime elasticities to capture the rise in house prices during the boom and the associated rise in leverage. Here, we examine the relation between these measures at the zip code level.

We first consider the stability of each ranking. Table 13 reports the fraction of zip codes that remain in the same quartile of each ranking in the subsequent year. We consider three indicators: the fraction of subprime borrowers, average personal disposable income (PDI) and average leverage, defined as total balances per capita over average personal disposable income. All rankings are very stable, with approximately $70 \%$ of all zip codes remaining in the same quartile of the fraction of subprime borrower distribution year to year, over $90 \%$ for personal disposable income and 59-75\% for leverage. We also examine the correlation between various rankings. The Spearman correlation between fraction of subprime and PDI ranges from -0.46 and -0.58 , and decreases over the sample period. The Spearman correlation 


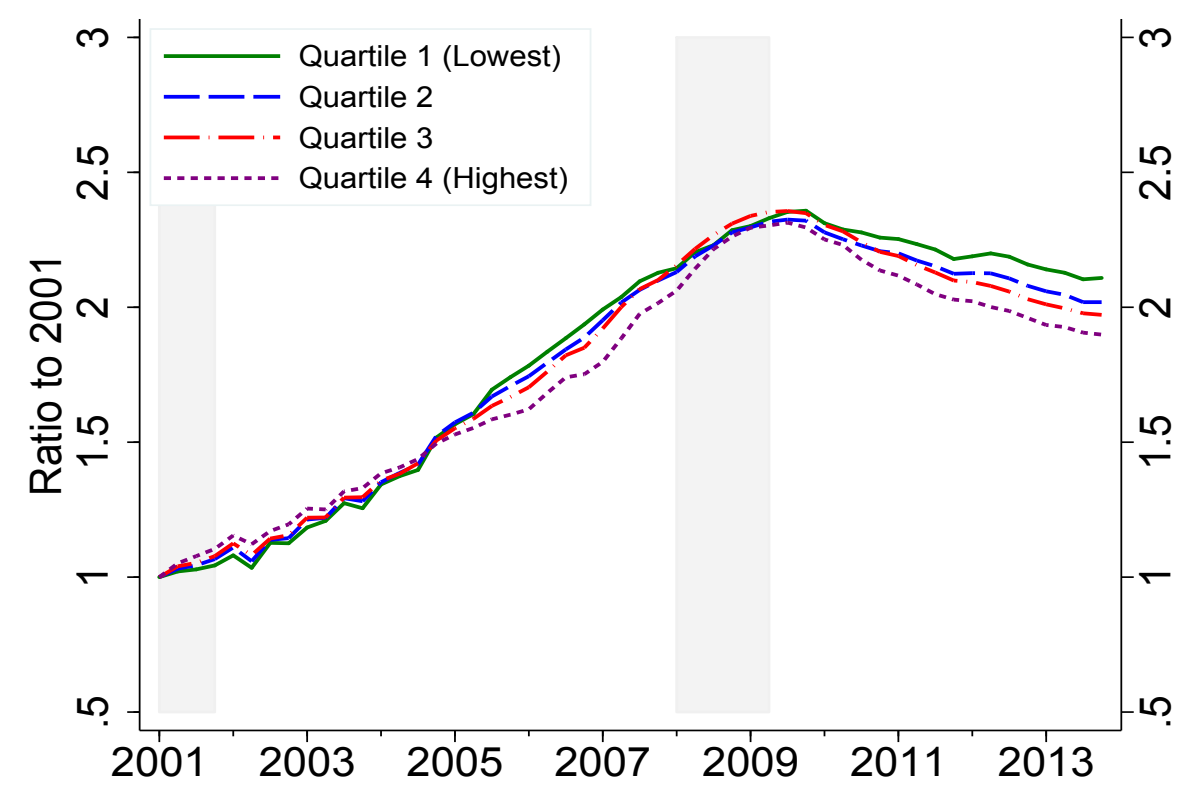

Figure 39: Growth in total balances by share of individuals with Equifax Risk Score below 660 in 1999. Source: Authors' calculations based on FRBNY CCP/Equifax Data.

between fraction of subprime and leverage is negative, ranging between -0.03 at the end of the sample and -0.15 at the height of the credit boom. This is consistent with a greater growth in leverage for zip codes with low fraction of subprime during the boom.

We now concentrate on quartile 4 by fraction of subprime on 2001. We examine their income and leverage ranking throughout the sample period. The results are reported in Table 14. Depending on the sample year, $51-58 \%$ of the zip codes in quartile 4 of the fraction of subprime borrowers in 2001 are in the lowest PDI quartile in 2001-2011. Moreover, the fraction of subprime zip codes in higher PDI quartiles declines later in the sample period. The distribution of zip codes with high fraction of subprime borrowers across the leverage distribution is more even, however, in all years more than $50 \%$ are in the first 2 quartiles of the leverage distribution, confirming the negative relation between fraction of subprime borrowers and leverage. 
Table 13: Stability and Correlation of Zip Code Rankings

\begin{tabular}{llllll}
\hline & \multicolumn{2}{c}{ Fraction in same quartile } & \multicolumn{2}{c}{ Correlation with \% subprime } \\
& \% subprime & PDI & Leverage & PDI & Leverage \\
\hline 2001 & 0.68 & 0.88 & 0.59 & $-0.46 * * *$ & $-0.04 * * *$ \\
2002 & 0.71 & 0.91 & 0.62 & $-0.50 * * *$ & $-0.05 * * *$ \\
2003 & 0.73 & 0.92 & 0.66 & $-0.51 * * *$ & $-0.06 * * *$ \\
2004 & 0.70 & 0.90 & 0.63 & $-0.53 * * *$ & $-0.10^{* * *}$ \\
2005 & 0.71 & 0.90 & 0.67 & $-0.53 * * *$ & $-0.15^{* * *}$ \\
2006 & 0.72 & 0.89 & 0.67 & $-0.55^{* * *}$ & $-0.15^{* * *}$ \\
2007 & 0.72 & 0.87 & 0.69 & $-0.58^{* * *}$ & $-0.09 * * *$ \\
2008 & 0.72 & 0.92 & 0.73 & $-0.58^{* * *}$ & $-0.11^{* * *}$ \\
2009 & 0.72 & 0.95 & 0.74 & $-0.58 * * *$ & $-0.04 * * *$ \\
2010 & 0.73 & 0.95 & 0.75 & $-0.58 * * *$ & $-0.03 * * *$ \\
2011 & 0.72 & & & $-0.57 * * *$ & $-0.03 * * *$ \\
\hline
\end{tabular}

Fraction of zip codes in same quartile in subsequent year, by fraction of subprime borrowers, PDI and leverage. Correlation (Spearman $\rho$ ) of fraction of subprime borrowers in 2001 and PDI or leverage in each sample year. Leverage is the ratio of total debt balances to PDI. ${ }^{* * *}$ denotes significance at the $1 \%$ level. Source: Authors' calculations based on FRBNY CCP/Equifax Data, IPUMS, IRS, BLS, ACS data. 
Table 14: Zip Codes in Quartile 4 by \% of Subprime Borrowers in 2001

\begin{tabular}{llllllllll}
\hline & \multicolumn{4}{c}{ PDI Quartile } & \multicolumn{4}{c}{ Leverage Quartile } \\
& 1 & 2 & 3 & 4 & 1 & 2 & 3 & 4 \\
\hline 2001 & 0.51 & 0.27 & 0.14 & 0.07 & 0.28 & 0.27 & 0.23 & 0.22 \\
2002 & 0.54 & 0.27 & 0.13 & 0.07 & 0.29 & 0.26 & 0.23 & 0.21 \\
2003 & 0.55 & 0.26 & 0.13 & 0.07 & 0.29 & 0.27 & 0.22 & 0.21 \\
2004 & 0.57 & 0.24 & 0.12 & 0.07 & 0.31 & 0.28 & 0.21 & 0.19 \\
2005 & 0.59 & 0.23 & 0.11 & 0.07 & 0.35 & 0.27 & 0.21 & 0.17 \\
2006 & 0.57 & 0.25 & 0.12 & 0.07 & 0.35 & 0.28 & 0.20 & 0.17 \\
2007 & 0.58 & 0.25 & 0.11 & 0.06 & 0.33 & 0.28 & 0.20 & 0.19 \\
2008 & 0.58 & 0.26 & 0.11 & 0.06 & 0.34 & 0.27 & 0.20 & 0.19 \\
2009 & 0.58 & 0.25 & 0.11 & 0.06 & 0.31 & 0.26 & 0.20 & 0.23 \\
2010 & 0.58 & 0.25 & 0.11 & 0.06 & 0.32 & 0.25 & 0.20 & 0.23 \\
2011 & 0.58 & 0.26 & 0.11 & 0.06 & 0.31 & 0.24 & 0.20 & 0.24 \\
$2002-06$ average & 0.56 & 0.25 & 0.12 & 0.07 & 0.32 & 0.27 & 0.21 & 0.19 \\
\hline
\end{tabular}

Fraction of zip codes in quartile 4 of the fraction of subprime borrowers in 2001 in various quartiles of the PDI and leverage distribution in each sample year. Leverage is the ratio of total per capital debt balances to average PDI. Source: Authors' calculations based on FRBNY CCP/Equifax Data, IPUMS, IRS, BLS, ACS data. 